Aus der Abteilung Vegetative Physiologie und Pathophysiologie

(Prof. Dr. med. G. Burckhardt)

im Zentrum Physiologie und Pathophysiologie

der Medizinischen Fakultät der Universität Göttingen

\title{
Interaktion des hNaDC3 mit Fumarat und Fumaratderivaten
}

\author{
INAUGURAL - DISSERTATION \\ zur Erlangung des Doktorgrades
}

der Medizinischen Fakultät

der Georg-August-Universität zu Göttingen

\author{
vorgelegt von \\ Andrea Isabella Schmidt
}

aus

München

Göttingen 2012 
Dekan: $\quad$ Prof. Dr. rer. nat. H. K. Kroemer

Berichterstatterin: $\quad$ Prof. Dr. phil. nat. Burckhardt

II. Berichterstatter / in: $\quad$ Priv.-Doz. Dr. med. Mößner

III. Berichterstatter / in: $\quad$ Prof. Dr. rer. nat. Virsik-Köpp

Tag der mündlichen Prüfung: $\quad$ 29.04.2013 


\section{Inhaltsverzeichnis}

1.) EINLEITUNG $10-$

1.1.) DIE SLC 13 - FAMILIE ..................................................................................... - 10 -

1.2.) DER HOCH-AFFINE NATRIUM-DICARBOXYLATTRANSPORTER .................................. 15 -

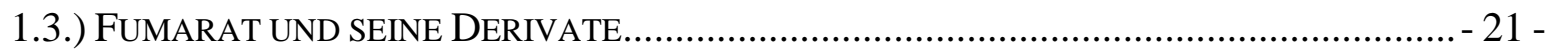

1.3.1.) Pharmakologische Dynamik und Einsatz der Fumaratderivate...................... - 22 -

1.3.2.) Fumarsäure und ihre Wirkmechanismen in der pharmakologischen Therapie der Psoriasis vulgaris und der Multiplen Sklerose ......................................................... - 23 -

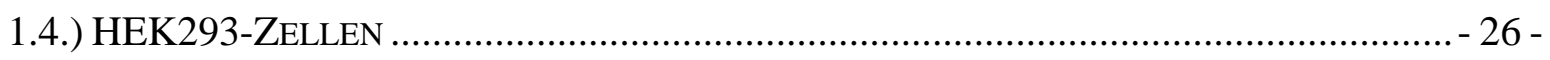

1.5.) XENOPUS-LAEVIS - OOZYTEN ALS EXPRESSIONSSYSTEM ......................................... 26 -

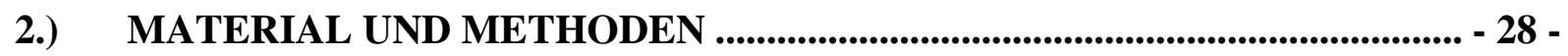

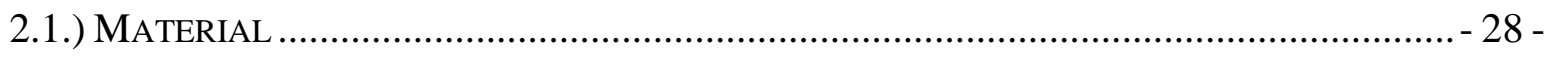

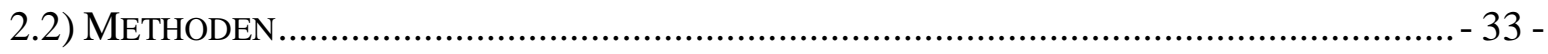

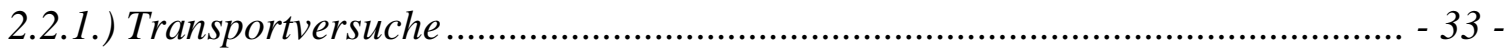

2.2.1.1.) Kultivieren und Ausplattieren der HEK293 ............................................. - 33 -

2.2.1.2.) Ernten und Pflege der Zellen ................................................................ - 33 -

2.2.1.3.) Bestimmung der Zellzahl und Ausplattieren .......................................... - 34 -

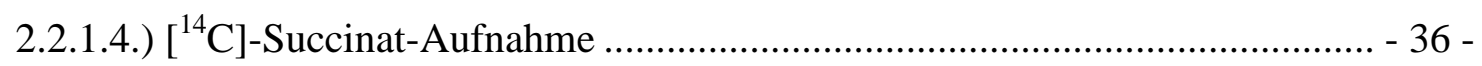

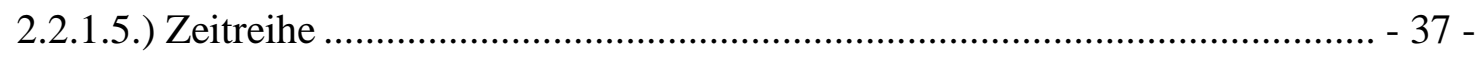

2.2.1.6.) Transporterfunktion unter Natrium-freien Bedingungen ......................... - 37 -

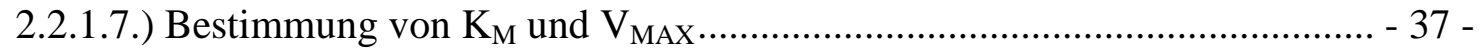

2.2.1.8.) Hemmung der Succinat-Aufnahme........................................................ - 38 -

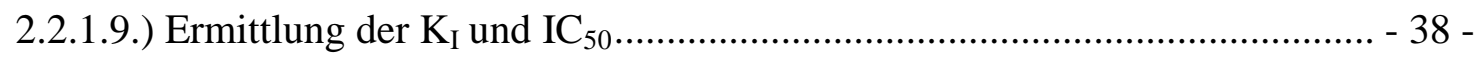

2.2.2.) Elektrophysiologische Experimente............................................................... - 39 -

2.2.2.1.) Entnahme und Selektion der Oozyten.................................................... - 39 -

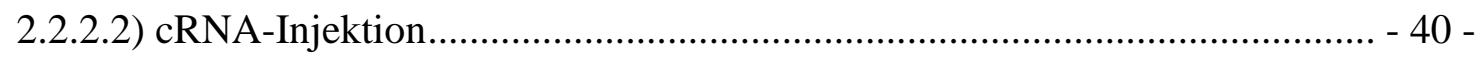

2.2.2.3.) Messungen mit der Zwei-Elektroden-Spannungsklemme ......................... - 40 -

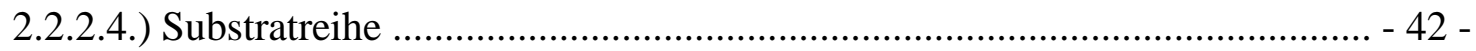

2.2.2.5.) Fumarat-Konzentrationsreihe ….......................................................... - 43 -

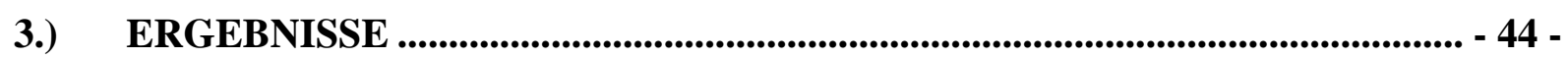

3.1.) ,AUFNAHMEEXPERIMENTE“ „.......................................................................... 44 - 
3.1.1.) Aufnahme von Succinat in hNaDC3-transfizierte HEK293-Zellen als Funktion der Inkubationszeit $-44-$

3.1.2.) Ergebnisse der Versuche unter Natrium-freier Lösung .................................. - 45 -

3.1.3.) Bestimmung der $K_{M}$ für Succinat ................................................................... - 46 -

3.1.4.) Hemmung der Aufnahme von Succinat durch Fumarat und Fumaratderivate - 47 -

3.1.5.) Bestimmung einer $K_{I}$ und der $I C_{50}$ für Fumarat ............................................... - 49 -

3.2.) ERGEBNISSE DER ELEKTROPHYSIOLOGISCHEN EXPERIMENTE …............................. 51 -

3.2.1.) Nachweis einer funktionellen Expression von hNaDC3 in Xenopus-laevis-Oozyten $-52-$

3.2.2.) Vergleich der Amplituden der Fumarat-, Dimethylfumarat-, Diethylfumaratmediierten Ströme mit den von Succinat hervorgerufenen Strömen............................ - 54 -

3.2.3.) Bestimmung einer $K_{M}$ für Fumarat ................................................................ - 56 -

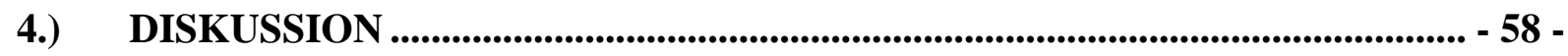

4.1.) VOR- UND NACHTEILE DES VERSUCHSAUFBAUS ..................................................... 58 -

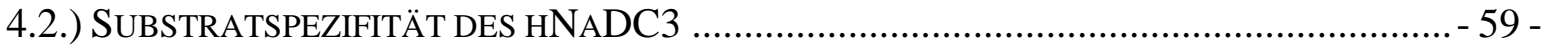

4.3.) $\mathrm{K}_{\mathrm{I}}$ UND $\mathrm{IC}_{50}$ FÜR FUMARAT, BESTIMMUNG EINER $\mathrm{K}_{\mathrm{M}}$ FÜR FUMARAT ........................ 60 -

4.4.) FUMARAT UND FUMARATDERIVATE IN DER PHARMAKOLOGIE UNTER EINBEZIEHUNG DES

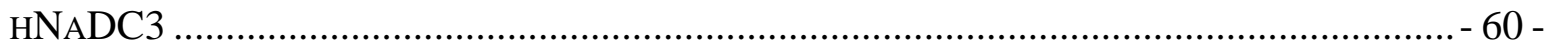

4.4.1.) Fumarate in der Psoriasis-Therapie ............................................................. - 60 -

4.4.2.) Fumarate in der Therapie der Multiplen Sklerose ........................................... - 61 -

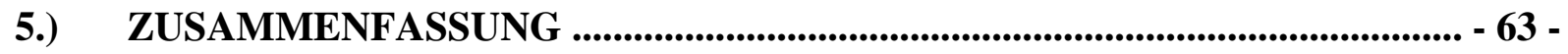

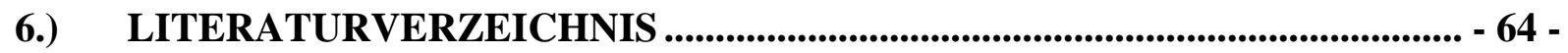




\section{Abbildungsverzeichnis}

Abbildung 1.1: Strukturformel der Fumarsäure ............................................................... - 21 -

Abbildung 1.2: Strukturformel der Bernsteinsäure .......................................................... - 21 -

Abbildung 1.3: Strukturformel der Maleinsäure .................................................................. - 21 -

Abbildung 1.4: Strukturformel Diethylfumarat ........................................................... - 22 -

Abbildung 1.5: Strukturformel Dimethylfumarat ............................................................ - 22 -

Abbildung 2.1: Fließschema zur Verdünnung und Aussaat der Zellen ............................. - 35 -

Abbildung 2.2: Schematische Darstellung einer Oozyte im Versuchsaufbau der Zwei-

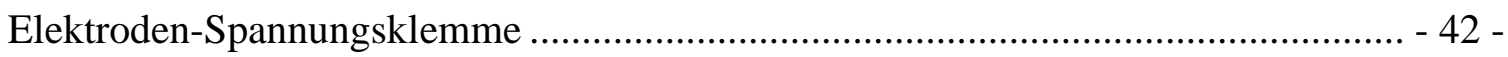

Abbildung 3.1: Aufnahme von $\left[{ }^{14} \mathrm{C}\right]-$ Succinat als Funktion der Inkubationszeiten in hNaDC3transfizierten ( ) und Vektor-transfizierten ( ) HEK293-Zellen.............................. - 45 -

Abbildung 3.2: Natriumabhängigkeit der Aufnahme von $\left[{ }^{14} \mathrm{C}\right]$-Succinat in hNaDC3- und Vektor-transfizierten HEK293-Zellen. ...................................................................... - 46 -

Abbildung 3.3: Aufnahme von $\left[{ }^{14} \mathrm{C}\right]$-Succinat als Funktion der extrazellulären Succinatkonzentration im Inkubationsmedium in hNaDC3-(-) und Vektor-transfizierten

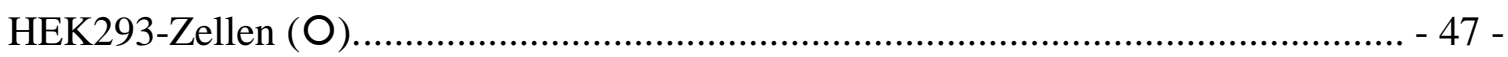

Abbildung 3.4: Einfluss von Fumarat und Fumaratderivaten auf die Aufnahme von $\left[{ }^{14} \mathrm{C}\right]-$

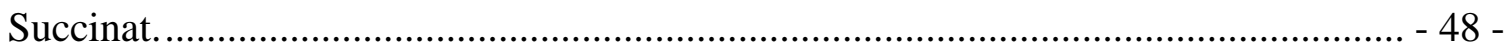

Abbildung 3.5: Einfluss von Fumarat und Fumaratderivaten auf die Aufnahme von $\left[{ }^{14} \mathrm{C}\right]-$ Succinat. -49 -

Abbildung 3.6: Dixon-Plot zur Ermittlung einer Inhibitorkonstanten $\mathrm{K}_{\mathrm{I}}$ für Fumarat. ...... - 50 Abbildung 3.7: Bestimmung einer $\mathrm{IC}_{50}$ für die Hemmung der Aufnahme von $\left[{ }^{14} \mathrm{C}\right]$-Succinat durch aufsteigende Konzentrationen von Fumarat. ................................................. - 51 -

Abbildung 3.8: Strom - Spannungs (I/V) - Kennlinien hNaDC3-exprimierender Oozyten in $\mathrm{Ab}$ - und Anwesenheit von Succinat. $-53-$

Abbildung 3.9: Durch Succinat, Fumarat, Dimethyl- und Diethylfumarat (je $1 \mathrm{mM}$ ) hervorgerufene substratabhängige Differenzströme in Abhängigkeit von $\mathrm{V}_{\mathrm{c}}$............. - 55 Abbildung 3.10: Durch den Transport verschiedener Substrate mittels hNaDC3 ableitbare Einwärtsströme; prozentual gemessen an den Einwärtsströmen, die durch SuccinatTransport entstanden sind. .............................................................................. - 56 -

Abbildung 3.11: Bestimmung einer $\mathrm{K}_{\mathrm{M}}$ für Fumarat an hNaDC3-exprimierenden Oozyten bei einem $\mathrm{V}_{\mathrm{c}}$ von $-60 \mathrm{mV}$. -57 - 


\section{Tabellenverzeichnis}

Tabelle 1: Übersicht über die SLC13-Familie (nach PAJOR 2006, S. 598) ....................... - 14 -

Tabelle 2: Substratspezifität des hNaDC3 (nach WANG et al. 2000, S. 1023) ................... - 20 - 


\section{Abkürzungsverzeichnis}

Abb.

Abbildung

ACE

Angiotensin Converting Enzyme; Angiotensin-

Konversionsenzym

Aqua dest.

destilliertes Wasser

Bcl-2

B-cell lymphoma 2; antiapoptotisches Protein

$\mathrm{CaCl}_{2}$

Calciumchlorid

CXCL

C-X-C motif Chemokine Ligand; Chemokin der C-X-CMotiv-Chemokingruppe

DIDS

DMEM-HG

4,4'-Diisothiozyano-2,2-Stilbendisulfonsäure

DMF

Dulbecco's Modified Eagle Medium High Glucose

DMSA

Dimethylfumarat

DNA

Dimercaptosuccinic acid; Dimercaptobernsteinsäure

DNS

Deoxyribonucleic acid; Desoxyribonukleinsäure

DOG

Desoxyribonukleinsäure

FCS

Dioctanoylglycerol

FISH

Fetal Calf Serum; fetales Kälberserum

HEK

Fluoreszenz-in-situ-Hybridisierung

Human Embryonic Kidney cells; menschliche embryonale Nierenzellen

HEPES

2-(4-(2-Hydroxyethyl)-1-piperazinyl)-Ethansulfonsäure

HLA

humanes Leukozytenantigen

HO-1

Haemoxigenase 1

HRPE

$\mathrm{IC}_{50}$

Humanes retinales Pigmentepithel

Konzentration einer Substanz, die die Aufnahme einer anderen Substanz um $50 \%$ hemmt

ICAM-1

Intercellular Adhesion Molecule 1; interzelluläres Adhäsionsmolekül 1

IL

Interleukin

INF

Interferon

IP-10

Interferon gamma-induced Protein 10; durch Interferon $\gamma$ induziertes Protein 10

$\mathrm{K}_{\mathrm{I}}$

Inhibitor-Konstante

$\mathrm{K}_{\mathrm{M}}$

Michaelis-Menten-Konstante 
$\mathrm{KCl}$

$\mathrm{KH}_{2} \mathrm{PO}_{4}$

LPS

$\mathrm{MgSO}_{2}$

Mig

MMF

MOG

MRi

MS

$\mathrm{NaCl}$

$\mathrm{NaCT}$

$\mathrm{NaDC}$

$\mathrm{NAD}(\mathrm{P}) \mathrm{H}$

$\mathrm{NaHCO}_{3}$

$\mathrm{Na}_{2} \mathrm{HPO}_{4}$

$\mathrm{NaH}_{2} \mathrm{PO}_{4}$

$\mathrm{NaOH}$

NQO-1

$\mathrm{NaS}$

NF- $\kappa B$

NMDG

NO

OAT

ORi

PBS

PMA

RNA

SLC

TGF

TMACl

TMAOH
Kaliumchlorid

Kaliumdihydrogenphosphat

Lipopolysaccharid

Magnesiumsulfat

Monokine Induced by Gamma interferon; durch

Interferon $\gamma$ induziertes Monokin

Monomethylfumarat

Myelin-Oligodendrozyten-Glykoprotein

Mammalian Ringer

Multiple Sklerose

Natriumchlorid

Natrium-abhängiger Citrattransporter

Natrium-abhängiger Dicarboxylattransporter

Nicotinamidadenindinukleotidphosphat

Natriumbikarbonat

Natriumhydrogenphosphat

Natriumdihydrogenphosphat

Natriumhydroxid

Quinonreduktase 1

Natrium-abhängiger Sulfattransporter

nukleärer Faktor kappa B

$N$-Methyl-D-Glucamin

Stickstoffmonoxid

organischer Anionen-Transporter

Oozyten-Ringer

Phosphate Buffered Saline;

Phosphat-gepufferte Salzlösung

Phorbolacetatmyristat

Ribonucleic acid; Ribonukleinsäure

Solute Carrier; Transporter löslicher Substanzen

Transforming Growth Factor;

Transformierender Wachstumsfaktor

Tetramethylammoniumchlorid

Tetramethylammoniumhydroxid 
$\mathrm{TMAPO}_{4}$

TNF

TRIS

$\mathrm{V}_{\text {MAX }}$

$\mathrm{V}_{\mathrm{c}}$

ZNS
Tetramethylammoniumphosphat

Tumornekrosefaktor

Tris(hydroxymethyl)-aminomethan

Maximalgeschwindigkeit

Klemmspannung, Haltepotential

Zentrales Nervensystem 


\section{1.) Einleitung}

\section{1.) Die SLC 13 - Familie}

Die fünf Gene der Solute-Carrier(SLC)-13-Familie kodieren für Transporter, die in Zellmembranen von Säugern exprimiert werden, aber auch in Fischen, anderen Wirbeltieren, Pflanzen, Bakterien und Hefen nachgewiesen werden konnten (PAJOR 2006). Generell sind sie in einer Vielzahl verschiedener Gewebe nachweisbar, vor allem aber in Epithelzellen der Nieren und des Gastrointestinaltraktes (MARKOVICH und MURER 2004). Sie sind untereinander $\mathrm{zu}$ 40-50\% identisch in ihrer Aminosäuresequenz und wurden in der Reihenfolge benannt, in der sie auch entdeckt wurden (PAJOR 2006): SLC13A1-5 kodieren für die Transporter NaS1, NaDC1, NaDC3, NaS2 und NaCT. Grundsätzlich ist ihnen Folgendes gemeinsam: Zum einen besitzen sie zwischen 8-13 Transmembrandomänen (MARKOVICH und MURER 2004), zum anderen ist ihre Funktion als sekundär-aktive Transporter von der Anwesenheit von Natrium abhängig (PAJOR 2006). Da sie elektrogene Transporter sind, müssen mindestens 3 Natriumionen im Symport mit einem divalenten Substratmolekül transportiert werden (MARKOVICH und MURER 2004). Als Substrate dienen vorzugsweise zweiwertige Oxy-Anionen. Hierzu gehören für die NaS-Kotransporter (NaS1 und NaS2) vor allem Sulfat, Selenat und Thiosulfat, während es für die anderen Kotransporter ( $\mathrm{NaDC} 1, \mathrm{NaDC} 3$ und $\mathrm{NaCT}$ ) meist Zwischenprodukte des Citratzyklus sind; also Di- und Tricarboxylate wie Succinat, $\alpha$-Ketoglutarat und Citrat. Bei Vorhandensein von Natrium und Substrat findet ein elektrogener Transport statt, der bei negativen Klemmpotentialen einwärtsgerichtete Ströme hervorruft (MARKOVICH und MURER 2004; PAJOR 2006). Zusätzlich wurden bei Messungen mit der „,Two-electrode-voltage-clamp“Methode Leckströme gefunden, die in Abwesenheit von Substraten, dafür aber in Anwesenheit von Kationen, insbesondere Natrium, nachweisbar waren (PAJOR 2006).

In Strukturanalysen wurde nach dem/den bestimmenden Faktor/en für die Funktion der einzelnen Transporter gesucht. Als einflussreichster Faktor wurde hierfür die Carboxyterminale Hälfte der jeweiligen Aminosäurensequenz identifiziert. Es wird angenommen, dass die Transmembranhelices 9 und 10 für die Akzeptanz der Substrate notwendig sind und dass diese Transmembranhelices außerdem an Konformationsänderungen während des Transportzyklus beteiligt sind (PAJOR 2006).

Alle Transporter der SLC13-Familie sind DIDS-unempfindlich. Das bedeutet, dass die Substrataufnahme nicht durch 4,4'-Diisothiozyano-2,2-Stilbendisulfonsäure (DIDS), einem 
Inhibitor für Anionen-Austauscher, blockiert werden (MARKOVICH und MURER 2004). Dies ist auch nicht verwunderlich, da alle bisher bekannten Mitglieder der SLC13-Familie als Sym- bzw. Kotransporter identifiziert wurden und nicht als Austauscher arbeiten.

Der NaS1, der durch das Gen SLC13A1 kodiert wird, wurde als erster Transporter der SLC13-Familie identifiziert. Der in menschlichen Zellen vorkommende hNaS1 besteht aus 595 Aminosäuren, die sich zu 13 Transmembrandomänen formieren, und wurde auf dem Chromosom 7 neben den Genen, die für die Sulfattransporter DRA (downregulated-inadenoma; Genname SLC26A3) und NaS2 (Genname SLC13A4) kodieren, lokalisiert (LEE et al. 2000). Die Bedeutung der Erkennung seiner Regulation und Funktion wird deutlich, wenn man die Bedeutung der Sulfate betrachtet. Sulfate und Sulfatderivate sind grundlegend an Wachstum, Entwicklung und Zellstoffwechselprozessen beteiligt. Sulfat wird in den Nieren frei filtriert und anschließend im proximalen Tubulus reabsorbiert. Der hNaS1 kommt im menschlichen Organismus ausschließlich in der apikalen Membran proximaler Tubuluszellen vor (BECK und MARKOVICH 2000) und ist dort entscheidend an der Reabsorption von Sulfat beteiligt (MARKOVICH und ARONSON 2007). Gezeigt werden konnte dies in Versuchen mit NaS1-Knockout-Mäusen. Diese litten an schwerer Hyposulfatämie, Hypersulfaturie, Wachstumsretardierung und Infertilität (DAWSON et al. 2003). NaS1Knockout-Mäuse zeigten zusätzlich Verhaltensauffälligkeiten verschiedenster Art (DAWSON et al. 2004), Gedächtnisstörungen und Einschränkungen des Riechvermögens (DAWSON et al. 2005).

Der zweite identifizierte Transporter aus der SLC13-Familie ist der NaDC1 mit dem Gennamen SLC13A2. Der humane NaDC1 ist auf Chromosom 17p11.1-q11.1 lokalisiert. Bisher liegen Klone des NaDC1 des Menschen, der Ratte, des Kaninchens, der Maus, des Opossums, des Xenopus und des Zebrafisches vor (MARKOVICH und MURER 2004). Der NaDC1 besteht Spezies-abhängig aus 590 - 593 Aminosäuren. In seiner Sekundärstruktur ähnelt er dem Natrium-Sulfattransporter NaS1 (PAJOR 1995). Sein Vorkommen beschränkt sich auf apikale Membranen von Nieren des proximalen Tubulus sowie des Dünndarms. Transkripte konnten allerdings auch in Leber, Lunge und Nebenniere nachgewiesen werden (PAJOR 1995). Der NaDC1 transportiert vorzugsweise Dicarboxylate in trans-Konfiguration mit einer Kettenlänge von vier Kohlenstoffatomen wie Succinat. Im Vergleich zu anderen Natrium-Dicarboxylattransportern besitzt er für Succinat eine niedrige Substrataffinität, d.h. die halbmaximale Sättigungskonstante $\left(\mathrm{K}_{\mathrm{M}}\right)$ für Succinat kann je nach Expressionssystem und 
Nachweismethode bis zu 0,8 mM betragen (PAJOR 2006). Die Aufnahme von Succinat wird durch Lithium, das kompetitiv zu Natrium eine Natriumbindungsstelle besetzt, inhibiert (PAJOR 2000). Der NaDC1 könnte eine Rolle bei metabolischer Azidose spielen. In Ratten mit chronischer metabolischer Azidose konnte im Bürstensaum der Nierentubuli sowohl eine vermehrte Konzentration an mRNA als auch eine erhöhte Expression des NaDC1-Proteins in der apikalen Membran detektiert werden (ARUGA et al. 2000). Jedoch zeigten Mäuse, bei denen das SLC13A2-Gen ,ausgeknockt“ war, keine offensichtlichen phänotypischen Abweichungen und wiesen lediglich eine erhöhte Ausscheidung von Citrat im Urin auf (PAJOR 2006).

Der nächste Transporter, der aus der Reihe der SLC13-Familie identifiziert wurde, ist der NaDC3 mit dem Gennamen SLC13A3. Aufgrund seiner Bedeutung für diese Arbeit wird er nicht hier, sondern im folgenden Kapitel einzeln ausführlich besprochen.

Der vierte Transporter aus dieser Reihe ist der NaS2 (Genname SLC13A4), welcher ursprünglich SUT-1 genannt wurde. NaS2 liegt beim Menschen auf Chromosom 7q33, unweit von NaS1 (GIRARD et al. 1999). Die im Menschen vorzufindenden Varianten dieser beiden Transporter, hNaS1 und hNaS2, besitzen zu $49 \%$ identische Aminosäurensequenzen (MARKOVICH und MURER 2004). Außerdem scheint es, als habe NaS2 nahezu die gleiche Substratspezifität wie der NaS1. Transportiert wird vor allem Sulfat; inhibiert werden kann dieser Transport durch Thiosulfat, Phosphat, Molybdat, Selenat und Wolframat (MARKOVICH et al. 2005). Nachgewiesen werden konnte mRNA des NaS2 vor allem in Plazenta, Hoden und hoch-endothelialen Venolen, eine niedrigere Transkriptionszahl aber auch in Herzen, Leber und Thymus (GIRARD et al. 1999; MARKOVICH et al. 2005).

Der letzte beschriebene Transporter aus der SLC13-Familie ist der NaCT, Genname SLC13A5. Im Menschen ist der NaCT auf Chromosom 17p12-13 vorzufinden, seine mRNA ist vor allem in der Leber, aber auch in den Nieren nachweisbar; in wesentlich geringeren Konzentrationen auch in Hirn und Hoden (INOUE et al. 2002a). Ähnlichkeiten in der Primärstruktur des Proteins hNaCT finden sich vor allem zum hNaDC1 und hNaDC3: erstere sind zueinander zu $54 \%$ identisch, hNaCT und hNaDC3 zueinander zu $47 \%$ (MARKOVICH und MURER 2004). Auch wenn es Ähnlichkeiten in der Substratspezifität im Hinblick auf Di- und Tricarboxylate zwischen dem NaCT und den NaDCs zu geben scheint, unterscheiden sich die Transporter durch ihre Affinität gegenüber Citrat: die Affinität des im Menschen nachweisbaren hNaCT zu den Citraten ist höher als die zu den Dicarboxylaten. Vergleichbar 
verhält es sich auch mit den Transportgeschwindigkeiten: $V_{\max }$ ist höher für Citrat als für Succinat (INOUE et al. 2004). Der Transportmodus und die Stöchiometrie von Natrium zu Substrat ähneln denen der anderen Transporter aus der SLC13-Familie (INOUE et al. 2002 b). Sein Verhalten gegenüber Lithium ist speziesabhängig. Während der NaCT der Ratte durch Lithium gehemmt wird, hat Lithium auf den menschlichen hNaCT stimulierende Wirkung und verbessert sogar die Transportrate. Deutlich wird das durch eine gemessene höhere Maximalgeschwindigkeit $\mathrm{V}_{\max }$ und eine niedrigere $\mathrm{K}_{\mathrm{M}}$ für Citrat (INOUE et al. 2003). 


\begin{tabular}{|c|c|c|c|c|c|c|c|c|c|c|c|c|c|c|c|c|c|c|c|c|c|c|}
\hline 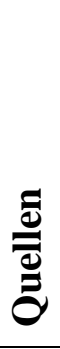 & 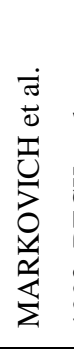 & 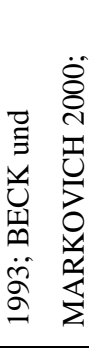 & 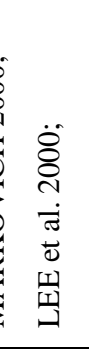 & 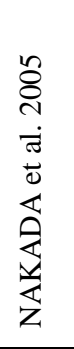 & 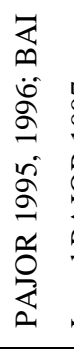 & 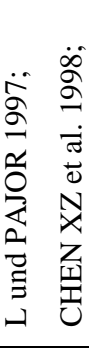 & 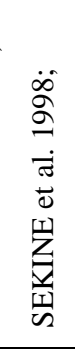 & 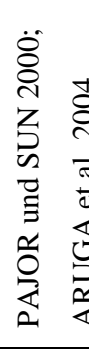 & 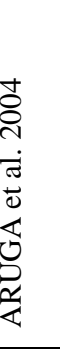 & 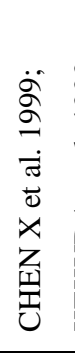 & 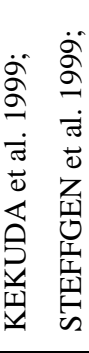 & 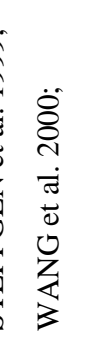 & 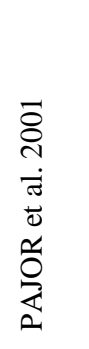 & & 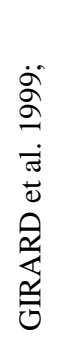 & 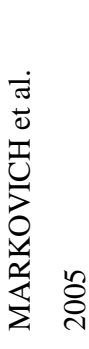 & & & 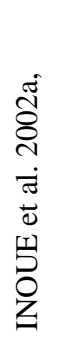 & 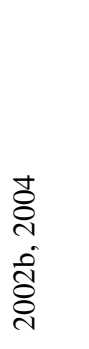 & & \\
\hline 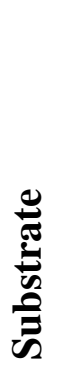 & $\begin{array}{l}\stackrel{\oplus}{E} \\
\stackrel{\Xi}{\Xi} \\
\tilde{\Xi}\end{array}$ & 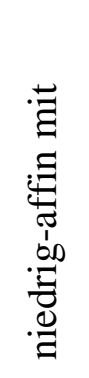 & 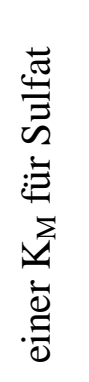 & 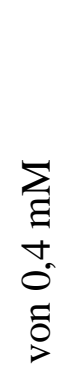 & 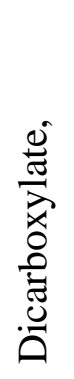 & 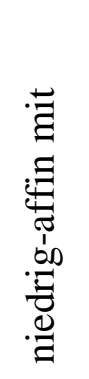 & 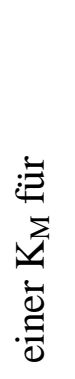 & 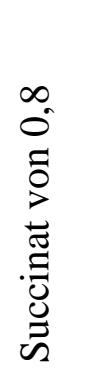 & $\sum_{\Xi}$ & 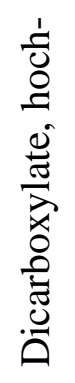 & 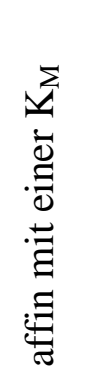 & 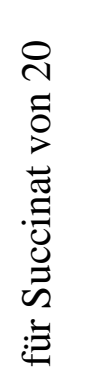 & $\sum_{\Xi}$ & & 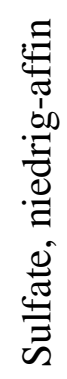 & 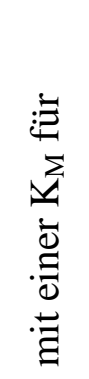 & 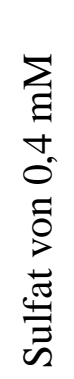 & & 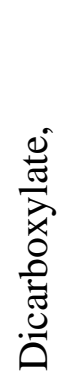 & 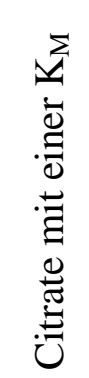 & 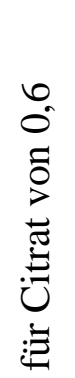 & $\sum_{\Xi}$ \\
\hline Uू & $\stackrel{\oplus}{\stackrel{ \pm}{ \pm}}$ & 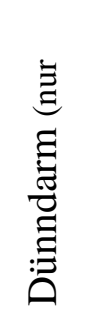 & 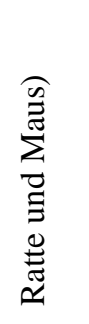 & & 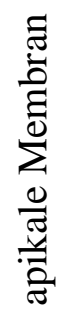 & 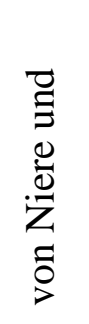 & 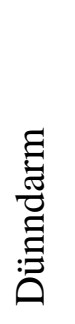 & & & 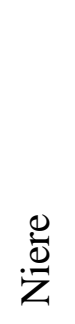 & 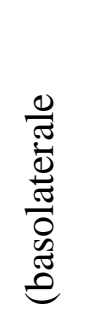 & 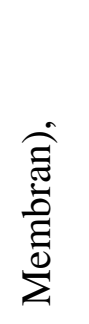 & 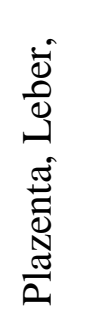 & $\stackrel{\Xi}{\Xi}$ & 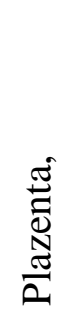 & $\frac{\frac{0}{\pi}}{\frac{\pi}{0}}$ & 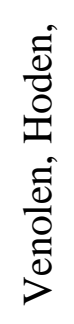 & 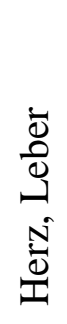 & 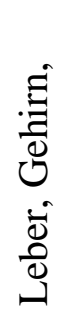 & $\begin{array}{l}\overline{0} \\
\frac{\bar{d}}{0} \\
\tilde{I}\end{array}$ & & \\
\hline 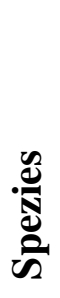 & 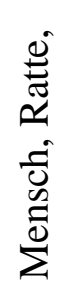 & 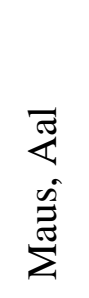 & & & $\begin{array}{l}\hat{D} \\
\text { Dे } \\
\sum_{i}^{0}\end{array}$ & 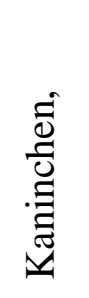 & 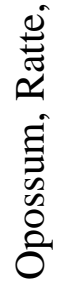 & 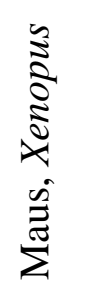 & $\begin{array}{l}\frac{a}{3} \\
\bar{d} \\
\mathbb{z}\end{array}$ & 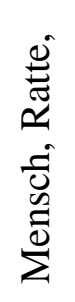 & 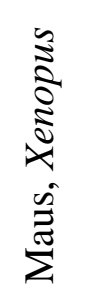 & 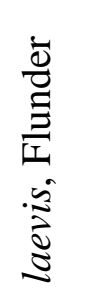 & & & 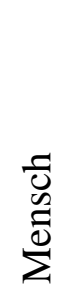 & & & & 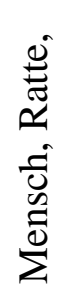 & $\stackrel{\mathscr{E}}{\Xi}$ & & \\
\hline 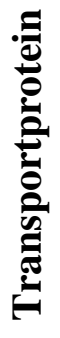 & $\begin{array}{l}\overline{\tilde{n}} \\
\overline{\mathbf{z}}\end{array}$ & $\begin{array}{l}\overparen{7} \\
\frac{1}{\tilde{z}} \\
\stackrel{z}{Z}\end{array}$ & & & $\begin{array}{l}\bar{U} \\
\bar{Z}\end{array}$ & 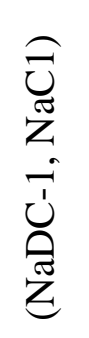 & & & & $\begin{array}{l}\mathscr{O} \\
\text { Z }\end{array}$ & 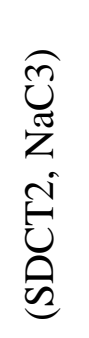 & & & & $\begin{array}{l}\tilde{N} \\
\tilde{z}\end{array}$ & 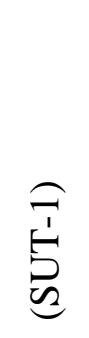 & & & & $\begin{array}{l}\text { U్ } \\
\text { Z }\end{array}$ & & \\
\hline 氖 & 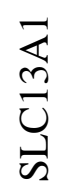 & & & & $\frac{\substack{c \\
ٍ}}{3}$ & & & & & $\frac{\sqrt[n]{d}}{\stackrel{m}{U}}$ & & & & & 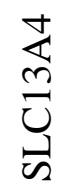 & & & & $\frac{n}{\sqrt[n]{n}}$ & & & \\
\hline
\end{tabular}

Tabelle 1: Übersicht über die SLC13-Familie (nach PAJOR 2006, S. 598) 


\section{2.) Der hoch-affine Natrium-Dicarboxylattransporter}

SLC13A3 codiert für den NaDC3, den hoch-affinen Natrium-Dicarboxylattransporter (PAJOR 2006) mit einer $\mathrm{K}_{\mathrm{M}}$ für Succinat unter 0,1 mM. Dieser konnte bisher aus den Nieren der Ratte (rNaDC3: CHEN X et al. 1999), der Winterflunder (fNaDC3: STEFFGEN et al. 1999), Mäusegehirnen (mNaDC3: PAJOR et al. 2001) und der menschlichen Plazenta (hNaDC3: WANG et al. 2000) isoliert und kloniert werden. In menschlichen Zellen wurde der NaDC3 über die FISH-Methode (Fluoreszenz-in-situ-Hybridisierung) auf Chromosom 20q213.1 nachgewiesen. Der humane NaDC3 ist mehr als 80 Kilobasenpaare lang und besteht aus 13 Exons und 12 Introns (WANG et al. 2000). Das transkribierte Protein wiederum enthält in seiner Primärstruktur 602 Aminosäuren (BAI XY et al. 2007). Nicht exakt geklärt werden konnte bisher, über wie viele Transmembrandomänen der hNaDC3 verfügt. WANG et al. veröffentlichten 2000 ihre Annahme, es seien 12 Transmembrandomänen, wobei sowohl Cals auch N-Terminus extrazellulär lägen. BAI XY et al. wiederum veröffentlichten 2007, es seien 11 Transmembrandomänen; mit dem C-Terminus extra-, dem N-Terminus aber intrazellulär gelegen. Die Erkennungsregion des NaDC3 für Substrate ist bisher nicht eindeutig identifiziert worden. Allerdings wird für den $\mathrm{NaDC} 3$, wie für alle Transporter der SLC13-Familie, die Erkennungsdomäne in der carboxyterminalen Hälfte des jeweiligen Proteins vermutet (MARKOVICH und MURER 2004). Vor allem Abschnitte der Transmembrandomänen 7-11 scheinen sowohl im Erkennen und Binden von Substraten, als auch von Kationen, beteiligt zu sein (PAJOR 2000). Eine große strukturelle Ähnlichkeit des NaDC3 lässt sich zum niedrig-affinen Natrium-Dicarboxylattransporter NaDC1 finden: die humanen Transporter ähneln sich zu $43 \%$ in ihrer Aminosäuresequenz (MARKOVICH und MURER 2004), die der Ratten sogar in 47-48 \% (CHEN X et al. 1999). Allerdings konnte der $\mathrm{NaDC} 3$ im Vergleich zum NaDC1 in einer größeren Vielzahl an unterschiedlichen Geweben gefunden werden. Zum einen wurde er in der basolateralen Membran proximaler Tubuluszellen der Niere nachgewiesen (fNaDC3: HENTSCHEL et al. 2003; hNaDC3: BAI X et al. 2006), zum anderen aber auch in Leberzellen, Plazenta und im Gehirn (KEKUDA et al. 1999); hier sowohl in den Meningen (CHEN X et al. 1999) als auch in Neuronen, den Zellen des Plexus choroideus (PAJOR et al. 2001) und in Astrozyten (YODOYA et al. 2006). Nicht nur sein Vorkommen scheint verbreiteter zu sein, er scheint auch eine breiter gefächerte Substratspezifität als der NaDC1 zu besitzen. So transportiert er, zusätzlich zu Dicarboxylaten in trans-Konfiguration mit vier Kohlenstoffatomen, den Hauptsubstraten des NaDC1 (PAJOR 2000), auch Substrate längerer Kettenlänge und verzweigte Dicarboxylate (PAJOR 2006). WANG et al. untersuchten 2000 die Substratspezifität des hNaDC3 anhand transfizierter 
HRPE-Zellen (human retinal pigment epithelial), deren $\left[{ }^{3} \mathrm{H}\right]$-Succinat-Aufnahme durch unterschiedliche Substrate unterschiedlich stark gehemmt wurde. Substrate mit einer Kettenlänge von vier oder fünf Kohlenstoffatomen stellten sich als stärkste Inhibitoren heraus - woraus sich die höchste Substrataffinität des hNaDC3 folgern lässt. Succinat, Fumarat, Glutarat und $\alpha$-Ketoglutarat reduzierten die $\left[{ }^{3} \mathrm{H}\right]$-Succinat-Aufnahme deutlich verglichen zur Kontrolle, wohingegen Malonat und Oxalat, Moleküle mit einer Kohlenstoffkettenlänge von nur drei, beziehungsweise zwei Kohlenstoffen, die Aufnahme nur auf $72 \%$ (Malonat) und 93 \% (Oxalat), senken konnten. Zusätzlich zur Länge des Kohlenstoffgrundgerüsts spielt auch die anionische Ladung eine Rolle. Monocarboxylate wie Laktat, Pyruvat, Butyrat und Valerat konnten die Aufnahme von $\left[{ }^{3} \mathrm{H}\right]$-Succinat nur geringfügig senken, wohingegen zweiwertige Dicarboxylate, wie oben erwähnt, die hauptsächlichen Substrate des NaDC3 sind. Citrat, ein Tricarboxylat, wird sehr wahrscheinlich auch nur in seiner divalenten Form als Substrat vom NaDC3 akzeptiert. Die Aminosäuren Aspartat und Glutamat, die unter physiologischen Bedingungen zwar zwei negativ geladene Carboxylgruppen, jedoch auch eine positiv geladene Aminogruppe besitzen, hemmen die Aufnahme von Succinat zu $42 \%$ bzw. $18 \%$. Die Substratspezifität des NaDC3 scheint weiterhin sogar von der Konfiguration der Dicarboxylate abzuhängen. Während Fumarat, ein trans-Isomer, einen äußerst potenten Inhibitor in dieser Versuchsreihe darstellte, konnte Maleat, dessen Carbonsäurereste in cisKonfiguration zueinanderstehen, den Transport von Succinat nur wenig beeinflussen. Als unbedeutende Kriterien bezüglich der Substrataffinität zeigten sich funktionelle Gruppen am $\alpha$-Kohlenstoffatom, wie Hydroxylgruppen (z.B. Malat) und Keto-Gruppen (z.B. $\alpha$ Ketoglutarat). Malat und $\alpha$-Ketoglutarat hemmen die Aufnahme von Succinat ähnlich gut wie Succinat und Glutarat. Die Affinität dieser Substanzen zum NaDC3 wird in einem späteren Abschnitt diskutiert. Die Substitution von Methylresten am zweiten und dritten Kohlenstoffatom (2,2- bzw. 2,3-Methylsuccinat) des Succinat schien keinen Einfluss auf die Aufnahme von Succinat zu haben (WANG et al. 2000).

Wie alle Transporter der SLC13-Familie ist die Funktion des NaDC3 Natrium-abhängig. In Versuchen, in denen Natriumionen in äquimolaren Konzentrationen durch andere einwertige Kationen wie Kalium, Cholin oder N-Methyl-D-Glucamin (NMDG) ersetzt wurden, wurde die Aufnahme von Succinat zu 99 \% gestoppt (KEKUDA et al. 1999), das heißt Succinat wurde nicht mehr über den NaDC3 transloziert. In Versuchen an Membranvesikeln aus der basolateralen Membran proximaler Tubuli der Ratte wurde festgestellt, dass bei der Natriumassoziierten Aufnahme eines Dicarboxylats (hier Methylsuccinat) in die Vesikel eine positive 
Nettoladung einwärts strömt (BURCKHARDT G 1984). Erklärt werden kann es durch die Stöchiometrie des Transports, da je Transportzyklus 3:1 Natriumionen zusammen mit einem zweiwertigen Substrat bewegt werden (WANG et al. 2000).

Bei steigendem Angebot von Natrium erhöht sich die Transportrate für Succinat sigmoidal (KEKUDA et al. 1999). Ein weiteres Ion, das Einfluss auf die Natrium-Bindungsstelle des hNaDC3 hat, ist Lithium. In Experimenten, in denen das Zwei-Elektroden-SpannungsklemmVerfahren an Xenopus-laevis-Oozyten angewendet wurde und die Außenlösung vollkommen Natrium-frei, jedoch aber Succinat- und Lithium-haltig war, wurden einwärtsgerichtete Ströme gemessen (WANG et al. 2000). In weiterführenden Versuchen, in denen Natrium in konstanter sättigender Konzentration $(70 \mathrm{mM})$ vorlag und Lithium-Konzentrationen in den Stufen 0, 5, 10, 20 und $30 \mathrm{mM}$ variiert wurden, zeigte sich bei allen Klemmspannungen eine Hemmung der durch Succinat induzierten Ströme mit steigender Lithium-Konzentration (WANG et al. 2000). Dies gilt aber erst ab Lithium-Konzentrationen, die größer als $5 \mathrm{mM}$ sind, wie BURCKHARDT BC et al. 2005 zeigten. Niedrigere Konzentrationen an Lithium scheinen keinen Einfluss auf die Aufnahme von Succinat oder die Succinat-mediierten Ströme $\mathrm{zu}$ haben. Bedeutsam ist dies in der Therapie bipolarer Störungen, da in therapeutischen Dosen Blut-Lithium-Konzentrationen zwischen 0,8-2 mM erreicht werden (SPROULE 2002), womit die Reabsorption von Succinat und anderen Dicarboxylaten aus dem Lumen des proximalen Tubulus der Niere nicht beeinträchtigt wird (BURCKHARDT BC et al. 2005).

Die kurzfristige Regulation des hoch-affinen Dicarboxylattransporters wurde am fNaDC3 hinsichtlich der Proteinkinase $\mathrm{C}$ untersucht. Für diese besitzt er fünf mögliche Phosphorylierungsstellen; weitere zwei für Proteinkinase A. Größtenteils wurde die Proteinkinase $\mathrm{C}$ im Versuch durch das stimulatorisch wirksame Phorbolacetatmyristat (PMA) und wiederum dessen Inhibitoren, zum Beispiel Staurosporin, gesteuert, welches ein Tumorpromoter ist und starke Ähnlichkeit zu einem anderen häufigen Stimulanz der Proteinkinase C in vivo darstellt: Dioctanoylglycerol (DOG) (CASTAGNA et al. 1982). Die Experimente ergaben, dass eine Aktivierung der Proteinkinase C die Aufnahme von Succinat über den fNaDC3 hemmt (HAGOS et al. 2003).

Letztendlich bleibt noch offen, welche klinische Bedeutung der hNaDC3 für den Menschen hat. Seine Transportspezifität für Dicarboxylate prädisponiert ihn selbstverständlich zur Bereitstellung wichtiger Substrate für den Krebszyklus, einem elementaren Bestandteil der Energiegewinnung der Zelle. Weiterhin versorgt er im plazentalen Synzytiotrophoblasten mit 
seinen Transportfähigkeiten den Fötus mit Dicarboxylaten zur Energiegewinnung (GANAPATHY et al. 1988). Der hNaDC3 dient jedoch nicht ausschließlich der Energiegewinnung. So wird in den perivenösen Hepatozyten Glutamin aus $\alpha$-Ketoglutarat hergestellt, das erst aus dem Blut resorbiert werden muss (PAJOR et al. 2001). Das Gehirn wiederum benötigt Dicarboxylate zur Synthese von Neurotransmittern wie Glutamat und $\gamma$ Aminobuttersäure; dazu bedarf es der Aufnahme von Glutamin und $\alpha$-Ketoglutarat (SHANK und CAMPBELL 1982). Myelinisierungsprozesse der Axone benötigen $N$-Acetylaspartat, das ebenfalls über den hNaDC3 bereitgestellt wird (HUANG et al. 2000). Außerdem soll hier im Folgenden trotz seiner zahlreichen Lokalisationen vorzugsweise auf seine Funktionen in der Niere Bezug genommen werden. Betrachtet man den hNaDC3 in den renalen proximalen Tubuluszellen, stößt man auf Thesen von DANTZLER (2002). Laut seiner Veröffentlichung transportiert der hNaDC3 bei ausreichender Verfügbarkeit von Natriumionen knapp 50 Prozent des, für die organischen Anionen-Austauscher OAT1 und 3 benötigten, $\alpha$ Ketoglutarats aus dem Blut in die Zelle. Die beiden OATs sitzen unter anderem ebenso in der basolateralen Membran proximaler Tubuluszellen und sind für den Austausch von intrazellulären Dicarboxylaten gegen hydrophile organische Anionen zuständig. Das können physiologisch im Menschen vorkommende Substanzen sein, wie Hippurat oder Prostaglandine, aber auch allogene Stoffe, wie zum Beispiel Medikamente - erwähnt seien hier nur die ACE-Hemmer und die ß-Laktamantibiotika (ENOMOTO und ENDOU 2005, SEKINE et al. 2006, ZHOU und YOU 2007, BURCKHARDT BC und BURCKHARDT G 2011). Dementsprechend ist der hNaDC3 über Umwege an der renalen Ausscheidung von Pharmaka beteiligt, da er den nötigen Substratgradienten schafft. Betrachtet man weiterhin Dicarboxylate, stößt man auf Dimercaptobernsteinsäure (DMSA). Diese ist ein Dicarboxylat mit Substitution zweier Mercaptogruppen am zweiten und dritten Kohlenstoffatom seiner vier Kohlenstoffatome langen Kette. Da Dicarboxylate mit Dimethyl-Substitution Substrate des hNaDC3 sind, wurde postuliert, dass auch DMSA ein Substrat des hNaDC3 sein könnte. DMSA ist ein wichtiger Chelator und wird in der Medizin bei Schwermetallvergiftungen therapeutisch eingesetzt (APOSHIAN HV und APOSHIAN MM 1990), da sich Schwermetalle vorzugsweise in Zellen des renalen proximalen Tubulus ansammeln (ZALUPS 2000). Mittels Elektrophysiologie wurde nachgewiesen, dass der hNaDC3 DMSA in die Zelle transportiert und damit wesentlich zur Entgiftung bei Schwermetallbelastung beiträgt (BURCKHARDT BC et al. 2005). Der Sonderfall des chronischen Nierenversagens sollte hier aufgrund seiner Lokalisation und Wirkung auch noch behandelt werden. Bei Betroffenen steigen viele unterschiedliche Metabolite an, die einwertigen unter ihnen - zum Beispiel 
Indolacetat und Hippurat - werden durch den OAT1 transportiert (MOTOJIMA et al. 2002). Allerdings findet ebenso ein Anstieg der dicarboxylischen Metabolite Guanidinosuccinat und Quinolinat statt (VANHOLDER et al. 2003). Daraus könnte eine Inhibition der Aufnahme anderer Dicarboxylate durch den hNaDC3, wie Succinat und anderer Substrate des KrebsZyklus, entstehen. BURCKHARDT BC et al. untersuchten dies 2005 anhand von elektrophysiologischen Untersuchungen und kamen zu den Ergebnissen, dass weder Guanidinosuccinat noch Quinolinat substratabhängige Ströme auslösen können. Allerdings zeigte Guanidinosuccinat eine latente inhibitorische Funktion von $20 \%$, als es im Zusammenhang mit Succinat-induzierten Strömen untersucht wurde. Somit ist es möglich, dass bei Patienten, die unter chronischem Nierenversagen leiden, eine Inhibition des hNaDC3 stattfindet und somit der Weg der Energiebereitstellung über den Krebs-Zyklus reduziert ist. Jedoch wird der Transporter nicht nur im chronischen Nierenversagen relevant. Nephrotoxische Substanzen, wie Aminoglykoside, Schwermetalle und Kontrastmittel, sorgen in renalen Zellen für eine Aktivitätssteigerung der Proteinkinase C (MILLER 2002). Wie oben erwähnt, sorgt allerdings eine Hochregulation der Proteinkinase C für eine Senkung der NaDC3-Funktion und somit für Einbußen im Energiestoffwechsel. Dies schädigt renale Zellen zusätzlich zu der Intoxikation, der sie ohnehin ausgesetzt sind. Daher wird ein Zusammenhang in der Entstehung des akuten Nierenversagens vermutet (HAGOS et al. 2003). 


\begin{tabular}{|c|c|}
\hline Substrat & $\begin{array}{l}\text { \% der }\left[{ }^{3} \mathbf{H}\right] \text {-Succinat-Aufnahme } \\
\text { (verglichen zur Kontrolle) }\end{array}$ \\
\hline Kontrolle $\left(\left[{ }^{3} \mathrm{H}\right]\right.$-Succinat $)$ & 100 \\
\hline$\alpha$-Ketoglutarat & 3 \\
\hline Aspartat & 58 \\
\hline Butyrat & 95 \\
\hline Citrat & 63 \\
\hline Dimethylsuccinat & 1 \\
\hline Fumarat & 4 \\
\hline Glutamat & 82 \\
\hline Glutarat & 3 \\
\hline Laktat & 100 \\
\hline Malat & 8 \\
\hline Maleat & 82 \\
\hline Malonat & 72 \\
\hline Oxalat & 93 \\
\hline Pyruvat & 87 \\
\hline Valerat & 119 \\
\hline
\end{tabular}

Tabelle 2: Substratspezifität des hNaDC3 (nach WANG et al. 2000, S. 1023)

hNaDC3-transfizierte und Vektor-transfizierte HRPE-Zellen wurden in 24-Well-Platten 1 min lang mit $2 \mathrm{nM}$ $\left[{ }^{3} \mathrm{H}\right]$-Succinat inkubiert und der Absolutwert der Kontrolle, sprich die nach intrazellulär aufgenommene $\left[{ }^{3} \mathrm{H}\right]-$ Succinat-Konzentration, ermittelt. Anschließend wurden bei gleichbleibenden Bedingungen jeweils $2 \mathrm{mM}$ der verschiedenen Substanzen hinzugegeben und erneut die nach intrazellulär aufgenommene [ $\left.{ }^{3} \mathrm{H}\right]$-SuccinatKonzentration gemessen. Als potenteste Inhibitoren der $\left[{ }^{3} \mathrm{H}\right]$-Succinat-Aufnahme zeigten sich in absteigender Reihenfolge Dimethylsuccinat, Glutarat und $\alpha$-Ketoglutarat gleichermaßen, Fumarat und schließlich Malat. 


\section{3.) Fumarat und seine Derivate}

Fumarat ist das Salz der Fumarsäure. Dieses wiederum ist der Trivialname der ungesättigten Dicarbonsäure trans-Butensäure, welche ebenso als trans-Ethylendicarbonsäure bezeichnet werden kann.<smiles>O=C(O)/C=C/C(=O)O</smiles>

\section{Abbildung 1.1: Strukturformel der Fumarsäure}

Fumarat ist ein Zwischenprodukt des Zitronensäurezyklus. Dieser ist entscheidend für die Energiegewinnung der Zelle und läuft bei Eukaryoten in Mitochondrien, bei Prokaryoten im Zytoplasma ab. Fumarat entsteht hierbei enzymatisch mithilfe der Succinatdehydrogenase aus Succinat, dem Salz der Bernsteinsäure (Butandisäure). Aus Fumarat wird unter Einwirkung des Enzyms Fumarase Maleat. Dieses ist das Salz der Maleinsäure, welches gleichzeitig das cis-Isomer der Fumarsäure darstellt.

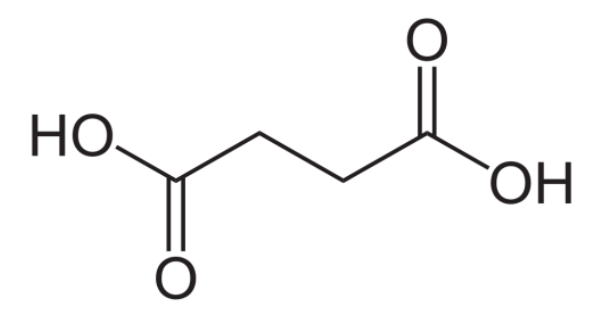

Abbildung 1.2: Strukturformel der Bernsteinsäure

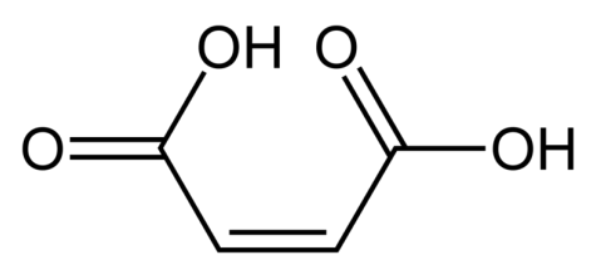

Abbildung 1.3: Strukturformel der Maleinsäure 


\subsection{1.) Pharmakologische Dynamik und Einsatz der Fumaratderivate}

Fumarate werden pharmakologisch vor allem in Form von Fumarsäureestern eingesetzt. Deren Wirksamkeit wurde in Doppel-Blind-Studien in den Therapiemodalitäten der Psoriasis vulgaris nachgewiesen (ALTMEYER et al. 1994). Der in den zugelassenen oralen Therapeutika enthaltene Wirkstoff ist Dimethylfumarat (DMF) (NIEBOER et al. 1990). Nach Resorption der Fumarsäureester im Dünndarm werden diese im Zitratzyklus metabolisiert; und Esterasen hydrolysieren DMF zu Monomethylfumarat (MMF). Auch dieser Metabolit wird im Anschluss im Zitratzyklus weiter metabolisiert (NIBBERING et al. 1993). Die Hydrolyse von DMF zu MMF erfolgt im alkalischen Milieu bei $\mathrm{pH}$ 8, was in etwa dem $\mathrm{pH}$ des Dünndarms entspricht, wohingegen keinerlei Hydrolyse bei $\mathrm{pH}$ 1, einer sauren Umgebung, die der des Magens entspricht, stattfindet. Die Halbwertszeit von DMF beträgt lediglich 12 Minuten, wohingegen dessen Metabolit MMF eine Halbwertszeit von 36 Stunden besitzt (LITJENS et al. 2004b). MMF ist quantitativ höchstens fünf bis sechs Stunden nach Einnahme per os im Serum nachweisbar (MROWIETZ et al. 1999; LEHMANN et al. 2007; MROWIETZ und ASADULLAH 2005).<smiles>CCOC(=O)/C=C/C(=O)OCC</smiles>

Abbildung 1.4: Strukturformel Diethylfumarat<smiles>COC(=O)/C=C/C(=O)OC</smiles>

Abbildung 1.5: Strukturformel Dimethylfumarat 


\subsection{2.) Fumarsäure und ihre Wirkmechanismen in der pharmakologischen Therapie der Psoriasis vulgaris und der Multiplen Sklerose}

Begründet ist die Anwendung der Fumarsäureester bei Psoriasis-Patienten durch ihre immunmodulatorische und -suppressive Wirkung. Dabei steht vor allem deren Einfluss auf die zellulären Bestandteile des adaptiven Immunsystems im Vordergrund. TREUMER und Kollegen (TREUMER et al. 2003) zeigten, dass es unter Einfluss von Dimethylfumarat, aber nicht von Monoethylfumarat, in T-Zellen zu einer Abnahme des antiapoptotischen Proteins Bcl-2 kommt - somit wird T-Zell-Apoptose induziert. Klinische Studien zeigten korrelierend damit einen Rückgang von CD4-positiven T-Lymphozyten um $90 \%$ und von CD8-positiven T-Lymphozyten um $53 \%$. Diskutiert und beschrieben wurde weiterhin die immunmodulatorische Komponente in Form einer Verschiebung der Zytokinproduktion, welche $\mathrm{T}_{\text {Helfer }}$-Zell-gesteuert abläuft. Während $\mathrm{T}_{\mathrm{H} 1}$-Zellen vor allem die Ausschüttung der Zytokine IL-2, TNF- $\alpha$ und IFN- $\gamma$ vermitteln, sorgen $\mathrm{T}_{\mathrm{H} 2}$-Zellen eher für die Sekretion der Zytokine IL-4, IL-5 und zum Teil IL-10. Sowohl DE JONG et al. (1996) als auch MROWIETZ et al. (1999) konnten in vitro nachweisen, dass unter Einfluss von MMF nach Stimulation mit bakteriellem Superantigen eine bis zu zehnfach erhöhte Ausschüttung der Interleukine 4 und 5 stattfand, eventuell vermittelt durch $\mathrm{T}_{\mathrm{H} 1} / \mathrm{T}_{\mathrm{H} 0}-\mathrm{Klone}$. Dabei wird vor allem dem Interleukin 4 eine anti-inflammatorische Wirkung zugeschrieben, da es überschießende Immunreaktionen vermeidet und die B-Zellaktivierung sowie IgE-Produktion verstärkt (HOLTER et al. 1992). So wird ein Zusammenhang der immunmodulatorischen Wirkung der Fumarsäureester darin gesehen, dass sich unter deren Einfluss die Zytokinproduktion vom $\mathrm{T}_{\mathrm{H} 1}$-Typ, was vorwiegend eine Sekretion von IL-2, TNF- $\alpha$, IFN- $\gamma$ mit sich bringt, in Richtung $\mathrm{T}_{\mathrm{H} 2}$-Typ, also vorwiegend Sekretion der als anti-inflammatorisch geltenden Interleukine 4, 5 und 10, verschiebt (DE JONG et al. 1996). Interleukin 10 gilt neben TGF- $\beta$ als wichtigster limitierender Faktor inflammatorischen Geschehens. Zunächst wurde ihm 1989 durch FIORENTINO et al. zugeschrieben, nach Sekretion durch $\mathrm{T}_{\mathrm{H} 2}$-Zellen die $\mathrm{T}_{\mathrm{H} 1 \text {-Effektor- }}$ Aktivität zu hemmen. Später jedoch stellten DEL PRETE et al. (1993) fest, dass Interleukin 10 ebenso von $\mathrm{T}_{\mathrm{H} 1}$-Zellen selbst sezerniert werden kann.

Die immunmodulatorische Wirkung von Fumarsäureestern beschränkt sich nicht nur auf die genannten Zellreihen. Dendritische Zellen, denen auch regulative Funktionen bei inflammatorischen Prozessen zukommen, sezernieren bei Stimulation durch Lipopolysaccharide (LPS) unter gleichzeitigem Einfluss von MMF deutlich weniger IL-12 
(LITJENS et al. 2004a). Besonders bedeutend ist eben beschriebene Erkenntnis hinsichtlich der Pathogenese sowohl der Psoriasis vulgaris als auch der Multiplen Sklerose - eine neben der Psoriasis vulgaris weiter als autoimmun bedingt geltende Erkrankung - deren Therapiemodalitäten anhand von Fumarsäurederivaten noch im Folgenden besprochen werden. Schließlich konnten Zusammenhänge nachgewiesen werden, in denen ein quantitativ höheres Auftreten von Interleukin 12, hier stimuliert durch mikrobiologische Produkte wie beispielsweise LPS, bei der Entstehung von Autoimmunerkrankungen beteiligt ist (SEGAL et al. 1997).

Jedoch lassen sich auch Veränderungen der Immunität unter Einsatz von Fumarsäurederivaten beschreiben, die abseits der $\mathrm{T}_{\mathrm{H}^{-}}$, beziehungsweise $\mathrm{T}_{\mathrm{H} 2}$-abhängigen Zytokinproduktion ablaufen. So hindert Dimethylfumarat die Zelldifferenzierung dendritischer Zellen (ZHU und MROWIETZ 2001), die wiederum entscheidend für die Aktivierung der spezifischen zellulären Immunität sind. Bedeutsam in der Therapie der Psoriasis sind folgende weitere Wirkungen des DMF auf dendritische Zellen: Einerseits lässt es dendritische Zellen apoptotisch werden; andererseits unterbindet die Substanz in Keratinozyten die Sekretion des proinflammatorischen IFN- $\gamma$, dem Immunreaktionen des $\mathrm{T}_{\mathrm{H} 1}$-Typs zuzuordnen sind, und potenziert zur selben Zeit die Produktion des immuninhibitorisch wirksamen Interleukin 10 (OCKENFELS et al. 1998). Hyperproliferierende Keratinozyten, wie sie typischerweise bei Psoriasis-Erkrankten vorkommen, reagieren auf Inhibition des INF- $\gamma$ mit verringerter Expression von HLA-DR (Humanes Leukozytenantigen DR), welches maßgeblich an Gewebeimmunität und -kompatibilität beteiligt ist, sowie verminderter Aktivität von ICAM-1, einem an der Zellmigration beteiligtem intrazellulären Adhäsionsmolekül (SEBÖK et al. 1994).

Obwohl Fumarat und seinen Derivaten eben genannte immunmodulatorische Kompetenzen zugeschrieben werden, ist bislang zu großen Teilen unklar, welche Vorgänge auf molekularer Ebene in den jeweiligen Zellpopulationen zu oben erwähnten Ergebnissen führten. NF- $\mathrm{B}$ (Nuclear-Factor-kappa-B) scheint zumindest in humanen Endothelzellen eine Schlüsselrolle zu spielen. Dimethylfumarat verhindert höchstwahrscheinlich den Übertritt von NF- $\mathrm{B}$ vom Zytoplasma in den Nucleus, wo es ansonsten über einen nicht DNA-bindenden Mechanismus zur verstärkten Transkription von Genen führen würde, die durch TNF- $\alpha$, einem wichtigen proinflammatorischen Mediator, induziert wird (LOEWE et al. 2002). Dieser Vorgang wird als entscheidend zur Therapie der Psoriasis vulgaris gesehen. Unterdrückt wird durch eben genannten Prozess die Steigerung der NF-кB-abhängigen Chemokine $\mathrm{CXCL}_{8}$ (IL-8), $\mathrm{CXCL}_{9}$ 
(Mig), $\mathrm{CXCL}_{10}$ (IP-10), wobei der Effekt proportional abhängig der verabreichten Konzentration an DMF abläuft (HAYDEN et al. 2006).

Bezüglich Wirkung in aktivierten und zur selben Zeit alloreaktiven T-Zellen wurde ein fördernder Einfluss der Fumarsäureester auf das anti-inflammatorische Stressprotein Haemoxigenase 1 (HO-1) festgestellt. Auch hier zeigen die Ergebnisse eine Reduktion der pro-inflammatorischen Zytokine TNF- $\alpha$, IL-12 und IFN- $\gamma$ (LEHMANN et al. 2007). In diesen Zellen führt DMF zum Abbau von Glutathion, was einerseits eine Verlängerung der Halbwertszeit des DMF selbst herbeiführt, zum anderen erhöht ein Abfall des Glutathions die Expression der HO-1, sodass oben genannte immunmodulatorische Effekte wieder zum Tragen kommen (HELD et al. 1988).

Auch wenn bisher keine näheren Untersuchungen zur Wirkung von Fumarsäureestern auf BZellen des Immunsystems vorliegen, so ist durch den bereits bekannten Einfluss von Fumarsäureestern auf NF-אB denkbar, dass über mehrere Zwischenschritte B-Zell-Apoptose ausgelöst wird. Mediiert werden könnte diese über die aus anderen Experimenten nachgewiesene Inhibition von NF-אB durch Fumarsäureester, was wiederum in humanen BZellen zu einer Minderexpression des anti-apoptotischen Bcl-2 führt (BUREAU et al. 2002).

Für die Therapie der Multiplen Sklerose eines Tages wegweisend könnten die diskutierten neuroprotektiven Effekte der Dimethylfumarate sein. In mit Lipopolysaccharid stimulierten Ratten-Mikrogliazellen und -Astrozyten erhöhte DMF, ähnlich Sulforaphan (1Isothiocyanato-4-methylsulfinyl-butan), die mRNA-Expression von $\mathrm{NAD}(\mathrm{P}) \mathrm{H}$ und der Quinonreduktase (NQO-1) und erniedrigte gleichzeitig die Expressionsrate von TNF- $\alpha$, IL-1 $\beta$ und IL-6, sowie das zelluläre Glutathion und das neurotoxisch wirkende Stickstoffmonoxid (NO) (WIERINCKX et al. 2005). Ferner gilt besonders eine Zunahme von TNF- $\alpha$ neurotoxisch, welchem DMF entgegenwirkt und sich somit weiter als neuroprotektiv erweist (BUNTINX et al. 2004).

Im Tiermodell kann durch Injektion des Myelin-Oligodendrozyten-Glykoproteins (MOG) die sogenannte experimentelle autoimmune Enzephalomyelitis, ein der Multiplen Sklerose (MS) ähnliches Krankheitsbild, ausgelöst werden (GOLD et al. 2006): Durch MOG-Injektion kommt es zu MS-ähnlichen Läsionen und Entzündungsreaktionen mit konsekutiver Demyelinisierung (STORCH et al. 1998). Auf diese Weise immunisierte C57BL/6-Mäuse zeigten in Versuchen mit anschließender Behandlung mit Fumarsäureester eine signifikante Verringerung der Mikroglia und Makrophagen in den Läsionen (SCHILLINGS et al. 2006). Jedoch kam es nicht zur Reduktion der T-Zellen und auch das Expressionsmuster der

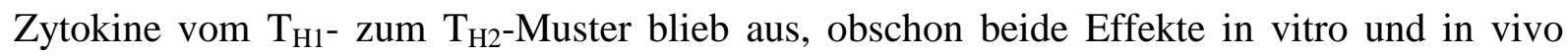


anderweitig beschrieben wurden. So bleibt die Folgerung, dass sich Fumarsäureester bei Multipler Sklerose vor allem immunmodulatorisch durch Hemmung der Mikroglia und Makrophagenrekrutierung bewähren könnten (STANGEL et al. 2008).

\section{4.) HEK293-Zellen}

HEK steht für Human Embryonic Kidney cells, was bedeutet, dass eine humane Zelllinie aus embryonalen Nierenzellen, die epithelialen Charakter haben, gezüchtet wurde (www.atcc.org). HEK293-Zellen wurden erstmals 1977 von GRAHAM et al. beschrieben. Diese Zelllinie besteht aus den in den frühen 1960ern in den Laboren von SHEIN in Boston, USA, gezüchteten HEK-Zellen (SHEIN und ENDERS 1962), die Jahre später dann von GRAHAM und VAN DER EB in Leiden, Niederlande, mit DNS-Fragmenten des humanen Adenovirus 5 transfiziert wurden (GRAHAM et al. 1977). Die Transfektion von geschnittenen DNS-Fragmenten des humanen Adenovirus 5 in eukaryotischen Zellen wurde von VAN DER EB und GRAHAM zunächst durch die Entwicklung einer sogenannten Calcium-Phosphat-Methode möglich gemacht (GRAHAM und VAN DER EB 1973a), und anschließend in Nagerzellen erprobt (GRAHAM und VAN DER EB 1973b), bis es dann 1977 möglich war, den Virus in HEK-Zellen zu transfizieren, ohne dass weiterhin Komplikationen wie Zelllyse auftraten (GRAHAM et al. 1977).

Das Genom der HEK293-Zellen ist hypotriploid. Das Wachstum verhält sich adhärent, was mit sich bringt, dass die Zellen dazu neigen, sich erst nach Erreichen der Konfluenz zu teilen und in Inseln zu wachsen. Dabei zeigen sie weite Größenunterschiede (GRAHAM et al. 1977). Seither war es möglich, diese Zelllinie in verschiedensten Experimenten zu verwenden, da sie als einfach zu kultivieren und zu transfizieren gelten. So wurden schon zahlreiche Proteine an HEK293-Zellen getestet und charakterisiert - neben Enzymen auch Kanäle und Transporter der Zellmembran (THOMAS und SMART 2005; VARGHESE et al. 2006).

\section{5.) Xenopus-laevis - Oozyten als Expressionssystem}

Die Oozyten des ursprünglich aus Südafrika stammenden Frosches Xenopus laevis werden häufig zur Expression verschiedenster exogener Proteine verwendet. Ein derartiges Experiment wurde erstmals 1971 von GURDON et al. durchgeführt. Diese Arbeitsgruppe konnte zeigen, dass nach vorangegangener Mikroinjektion von mRNS, die für das 
menschliche Protein Globin kodiert, jenes auch durch die injizierten Oozyten synthetisiert wurde. Sechs Jahre später zeigten GURDON und MERTZ, dass es sogar möglich sei, entsprechende DNS durch Mikroinjektion in den Zellkern der Oozyten einzubringen, die dann wiederum ebenso zur Synthese von Globin führte (MERTZ und GURDON 1977). SUMIKAWA et al. entdeckten dann 1981, dass nicht nur zytoplasmatische Proteine zur Expression gebracht werden können, sondern auch Proteine der Zellmembran. So konnte durch radioaktiv markierte Liganden, die an der Zelloberfläche vorzufinden waren, das Vorhandensein von nikotinergen Acetylcholinrezeptoren nachgewiesen werden. Deren mRNS war zuvor in die jeweiligen Oozyten injiziert worden. Bedeutend für spätere Untersuchungen an Proteinen der Zellmembran war schließlich ein Jahr später der Beweis, dass die Expression von injizierter mRNA für nikotinerge Acetylcholinrezeptoren $\mathrm{zu}$ funktionierenden Zellmembranrezeptoren führt, deren Eigenschaften somit sehr einfach und ohne weitere störende Einflüsse elektrophysiologisch untersucht werden konnten (BARNARD et al. 1982). Ausgehend von diesen Versuchen wurden die Oozyten des Xenopus laevis vielfach für elektrophysiologische Experimente genutzt, wie die „Two-electrode-voltage-clamp“Methode, die „Patch-clamp“-Methode oder „Ionen-selektive-Elektroden“-Methode; aber auch für zellbiologische und biochemische Untersuchungen von Proteinen (WAGNER et al. 2000). Besonders für eben erwähnte Methoden ist der relativ große Zelldurchmesser von Vorteil: eine Oozyte im Stadium V und VI nach DUMONT misst 1,1-1,3 mm im Durchmesser (DUMONT 1972). Das bedingt eine leichtere Handhabung, ebenso wie deren Resistenz gegenüber äußeren Einflüssen (SIGEL und MINIER 2005).

Die Oogenese im Xenopus-laevis-Weibchen verläuft asynchron; das bedeutet, dass man mehrere Stadien gleichzeitig vorfinden kann (SMITH et al. 1991). Klassifiziert wurden diese Stadien von DUMONT 1972. Demnach gibt es die Stadien I-VI, wobei V und VI zahlenmäßig am häufigsten vorzufinden sind (WAGNER et al. 2000). Diese Stadien sind am besten geeignet für sämtliche Expressions-Experimente. Währenddessen sind die Oozyten groß und rund, weiterhin lässt sich der dunkle animalische Pol, der den Zellkern enthält, deutlich vom hellen vegetativen Pol unterscheiden (SIGEL und MINIER 2005). Im Stadium VI verharren die Oozyten mehrere Monate, bevor sie absterben (WAGNER et al. 2000). 


\section{2.) Material und Methoden}

\section{1.) Material}

\section{Zellen und Oozyten}

HEK293 - Vektor-transfiziert: zur Verfügung gestellt durch einen Mitarbeiter der Abteilung „Vegetative Physiologie und Pathophysiologie“ der Universität Göttingen

HEK293-hNaDC3-transfiziert: zur Verfügung gestellt durch einen Mitarbeiter der Abteilung „Vegetative Physiologie und Pathophysiologie“ der Universität Göttingen

Xenopus-laevis-Oozyten: zur Verfügung gestellt durch eine Mitarbeiterin der Abteilung „Vegetative Physiologie und Pathophysiologie“ der Universität Göttingen; die Tiere selbst stammen von der Firma NASCO (Fort Atkinson, WI, USA)

\section{Zellkulturmedien und Lösungen}

Dulbecco's Modified Eagle Medium (DMEM) High Glucose (HG)

AppliChem / A13169050

13,44 g DMEM-HG

$3,7 \mathrm{~g} \mathrm{NaHCO}_{3}$

mit Aqua dest. auf 11 aufgefüllt

$\mathrm{pH}$ auf 7,2 eingestellt

\section{$\underline{\text { HEK293-Medium }}$}

DMEM-HG

2 mM Glutamin

1,25 mM Natriumpyruvat

100 U/ml Penicillin

$100 \mu \mathrm{g} / \mathrm{ml}$ Streptomycin

$10 \%$ FCS (,Fetal Calf Serum”) 
Mammalian Ringer (MRi)

$130 \mathrm{mM} \mathrm{NaCl}$

$4 \mathrm{mM} \mathrm{KCl}$

$1 \mathrm{mM} \mathrm{CaCl}_{2}$

$1 \mathrm{mM} \mathrm{MgSO}_{4}$

$1 \mathrm{mM} \mathrm{NaH}_{2} \mathrm{PO}_{4}$

20 mM HEPES

$1 \mathrm{mM} \mathrm{TMAPO}_{4}$

$18 \mathrm{mM}$ Glucose

$\mathrm{pH}$ mit $\mathrm{NaOH}$ auf 7,4 eingestellt

$\underline{\operatorname{MRi}\left(\mathrm{Na}^{+}-\text {frei) }\right.}$

130 mM TMACl

$4 \mathrm{mM} \mathrm{KCl}$

$1 \mathrm{mM} \mathrm{CaCl}_{2}$

$1 \mathrm{mM} \mathrm{MgSO}_{4}$

20 mM HEPES

$1 \mathrm{mM} \mathrm{TMAPO}_{4}$

$18 \mathrm{mM}$ Glucose

pH mit TMAOH auf 7,4 eingestellt

PBS (Phosphat-gepufferte Salzlösung)

AppliChem / A0964,9100

Oozyten-Ringer (ORi) für die elektrophysiologischen Versuche mit Xenopus-laevis-Oozyten $110 \mathrm{mM} \mathrm{NaCl}$

$3 \mathrm{mM} \mathrm{KCl}$

$2 \mathrm{mM} \mathrm{CaCl}_{2}$

5 mM HEPES

pH mit TRIS auf 7,5 eingestellt 
$\underline{\text { ORi }\left(\mathrm{Ca}^{2+} \text {-frei }\right)}$

$110 \mathrm{mM} \mathrm{NaCl}$

$3 \mathrm{mM} \mathrm{KCl}$

5 mM HEPES

$\mathrm{pH}$ mit TRIS auf 7,5 eingestellt

\section{$\underline{\text { ORi zum Aufbewahren der Oozyten }}$}

$110 \mathrm{mM} \mathrm{NaCl}$

$3 \mathrm{mM} \mathrm{KCl}$

$2 \mathrm{mM} \mathrm{CaCl}_{2}$

5 mM HEPES

2,5 mM Natriumpyruvat

$50 \mathrm{mg} / \mathrm{l} \mathrm{Gentamicin}$

$\mathrm{pH}$ mit TRIS auf 7,5 eingestellt

\section{$\underline{\text { Kollagenase-Lösung }}$}

$20 \mathrm{ml}$ Oozyten-Ringer

7 mg Kollagenase (Biochrom, Berlin, Deutschland)

\section{Chemikalien}

Die verwendeten Chemikalien als Bestandteile sämtlicher Lösungen, Medien und Puffer wurden von den Firmen AppliChem (Darmstadt, Deutschland), Biochrom (Berlin, Deutschland), Invitrogen (Karlsruhe, Deutschland), Merck (Darmstadt, Deutschland), Roche (Grenzach-Wyhlen, Deutschland), Roth (Karlsruhe, Deutschland) und Sigma-Aldrich (Taufkirchen, Deutschland) bezogen und hatten den Reinheitsgrad „zur Analyse“.

Das im Isotopenlabor verwendete $\left[{ }^{14} \mathrm{C}\right]$-markierte Succinat $(118 \mathrm{mCi} / \mathrm{mmol})$ stammt von der Firma NEN Life Science/PerkinElmer (Wellesley, MA, USA). Die für den Gebrauch des Szintillationszählers verwendete Szintillationslösung stammte von der Firma Packard Bioscience/PerkinElmer (Wellesley, MA, USA). 


\section{Geräteliste}

Geräte

Binokular

Brutschrank

Feinwaage

Glaskapillaren

Glasmaterialien

Kaltlichtlampe

Kapillarziehgerät

Magnetrührer

Zwei- Elektroden-

Spannungsklemme

Nanoliter-Injektor

Neubauer-Zählkammer

Reinstwasseranlage

Oozyteninkubator $\left(16{ }^{\circ} \mathrm{C}\right)$

Petrischalen $\underline{\text { Modell }}$

M3B

Function Line

BB16

2001 MP1

Sodaklar-,

Bonosilikatglas

Duran

KL1500

PE-II

KM02 electronic

Oozyte Clamp

OC-725 C

Nanoliter2000

hell-linig

Millipore (Molsheim, Frankreich)

Eigenbau der Institutswerkstatt

Nunc (Langenselbold, Deutschland) 


\begin{tabular}{|c|c|c|}
\hline pH-Meter & CG820 & Schott (Mainz, Deutschland) \\
\hline - " - & 611 & Orion Research (Beverly, MA, USA) \\
\hline RNA/DNA -Calculator & GeneQuantII & $\begin{array}{l}\text { Pharmacia Biotech } \\
\text { (Freiburg, Deutschland) }\end{array}$ \\
\hline Zweikanalschreiber & & Kipp\&Zonen (Delft, Niederlande) \\
\hline Schüttelinkubator & 3031 & GFL (Burgwedel, Deutschland) \\
\hline Sterile Werkbank & Microflow & Nunc (Langenselbold, Deutschland) \\
\hline Szintillationszähler & 1500 Tri-Carb & $\begin{array}{l}\text { Packard Bioscience / PerkinElmer } \\
\text { (Wellesley, MA, USA) }\end{array}$ \\
\hline Thermocycler & GeneAmp & PerkinElmer (Wellesley, MA, USA) \\
\hline Vortex & MS1 & IKA (Staufen, Deutschland) \\
\hline Waage & LC6215 & Sartorius (Göttingen, Deutschland) \\
\hline Wasserbad & D8 & Haake (Karlsruhe, Deutschland) \\
\hline Zentrifugen & Biofuge fresco & Heraeus (Hanau, Deutschland) \\
\hline - - - & 5417R, 5415D & Eppendorf (Hamburg, Deutschland) \\
\hline \multicolumn{2}{|l|}{ „24-Well-Platten“ für } & Sarstedt (Nümbrecht, Deutschland) \\
\hline 293-Zelle & & \\
\hline
\end{tabular}




\section{2) Methoden}

\subsection{1.) Transportversuche}

$\mathrm{Zu}$ diesen Experimenten werden hier sämtliche notwendigen Schritte - von der Aufzucht der Zellen in der Zellkultur bis hin zur Messung der Aufnahme von $\left[{ }^{14} \mathrm{C}\right]$-Succinat in Abhängigkeit der Fumaratderivate -im Folgenden Aufnahmeexperiment genannt - erläutert. Gerade im Umgang mit den radioaktiven Substanzen erfolgte gesonderte Belehrung und Einarbeitung durch erfahrene Mitarbeiter des Labors. Sämtliche gebotenen Sicherheitsmaßnahmen und Dokumentationen bezüglich der Verwendung und Entsorgung radioaktiver Stoffe wurde nach bestem Wissen und Gewissen beachtet und eingehalten.

\subsubsection{1.) Kultivieren und Ausplattieren der HEK293}

Die HEK293-Zellen wurden freundlicherweise von einem Institutsmitarbeiter bereits aufgetaut und mit dem hNaDC3 beziehungsweise dem Vektor transfiziert zur Verfügung gestellt. Übergeben wurden sie als konfluenter Zellrasen in Petrischalen von einem Durchmesser von $10 \mathrm{~cm}$. Daher mussten sie zunächst geerntet werden. Alle folgenden Arbeitsschritte in der Kultivierung der Zellen geschahen unter einer sterilen Werkbank, um mikrobielle Kontamination in den Petrischalen, bei der weiteren Aufbereitung und letztlich auch im Brutschrank zu vermeiden.

\subsubsection{2.) Ernten und Pflege der Zellen}

Die Ernte der transfizierten HEK293 begann damit, dass das Medium, in dem die Zellen kultiviert wurden, abgesaugt wurde und zum Spülen $2 \cdot 5 \mathrm{ml}$ PBS in die Petrischale pipettiert und abgesaugt wurden. Nach dem zweiten Absaugen wurden 3 ml Trypsin für 10 Minuten zu den Zellen gegeben. Anschließend wurde durch 5-maliges vorsichtiges Aufsaugen die Trypsin-Zellmischung vom Boden der Petrischale gelöst und in ein Zentrifugengefäß mit $3 \mathrm{ml}$ Medium überführt. Diese Suspension wurde für 5 Minuten bei 1000 Umdrehungen pro Minute bei $23^{\circ} \mathrm{C}$ zentrifugiert. Danach dekantierte man vorsichtig den Überstand, während man sorgsam versuchte nicht das Pellet zu lösen. Auf das Pellet gab man erneut $1 \mathrm{ml}$ des Mediums, und durchmischte alles indem man mit einer Pipette mehrmals die Suspension auf und ab zog. Hatte sich das Pellet gelöst und homogen im Medium verteilt, konnte man sich je nach Zeitspanne, die für die Kultivierung der Zellen vorgesehen war, einen Anteil aus der Zelllösung mit der Pipette abziehen und in neue Petrischalen überführen, die mit $10 \mathrm{ml}$ des 
Mediums plus $35 \mu 1$ des Antibiotikums Hygromycin gefüllt waren. Die Zellen wurden bis zur weiteren Verwendung in den Brutschrank bei $37^{\circ} \mathrm{C}$ gestellt.

\subsubsection{3.) Bestimmung der Zellzahl und Ausplattieren}

Oben beschriebene Vorgehensweise wurde zur Zellgewinnung für die Aufnahmeexperimente bis zu Zentrifugiervorgang und Resuspension des Pellets mit 1 ml HEK293-Medium genauso wiederholt. Um dann eine 1:20-Verdünnung zu erstellen, nahm man $10 \mu 1$ der Resuspension aus Medium und HEK293-Zellen und gab diese in ein Eppendorfgefäß, in das zuvor $190 \mu 1$ fetales Kälberserum eingebracht wurden. Mit der $1000 \mu$ l-Pipette wurde die Suspension gründlich durchmischt, um eine homogene Verteilung der Zellen in der Lösung zu erreichen. Die Zellen mussten nun mit der Neubauer-Zählkammer gezählt werden. Dazu wurden aus der 1:20-Verdünnung $20 \mu \mathrm{l}$ der Lösung entnommen und zwischen Deckglas und Zählkammer eingebracht. Nun zählte man die Zellen in allen 4 Quadranten unter dem Mikroskop. Aus den Werten der 4 Quadranten bildete man den Mittelwert. Die Zellzahl, die man anhand der Neubauer-Zählkammer ermittelt, ist folgendermaßen definiert: In der zum Zählen verwendeten Zelllösung befinden sich im Mittel pro Milliliter so viele Zellen wie der Mittelwert der Quadranten multipliziert mit $10^{4}$. Da man sich einer 1:20-Verdünnung zum Zählen bedient hatte, musste man den Mittelwert nicht nur mit $10^{4}$, sondern auch noch mit 20 multiplizieren, um die gemittelte Zellzahl pro Milliliter in der Resuspensionslösung zu erhalten. Da per definitionem für die Versuche $2 \cdot 10^{5}$ Zellen pro Well gebraucht werden, und in jedem der 24 Wells einer Platte $500 \mathrm{ml}$ Suspension für das Anwachsen der Zellen enthalten sein müssen, benötigt man $12 \mathrm{ml}$ einer entsprechenden konzentrierten Zelllösung. Anhand einer Dreisatzrechung konnte das Volumen an Zelllösung errechnet werden, das man gemeinsam mit Medium auf insgesamt $12 \mathrm{ml}$ auffüllen musste, um eben genannte Bedingungen erfüllen zu können. Die $12 \mathrm{ml}$ der neuen Zellsuspension wurden dann auf die 24 Wells aufgeteilt. Vor dem Aussäen der Zellen musste man allerdings die 24-Well-Platten mit Polylysin beschichtet haben, um ein Anwachsen der Zellen zu garantieren und um zu vermeiden, dass sich während der Versuche Zellen vom Boden der Wells lösen. Dies tat man, in dem man vor Aussäen der Zellen je $500 \mu$ l Polylysin in jedes Well gegeben hatte und für 10 min darin belassen hatte. Anschließend wurde das Polylysin abgesaugt und die Platten sollten etwa $20 \mathrm{~min}$ in der sterilen Zellbank trocknen. Dann schon konnte man mit dem Aussäen der Zellen beginnen. Die fertig präparierten 24-Well-Platten wurden 48 Stunden im Brutschrank bei $37^{\circ} \mathrm{C}$ belassen. Nach dieser Zeit waren ausreichend Zellen für die „Aufnahmeversuche“ vorhanden. 


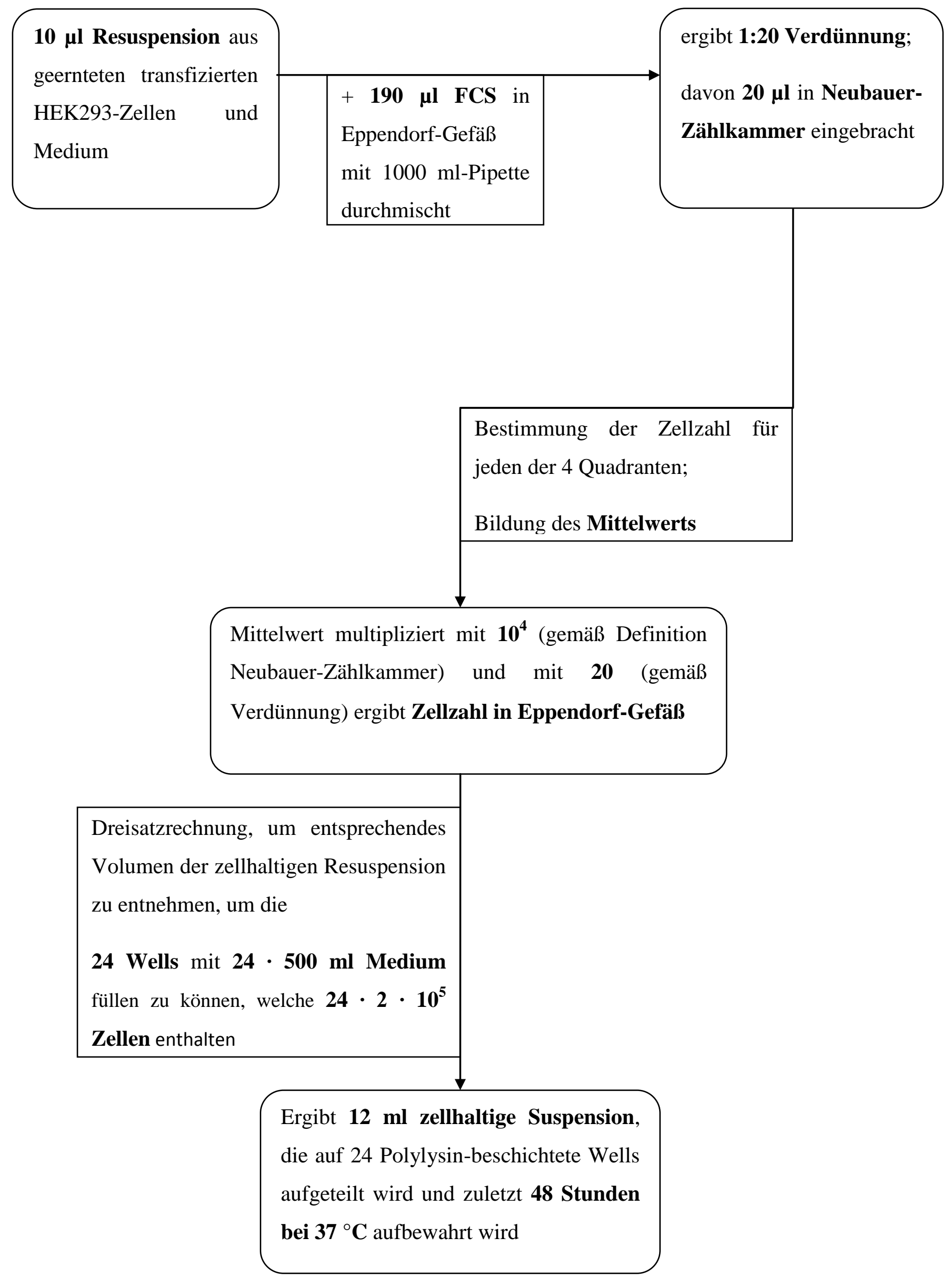

Abbildung 2.1: Fließschema zur Verdünnung und Aussaat der Zellen 


\subsubsection{4.) $\left[{ }^{14} \mathrm{C}\right]-$ Succinat-Aufnahme}

Anhand der Transport-Versuche sollte ermittelt werden, ob und wie viel Succinat abhängig von Zeit und Konzentration durch den $\mathrm{hNaDC} 3$ über die Zellmembran in die Zellen transportiert wurde und, zusätzlich, ob Fumarat und seine Derivate Diethyl- und Dimethylfumarat in der Lage sind, die Aufnahme von Succinat zu beeinflussen.

Um die Aufnahme von Succinat in den Zellen nachzuweisen, wurde für alle Transportversuche $\left[{ }^{14} \mathrm{C}\right]$-Succinat verwendet, dessen intrazelluläre Konzentration wie nachfolgend beschrieben gemessen werden konnte. Dazu musste eine Inkubationslösung hergestellt werden, die anteilig radioaktivmarkiertes und -unmarkiertes Succinat enthielt. Je nach gewünschter Molarität wurden verschiedene Succinatvolumina in Mammalian Ringer (MRi) gelöst. Ebenso wurden Fumarat und dessen Derivate Diethyl- und Dimethylfumarat je nach gewünschter Konzentration in MRi gelöst. Als Zellen im Versuch dienten hNaDC3transfizierte HEK293-Zellen. Zur Kontrolle wurden HEK293-Zellen verwendet, die lediglich mit dem leeren Vektor transfiziert waren und demzufolge keinen hNaDC3 exprimieren.

Bevor die Zellen dann für die Transport-Versuche bereit waren, mussten die Wells mit den entsprechenden Zellen noch zwei Mal vorsichtig mit $500 \mu$ PBS gespült werden, bevor 200 $\mu 1$ MRi mit pH 7,4 zugegeben wurden. Die „Aufnahmeexperimente“ wurden in dafür zugelassenen Räumen durchgeführt. Dort wurde in jedes Well der 24-Well-Platten $200 \mu 1$ der $\mathrm{zu}$ untersuchenden Test-Lösungen pipettiert und über eine definierte Zeitspanne lang zur Inkubation belassen. Anschließend wurden die Inkubationsvorgänge mit eiskaltem PBS gestoppt, indem von dieser je dreimal $500 \mu \mathrm{l}$ auf die Zellen pipettiert und sofort abgesaugt wurden. Zur Erfassung der intrazellulär aufgenommenen $\left[{ }^{14} \mathrm{C}\right]$-Succinat-Konzentration mussten die Zellen lysiert werden, durch Zugabe von $500 \mu$ l einer 1 M NatriumhydroxidLösung pro Well. Die 24-Well-Platten wurden zur Zelllyse wahlweise so für $24 \mathrm{~h}$ belassen oder für 2-3 h auf einen Schüttler gestellt. Die stark alkalische Lösung der Wells musste durch Zugabe von $500 \mu \mathrm{l}$ einer $1 \mathrm{M}$ Salzsäure-Lösung pro Well neutralisiert werden. Daraufhin wurde der gesamte Inhalt eines jeden Wells einzeln mithilfe einer Pipette in Szintillationsbehälter („Vials“) überführt. In jene wurden noch jeweils 2,5 $\mathrm{ml}$ Szintillationslösung gegeben, verschlossen, und jedes einzeln von Hand geschüttelt. Die „Vials“ wurden dann in den Szintillations-Zähler gestellt, der die Radioaktivität in jedem der „Vials“ misst und dann in dpm (,decays per minute“) angibt (1 dpm entspricht 60 Becquerel). Benötigt wird für die Auswertung der Daten und die Interpretation der dpm-Werte noch die spezifische Aktivität des $\left[{ }^{14} \mathrm{C}\right]-$ Succinats. Hierzu wurden vor Versuchsbeginn vier Proben à 5 
$\mu 1$ jeder der Substratlösungen entnommen, ebenfalls mit 2,5 ml Szintillations-Lösung versehen und $\mathrm{zu}$ den entsprechenden Proben in den Szintillations-Zähler (PerkinElmer) gestellt wurden.

Unter Einbeziehung der spezifischen Aktivität des Succinats und der gesetzten Volumina konnte die in die HEK293-Zellen aufgenommene Succinat-Konzentration pro Well berechnet werden.

Spezifische Aktivität $($ dpm/pmol $)=d p m$ Standard $/($ Standard Konzentration $\cdot$ Standard Volumen)

$\left[{ }^{14}\right.$ C]-Succinat-Aufnahme $($ pmol $)=$ Proben dpm $/($ Spezifische Aktivität $)$

\subsubsection{5.) Zeitreihe}

Im ersten Experiment, der Zeitreihe, sollte der hNaDC3 auf seine Succinat-Aufnahme über die Zeit hin beobachtet werden. So sollte ein zeitliches Aufnahme-Profil erstellt werden, sodass auch für nachfolgende Versuche ein Zeitpunkt definiert werden konnte, an dem die Aufnahme näherungsweise proportional zur abgelaufenen Zeit erfolgt und noch keine Sättigung erreicht wird.

Hierzu wurde eine $2 \mu \mathrm{M}\left[{ }^{14} \mathrm{C}\right]$-Succinat-haltige MRi-Lösung hergestellt, die sowohl den hNaDC3-transfizierten als auch den Vektor-transfizierten Zellen zugeführt wurde. Die Inkubationszeiten betrugen $0,0,5,1,2,5$ und 10 Minuten.

\subsubsection{6.) Transporterfunktion unter Natrium-freien Bedingungen}

Verglichen wurde die Aufnahme von $\left[{ }^{14} \mathrm{C}\right]$-Succinat in einer Natrium-haltigen Lösung (MRi) mit der Aufnahme, die in einer Lösung erzielt wurde, in der $\mathrm{NaCl}$ durch äquimolare Mengen an TMACl ersetzt wurde. Die Inkubationszeit betrug 5 Minuten.

\subsubsection{7.) Bestimmung von $K_{M}$ und $V_{M A X}$}

Mit diesen Versuchen sollten $\mathrm{K}_{\mathrm{M}}$ (Michaelis-Menten-Konstante) und $\mathrm{V}_{\text {MAX }}$ bestimmt werden. $\mathrm{Zu}$ dieser Fragestellung wurden die hNaDC3-transfizierten Zellen so wie die Kontrollzellen in 
einer Inkubationszeit von 5 min aufsteigenden Succinat-Konzentrationen, bei einer konstanten $\left[{ }^{14} \mathrm{C}\right]$-Succinat-Konzentration von $2 \mu \mathrm{M}$, ausgesetzt $(1,2,5,10,25,50,75,100 \mu \mathrm{M})$.

Aus Abbildung 3.2 lassen sich die entsprechenden Werte ablesen. Zusätzlich wurden diese noch über das Graphikprogramm SigmaPlot 10 software (Systat, Point Richmond, CA, USA) berechnet.

\subsubsection{8.) Hemmung der Succinat-Aufnahme}

Hierbei sollten die Substanzen ermittelt werden, die den Transport von $\left[{ }^{14} \mathrm{C}\right]$-Succinat durch den hNaDC3 kompetitiv inhibieren konnten. Die Inkubationszeit lag im gesamten Versuch bei fünf Minuten. Mit einer Konzentration von $2 \mu \mathrm{M}\left[{ }^{14} \mathrm{C}\right]-S u c c i n a t$ wurde an beiden Zelllinien die Aufnahme von Succinat in Ab- und Anwesenheit von Fumarat und den Fumaratderivaten, Diethyl- sowie Dimethylfumarat in einer Konzentration von $100 \mu \mathrm{M}$, gelöst in ORi, hinzugegeben.

\subsubsection{9.) Ermittlung der $K_{I}$ und $I C_{50}$}

Anhand dieser Versuche sollte ein Inhibitorprofil des Fumarats erstellt werden. Dazu war es nötig, verschiedene Konzentrationen - 0, 100, 200, $300 \mu \mathrm{M}-$ an Fumarat in einer $\left[{ }^{14} \mathrm{C}\right]-$ Succinat-Lösung zu verwenden, um dessen inhibitorischen Einfluss auf die $\left[{ }^{14} \mathrm{C}\right]$-SuccinatAufnahme konzentrationsabhängig $\mathrm{zu}$ untersuchen. Der $\mathrm{K}_{\mathrm{I}}$-Wert ist eine deskriptive Konstante des Fumarats in Bezug auf seine inhibitorische Potenz der Succinataufnahme durch den $\mathrm{hNaDC} 3$, die unabhängig von der Konzentration des vorliegenden Succinats ist. Es wurden hierzu zwei $\left[{ }^{14} \mathrm{C}\right]$-Succinat-Konzentrationen verwendet $(1 \mu \mathrm{M}$ und $5 \mu \mathrm{M})$. Außerdem sollte die jeweilige $\mathrm{IC}_{50}$ ermittelt werden, also die Konzentration an Fumarat, die es bedarf, um $50 \%$ der jeweils vorliegenden $\left[{ }^{14} \mathrm{C}\right]$-Succinat-Konzentration aus den Substratbindungsstellen des hNaDC3 zu verdrängen. Hatte man die Aufnahmeversuche nun wie eben beschrieben durchgeführt, konnte man die gesuchten Werte, $\mathrm{K}_{\mathrm{I}}$ und $\mathrm{IC}_{50}$, für Fumarat bestimmen:

Wurden die Graphen, die im ersten in diesem Abschnitt erklärten Versuch aus den Werten mit den verwendeten $1 \mu \mathrm{M}$ und dann $5 \mu \mathrm{M}\left[{ }^{14} \mathrm{C}\right]$-Succinat bei jeweils $0,100,200,300 \mu \mathrm{M}$ Fumarat als Inhibitor, entstanden, reziprok dargestellt, so ergab sich eine linearisierte Darstellung. Diese wird als Dixon-Plot bezeichnet. Aufgetragen wurden die Werte 1/(pmol/Well) auf der y-Achse - entsprechend des reziproken Werts der Aufnahme pro Well 
- und die eingesetzten Fumaratkonzentrationen auf der x-Achse. Nachfolgend konnte der Schnittpunkt beider Geraden errechnet werden, der im Dixon-Plot dem Wert $-1 / \mathrm{K}_{\mathrm{I}}$ entspricht. Die $\mathrm{IC}_{50}$ wurde nach linearer Auftragung der Daten mit SigmaPlot 10 berechnet.

\subsection{2.) Elektrophysiologische Experimente}

\subsubsection{1.) Entnahme und Selektion der Oozyten}

Die Oozyten wurden Xenopus-laevis-Weibchen durch eine hierfür qualifizierte Mitarbeiterin mit entsprechender Ausnahmegenehmigung ( $\$ 9$ Abs. 1 des Tierschutzgesetzes) entnommen und für die folgenden Experimente freundlicherweise zur Verfügung gestellt. Das heißt, im Folgenden werden nicht die eigenen, sondern die Schritte der genannten Mitarbeiterin zur Entnahme und Selektion der Oozyten erläutert.

$\mathrm{Zu}$ Beginn wurden die Xenopus-laevis-Weibchen in eiskalte 0,17\%ige Tricain-Lösung getaucht, um so anästhesiert zu werden. Zusätzlich wurden sie auch auf Eis gebettet, wo dann mit dem Skalpell ein kurzer, etwa 1-2 cm langer abdomineller Schnitt durch Haut und Muskulatur folgte. Mit einer stumpfen Pinzette konnten durch das Schnittfenster direkt einige Ovariallappen frei präpariert, nach Ligatur der distalen Ovarialanteile entnommen, und schließlich in eine Petrischale mit ORi gegeben werden. Anschließend wurden die Schnittränder durch Naht mit absorbierbaren Fäden wieder adaptiert, wobei zunächst die muskuläre Schicht verschlossen wurde, bevor separat die Haut zugenäht wurde, um Verschieblichkeit der beiden Schichten gegeneinander zu garantieren. Das Xenopus-laevisWeibchen wurde in $16-18{ }^{\circ} \mathrm{C}$ temperiertes Wasser getan und noch einige Zeit beobachtet, bevor es wieder in sein Becken zurückgeführt wurde.

Einige Stunden später wurden die ovariellen Bestandteile aus dem ORi herausgenommen und mithilfe einer Pinzette in kleine Stücke zerrupft. Anschließend wurden sie dann erst einige Male mit ORi gespült, bevor sie über Nacht $(16-18$ h) in 0,4 \% Kollagenase-Lösung einweichen sollten und dafür im Oozyten-Inkubator bei $18{ }^{\circ} \mathrm{C}$ gelagert wurden. Nach Ablauf der Inkubationszeit wurde die Kollagenase durch mehrfaches Spülen der Oozyten mit $\mathrm{Ca}^{2+}$ freiem ORi herausgewaschen. Es folgte eine 10-minütige Inkubation in $\mathrm{Ca}^{2+}$-freiem ORi. Im Anschluss wurden die Oozyten ein weiteres Mal mehrfach mit ORi gespült und waren somit zur Selektion bereit.

Hierzu wurden die Oozyten in ihrer Lösung unter dem Binokular einzeln betrachtet. Entscheidend waren verschiedene morphologische Kriterien, wie sichtbar erhaltene Integrität 
und vitale Färbung. So wurden Oozyten der Stadien V und VI nach DUMONT JN (1972) vereinzelt, deren vegetativer und animalischer Pol gut optisch voneinander abgrenzbar waren. Diese Oozyten standen dann zur Injektion bereit.

\subsubsection{2) cRNA-Injektion}

Die hier beschriebene cRNA wurde von einer Mitarbeiterin des Instituts hergestellt und ebenso freundlicherweise zur Verfügung gestellt.

Zunächst wurden geeignete Oozyten unter dem Binokular heraussortiert. Dann wurden diese mithilfe einer Glaspipette auf eine von der Institutswerkstatt angefertigte PlexiglasInjektionsbank überführt. Auf dieser konnten die Oozyten in 4-5 vertieften parallelen Linien einreihig positioniert werden. In die Vertiefungen der Plexiglas-Injektionsbank wurde ORi gegeben, damit die Oozyten nicht austrockneten. Mithilfe eines Nadelausziehgerätes wurden aus Glaskapillaren Injektionsnadeln gefertigt. Diese mussten weiterhin für die Injektion präpariert werden, indem ihnen zunächst ein kleiner Teil der Spitze mit einer Schere entfernt wurde, sodass sie an der Spitze eine Öffnung besaßen. Danach wurden sie mithilfe einer Spritze mit Paraffin-Öl blasenfrei zur Abdichtung befüllt und in den Nanoliter-Injektor eingebracht. Unter dem Binokular wurde in die erste präparierte Glaskapillare 0,5 $\mu 1 \mathrm{H}_{2} \mathrm{O}$ blasenfrei mithilfe des Nanoliter-Injektors aufgesogen; in eine zweite, ebenso präparierte Glaskapillare wurde ebenso $0,5 \mu \mathrm{l}$ cRNA blasenfrei aufgesogen. Injiziert wurde zur besseren Sicht unter dem Binokular. Erst wurden in einige Oozyten jeweils $23 \mathrm{nl} \mathrm{H}_{2} \mathrm{O}$, später dann in weitere Oozyten jeweils $23 \mathrm{nl}$ cRNA in den vegetativen Pol eingebracht.

Die injizierten Oozyten wurden anschließend in Gruppen von bis zu 5 in jeweils $2 \mathrm{ml} \mathrm{ORi} \mathrm{auf}$ Wells einer 24-Well-Platte aufgeteilt. Zur Lagerung wurden diese für 2-3 Tage in einem $18^{\circ} \mathrm{C}$ temperierten, lichtgeschützten Inkubator untergebracht. In dieser Zeit musste täglich das ORi gewechselt, und Oozyten, die unter dem Binokular morphologische Veränderungen aufwiesen, aus dem ORi entfernt werden.

\subsubsection{3.) Messungen mit der Zwei-Elektroden-Spannungsklemme}

Diese Methode ermöglicht es, elektrogene Transporter auf ihre Substrat- und Potentialabhängigkeit zu untersuchen. Die Oozyten werden auf ein definiertes, vorgegebenes Potential (Klemmspannung, Kommandospannung, $\mathrm{V}_{\mathrm{c}}$ ) geklemmt und der Strom, der zur 
Aufrechterhaltung von $\mathrm{V}_{\mathrm{c}}$ notwendig ist, wird über ein Steuergerät eingespeist und von einem Zweikanalschreiber aufgezeichnet. Im Versuch wird die Oozyte in die Perfusionskammer gelegt und mit ORi umspült. Die KCl-gefüllten Mikroelektroden wurden auf Manipulatoren montiert und in einem Winkel von $180^{\circ}$ in die Oozyte eingestochen. Über eine Elektrode werden Abweichungen vom Klemmpotential gemessen; die andere Elektrode speist den Strom, der zur Aufrechterhaltung von $\mathrm{V}_{\mathrm{c}}$ nötig ist, ein.

Der Versuch lief folgendermaßen ab: Nachdem sich unter Perfusion mit ORi ein stabiles Ruhemembranpotential eingestellt hatte, wurde die Oozyte auf -60 mV geklemmt. Anschließend wurde, ausgehend von diesem Klemmpotential, das Potential für 5 Sekunden um $10 \mathrm{mV}$ bis zu einem Potential von $-90 \mathrm{mV}$ hyperpolarisiert und dann ebenfalls in $10 \mathrm{mV}$ Schritten bis auf $0 \mathrm{mV}$ depolarisiert. Der bei jedem Potential (V) einzuspeisende Strom (I) wurde registriert. Dieser Vorgang wurde zuerst unter Perfusion mit ORi und anschließend unter Perfusion mit ORi und einer der Testsubstanzen durchgeführt. Diese Vorgehensweise ermöglicht das Aufnehmen von I/V-Kennlinien, wie sie beispielsweise in Abbildung 3.8A dargestellt sind. Die Differenz der Ströme in An- und Abwesenheit der Testsubstanz ergibt den substratmediierten Strom $(\Delta \mathrm{I})$, wie er in Abbildung 3.8B und $3.9 \mathrm{zu}$ sehen ist. Alternativ kann auch, wie in Abbildung 3.3, der bei einem festen $\mathrm{V}_{\mathrm{c}}$ in Abhängigkeit ansteigender Substratkonzentrationen ermittelte Strom, aufgetragen werden. In allen Versuchsreihen musste zuerst getestet werden, ob die Oozyten den hNaDC3 in ausreichendem Maße exprimiert hatten. War dies der Fall, konnte mit den eigentlichen Messungen begonnen werden. Der Versuchsaufbau ist schematisch in Abbildung 2.2 dargestellt. 


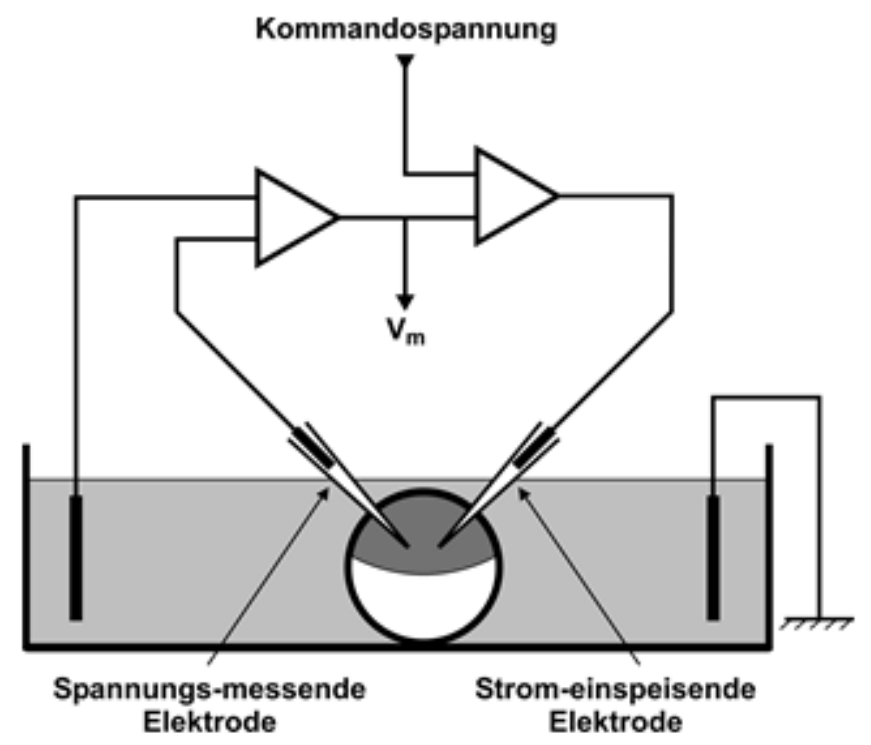

Abbildung 2.2: Schematische Darstellung einer Oozyte im Versuchsaufbau der Zwei-ElektrodenSpannungsklemme

Abgebildet wird hier das Bad mit einer Oozyte, in die sowohl eine Spannungs-messende als auch eine Stromeinspeisende KCl-gefüllte Mikroelektrode. Der Stromkreis wird über Bad- und Erdungselektroden geschlossen.

\subsubsection{4.) Substratreihe}

Anhand der Substratreihe sollte ermittelt werden, welche Substrate vom hNaDC3 elektrogen transportiert werden. Zum Nachweis einer ausreichenden hNaDC3-Expression der Oozyte wurden I/V-Kennlinien unter Perfusion mit ORi und ORi plus $1 \mathrm{mM}$ Succinat aufgenommen (Abb. 3.8A). Anschließend erfolgten die Messungen mit den möglichen Substraten Fumarat, Diethyl- und Dimethylfumarat in einer Konzentration von $1 \mathrm{mM}$ und der substratmediierte Strom wurde berechnet (Abb. 3.9). An einer Oozyte konnten alle potentiellen Substrate ausgetestet werden. Zwischen den einzelnen Substanzen wurde eine Auswasch- und Ruhephase von ca. 15 Minuten eingehalten. Idealerweise sollte der zur Aufrechterhaltung eines $V_{c}$ von $-60 \mathrm{mV}$ notwendige Klemmstrom vor Einsatz einer jeden neuen Substanz identisch sein. 


\subsubsection{5.) Fumarat-Konzentrationsreihe}

Bei einem $V_{c}$ von $-60 \mathrm{mV}$ wurden nach Applikation von Succinat (1 mM in ORi) subsequent Fumaratkonzentrationen von $0,01,0,025,0,05,0,1$ und $1 \mathrm{mM}$ angeboten und die entsprechenden, einzuspeisenden Ströme gemessen. Zwischen jeder der Fumaratkonzentrationen wurde 15 Minuten mit ORi perfundiert, um die vorhergehende Konzentration an Fumarat herauszuwaschen und eine Konstanz des Stromes unter Ruhebeziehungsweise Kontrollbedingungen zu gewährleisten. 


\section{3.) Ergebnisse}

Der erste Teil umfasst die Charakterisierung des hNaDC3 mittels der „Aufnahmeexperimente“ und damit seine Transporteigenschaften für Succinat, Fumarat, Diethyl- und Dimethylfumarat. Der zweite Teil gibt die Ergebnisse der elektrophysiologischen Versuchsreihen wieder.

\section{1.) „Aufnahmeexperimente“}

\subsection{1.) Aufnahme von Succinat in hNaDC3-transfizierte HEK293-Zellen als Funktion der Inkubationszeit}

Um die $\left[{ }^{14} \mathrm{C}\right]$-Succinat-Aufnahme über den hNaDC3 im zeitlichen Verlauf zu betrachten, wurden die Zellen unterschiedliche lange Zeiten in MRi inkubiert, der $2 \mu \mathrm{M}\left[{ }^{14} \mathrm{C}\right]$-Succinat zugegeben war. Abbildung 3.1 zeigt die erzielten Ergebnisse, wobei die Aufnahme von $\left[{ }^{14} \mathrm{C}\right]-$ Succinat in hNaDC3-transfizierten als (O), die in Vektor-transfizierten HEK293-Zellen als (O) dargestellt ist. Die beiden Regressionsgeraden wurden mit dem Programm SigmaPlot 10 berechnet. Die Aufnahme von $\left[{ }^{14} \mathrm{C}\right]$-Succinat liegt in den ersten 2 Minuten oberhalb der Regressionsgeraden. $\mathrm{Ab}$ einer Inkubationszeit $>2$ Minuten wird ein linearer Anstieg der intrazellulären Succinatkonzentration mit der Zeit beobachtet, der bis zu einer Inkubationszeit von 10 Minuten anhält. Vektor-transfizierte Zellen (O) zeigen eine vernachlässigbare Aufnahme von $\left[{ }^{14} \mathrm{C}\right]$-Succinat. Basierend auf diesen Versuchen wird als Inkubationszeit in allen folgenden Versuchen 5 Minuten gewählt. 


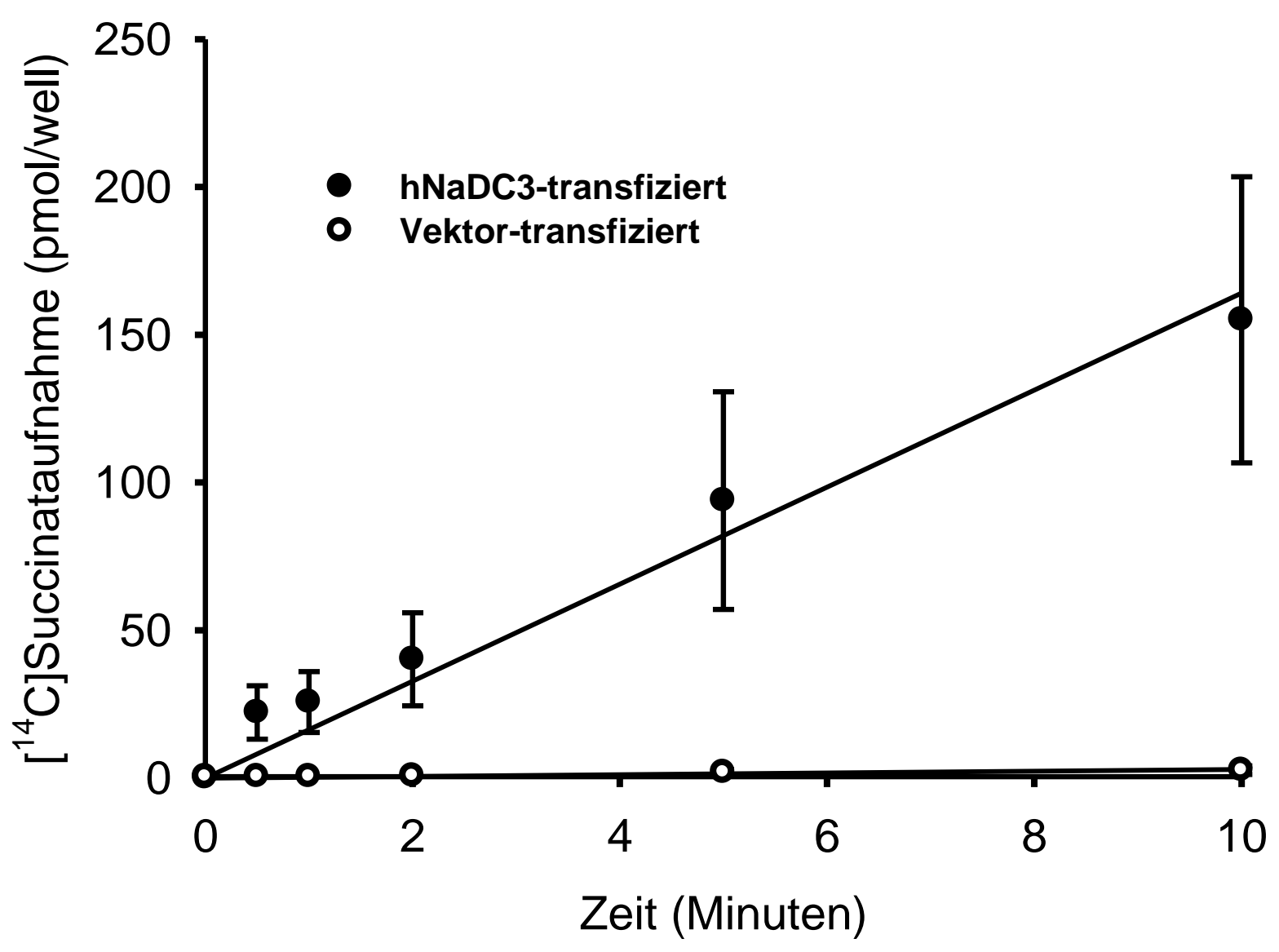

Abbildung 3.1: Aufnahme von $\left[{ }^{14} \mathrm{C}\right]$-Succinat als Funktion der Inkubationszeiten in hNaDC3transfizierten $(\odot)$ und Vektor-transfizierten $(O)$ HEK293-Zellen.

Die $\left[{ }^{14} \mathrm{C}\right]$-Succinatkonzentration in Vektor-transfizierten HEK293-Zellen ist zu vernachlässigen, diejenige in hNaDC3-transfizierten Zellen nimmt linear mit der Inkubationszeit zu. Die Standardabweichungen betragen mehr als $20 \%$ des Mittelwerts. Die Abbildung zeigt Mittelwerte von 3 Versuchen aufeinanderfolgender Zellpassagen.

\subsection{2.) Ergebnisse der Versuche unter Natrium-freier Lösung}

Um die Abhängigkeit der Transportfunktion des hNaDC3 vom Natrium zu überprüfen, wurden Experimente mit hNaDC3-transfizierten und Vektor-transfizierten HEK293-Zellen in Natrium-haltiger und Natrium-freier Inkubationslösung durchgeführt. Betrachtet man zunächst die Versuche mit den hNaDC3-transfizierten HEK293-Zellen, zeigt sich eine $\left[{ }^{14} \mathrm{C}\right]-$ Succinat-Konzentration intrazellulär von $24,4 \mathrm{pmol} /$ Well unter Natrium-haltigem MRi, jedoch nur noch eine Aufnahme von 0,3 pmol/Well unter Natrium-armem MRi. Zur Kontrolle 
wurden Vektor-transfizierte HEK293-Zellen mit dem gleichen Verfahren getestet. Hier ergaben sich sowohl in An- als auch in Abwesenheit Werte von 0,2 pmol/Well.

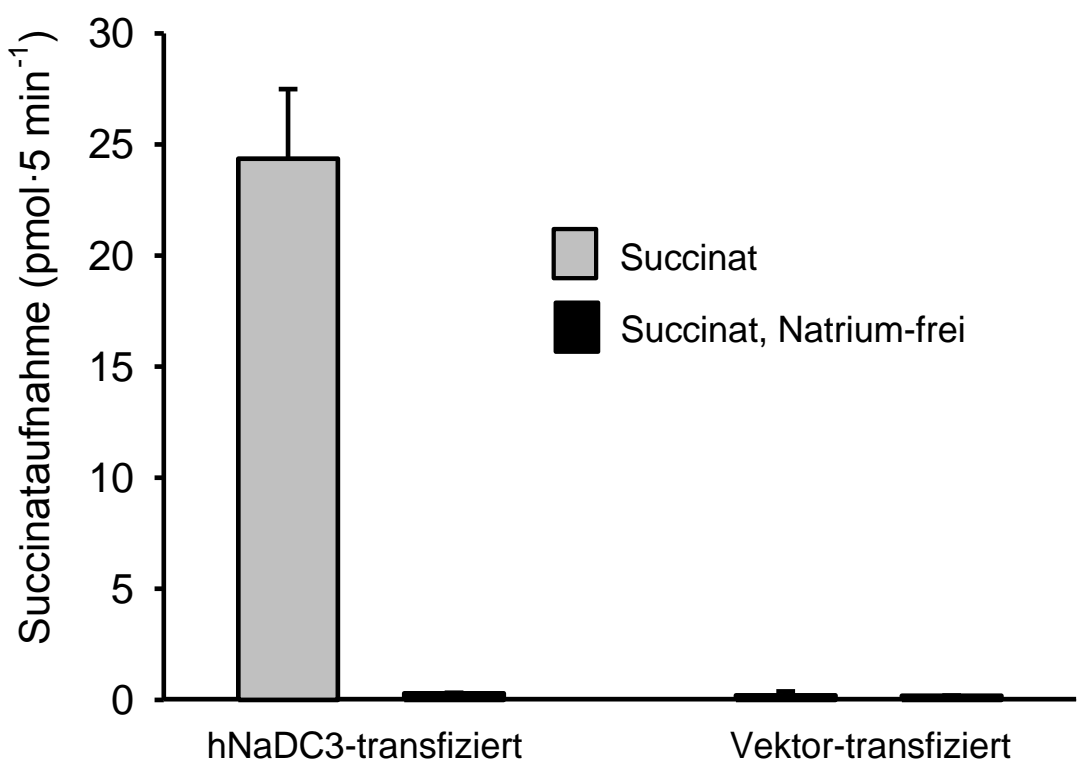

Abbildung 3.2: Natriumabhängigkeit der Aufnahme von $\left[{ }^{14} \mathrm{C}\right]-$ Succinat in hNaDC3- und Vektortransfizierten HEK293-Zellen.

Die Aufnahme von Succinat in hNaDC3-transfizierte Zellen ist gegenüber den Vektor-transfizierten Zellen um den Faktor 50 erhöht. Sowohl hNaDC3- als auch Vektor-transfizierte Zellen nehmen in Abwesenheit von Natrium kaum Succinat auf. Dargestellt sind Mittelwerte aus drei aufeinanderfolgenden Zellpassagen.

\subsection{3.) Bestimmung der $K_{M}$ für Succinat}

Mithilfe dieser Experimente sollte die $\mathrm{K}_{\mathrm{M}}$, also die Michaelis-Menten-Konstante, des hNaDC3 für Succinat bestimmt werden. Dazu wurden für 5 Minuten hNaDC3- ( ) und Vektor-transfizierten Zellen (O) aufsteigende Konzentrationen an Succinat angeboten. Die Lösungen beinhalteten jeweils $1 \mu \mathrm{M}\left[{ }^{14} \mathrm{C}\right]$-Succinat, höhere Succinatkonzentrationen wurden durch Auffüllen mit nicht-markiertem Succinat (Natriumsuccinat) erreicht. In Abbildung 3.3 ist die Zusammenfassung der drei Experimente in Form eines Graphen dargestellt. Bei einer Konzentration von $1 \mu \mathrm{M}\left[{ }^{14} \mathrm{C}\right]$-Succinat lag die Aufnahme von Succinat bei 19,5 pmol/Well, stieg dann bei $2 \mu \mathrm{M}$ auf 74,7 pmol/Well, bei $5 \mu \mathrm{M}$ auf 185,9 pmol/Well, bei $10 \mu \mathrm{M}$ auf 350,4 $\mathrm{pmol} / \mathrm{Well}$, bei $25 \mu \mathrm{M}$ auf 593,0 pmol/Well, bei $50 \mu \mathrm{M}$ auf 924,8 pmol/Well, bei $75 \mu \mathrm{M}$ auf 1023,4 pmol/Well an. Bei der höchsten eingesetzten Konzentration von Succinat $(100 \mu \mathrm{M})$ betrug sie 685,2 pmol/Well. Wird die Aufnahme von Succinat als Funktion der 
extrazellulären Succinatkonzentration aufgetragen (Abbildung 3.3) zeigt sie Sättigungscharakter, das heißt ab einer Konzentration von ca. $50 \mu \mathrm{M}$ Succinat nimmt die Aufnahme von Succinat in den Zellen nicht mehr zu. Aus diesen Daten konnten die maximale Aufnahme von Succinat und die Michaelis-Menten-Konstante $K_{M}$ berechnet werden. Sie betrugen $1084 \pm 173 \mathrm{pmol} /$ Well und 18,9 $\pm 9,7 \mu \mathrm{M}$.

Vektor-transfizierte Zellen antworten auf aufsteigende Konzentrationen an Succinat mit weitaus geringeren Aufnahmen. Diese betrugen bei $1 \mu \mathrm{M}$ Succinat 1,4 pmol/Well, bei 100 $\mu \mathrm{M} 36,5 \mathrm{pmol} / \mathrm{Well}$.

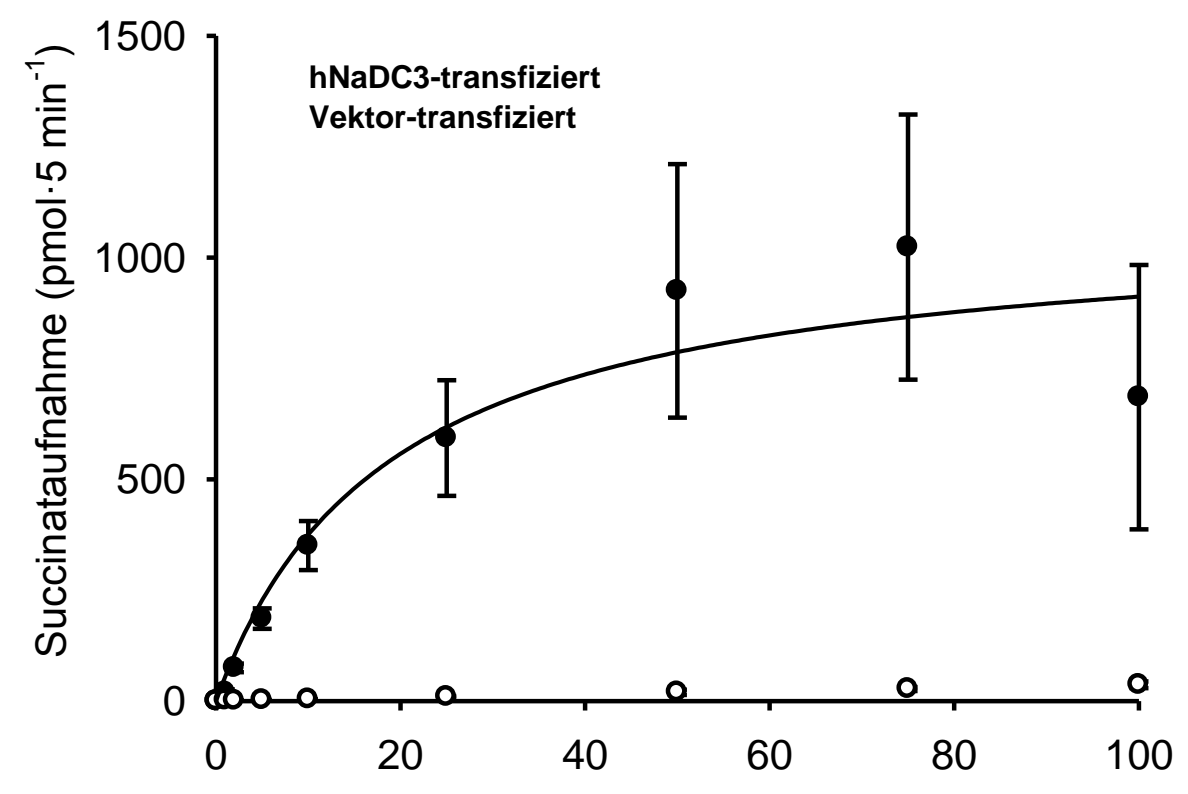

Succinat $(\mu \mathrm{M})$

Abbildung 3.3: Aufnahme von $\left[{ }^{14} \mathrm{C}\right]$-Succinat als Funktion der extrazellulären Succinatkonzentration im Inkubationsmedium in hNaDC3- (O) und Vektor-transfizierten HEK293-Zellen (O).

Als extrazelluläre Succinatkonzentrationen wurden eingesetzt: 1, 2, 5, 10, 25, 50, 75 und $100 \mu \mathrm{M}$. Die Aufnahmezeit betrug 5 Minuten. Dargestellt sind die Mittelwerte aus Messungen an drei aufeinanderfolgenden Zellpassagen.

\subsection{4.) Hemmung der Aufnahme von Succinat durch Fumarat und Fumaratderivate}

Diese Versuchsreihe sollte den Einfluss von Fumarat, Diethyl- und Dimethylfumarat auf die Aufnahme von Succinat untersuchen. Dazu wurden hNaDC3-transfizierte und Vektortransfizierte HEK293-Zellen 5 Minuten lang mit $2 \mu \mathrm{M}-\left[{ }^{14} \mathrm{C}\right]$-Succinat-Lösungen inkubiert und je nach Fragestellung einer der potentiellen Inhibitoren in einer Konzentration von 100 
$\mu \mathrm{M}$ hinzugegeben. In diesen Versuchsreihen betrug die Aufnahme von Succinat nach 5 Minuten in den hNaDC3-transfizierten Zellen 35,4 pmol/Well, Bei Zugabe von $100 \mu \mathrm{M}$ Dimethylfumarat bzw. Diethylfumarat wurde eine Aufnahme von 37,9 pmol/Well bzw. 41,3 pmol/Well gemessen. Die Zugabe von $100 \mu \mathrm{M}$ Fumarat reduzierte die Aufnahme von Succinat auf 17,0 pmol/Well. Diese Aufnahme war signifikant unterschiedlich ( $*$ in Abbildung 3.4) zu der in Abwesenheit von Fumarat gemessenen Aufnahme von Succinat. Die Vektor-transfizierten HEK293-Zellen verhielten sich unabhängig von den wechselnden Substanzen in jedem der Experimente annähernd gleich. Die Aufnahme von Succinat schwankte zwischen 0,4 und $0,5 \mathrm{pmol} / \mathrm{Well}$.

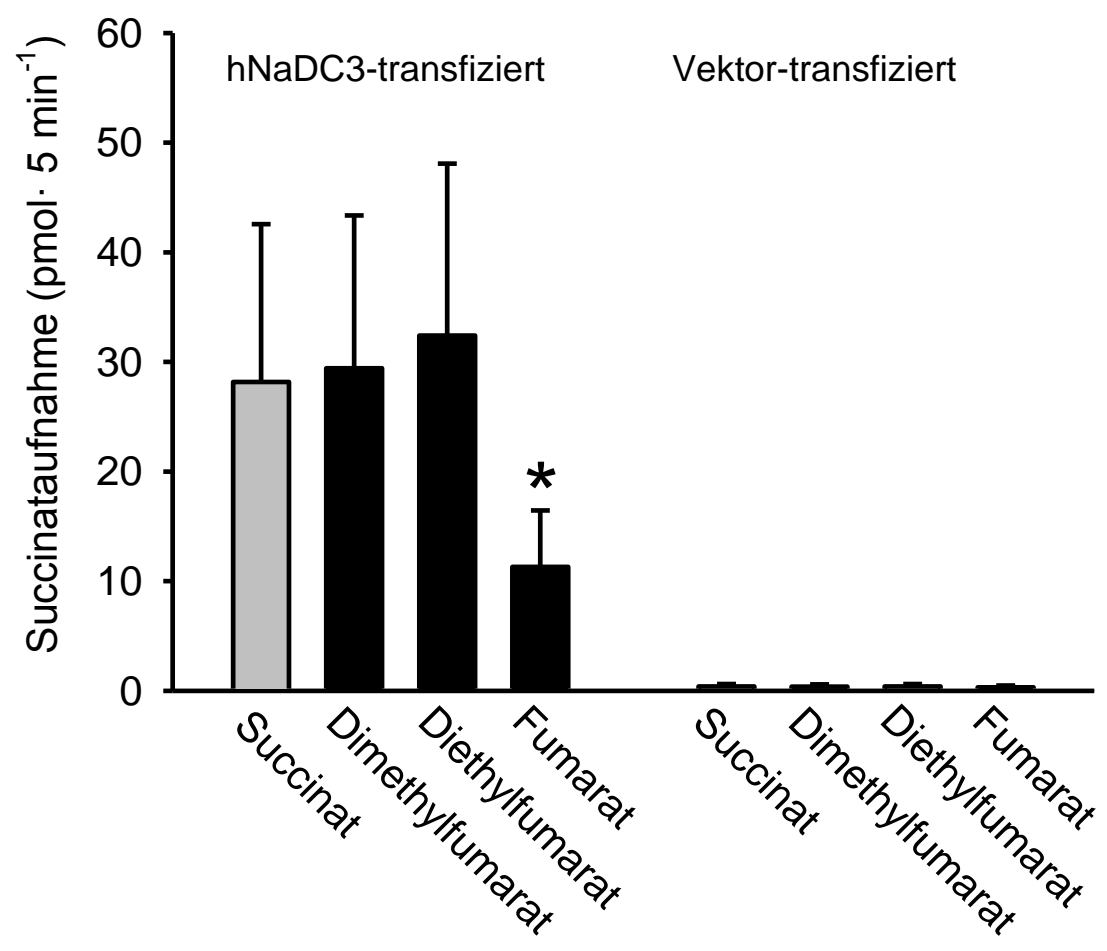

Abbildung 3.4: Einfluss von Fumarat und Fumaratderivaten auf die Aufnahme von $\left[{ }^{14} \mathrm{C}\right]-$ Succinat.

Es erfolgten Aufnahmeexperimente mit $2 \mu \mathrm{M}\left[{ }^{14} \mathrm{C}\right]$-Succinat, welches dann sukzessive mit anderen Substanzen (Fumarat, Diethyl- und Dimethylfumarat) in jeweils der Konzentration $100 \mu \mathrm{M}$ inhibiert wurde. Die Säulen im linken Teil der Abbildung repräsentieren die an hNaDC3-transfizierten Zellen erhobenen Daten, die Säulen im rechten Teil der Abbildung die an Vektor-transfizierten HEK293-Zellen gewonnenen Daten. Gezeigt sind wieder die Mittelwerte aus drei Versuchen.

Da die Aufnahmen sehr starke Standardabweichungen zeigten, die einen möglichen Effekt von Dimethyl- oder Diethylfumarat auf die Aufnahme von Succinat möglicherweise maskierten, wurde die Aufnahme von Succinat in jedem einzelnen Experiment zu $100 \%$ 
gesetzt und die Aufnahmen der Fumarate in jedem entsprechenden Experiment darauf bezogen. Diese Daten sind in Abbildung 3.5 zusammengefasst. Dies führte zu geringeren Standardabweichungen, die Aussage des Experiments änderte sich dadurch aber nicht. Nur Fumarat war in der Lage, die Aufnahme von Succinat signifikant zu reduzieren.

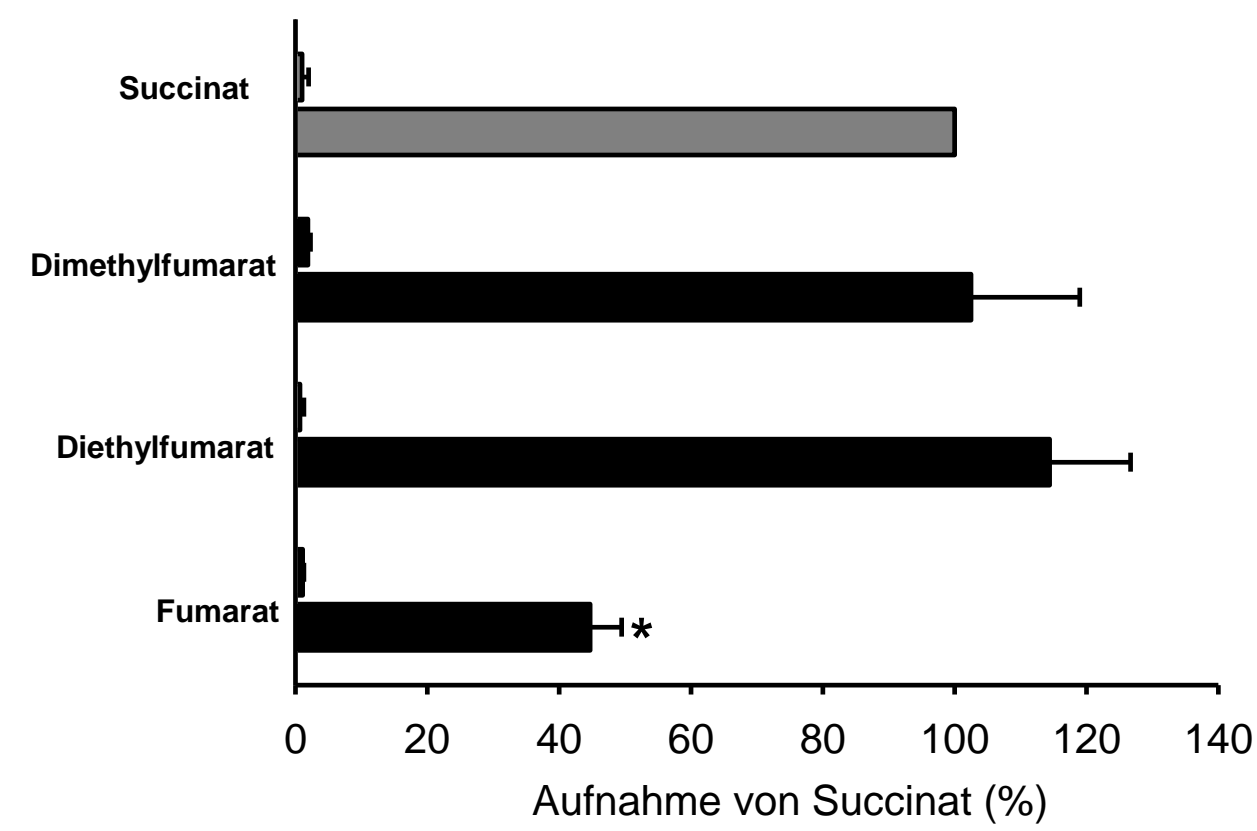

Abbildung 3.5: Einfluss von Fumarat und Fumaratderivaten auf die Aufnahme von $\left[{ }^{14} \mathrm{C}\right]-$ Succinat.

Die Ergebnisse des in Abbildung 3.3 gezeigten Experiments werden in dieser Abbildung prozentual verglichen. Fumarat $(100 \mu \mathrm{M})$ senkte die Aufnahme von Succinat auf circa $45 \%$ des Ausgangswerts.

\subsection{5.) Bestimmung einer $\mathrm{K}_{\mathrm{I}}$ und der $\mathrm{IC}_{50}$ für Fumarat}

Zur Bestimmung einer $\mathrm{K}_{\mathrm{I}}$ für Fumarat wurden Dixon-Plot Experimente durchgeführt. Hierzu wurden zwei Konzentrationen an Succinat $(1$ und $5 \mu \mathrm{M})$ und Fumaratkonzentrationen von 100, 200 und $300 \mu \mathrm{M}$ und wiederum die Inkubationszeit von 5 Minuten gewählt. Die Succinataufnahme hNaDC3-transfizierter HEK293-Zellen und Einsatz von $1 \mu \mathrm{M}\left[{ }^{14} \mathrm{C}\right]-$ Succinat fiel von 28,1 pmol/Well in Abwesenheit von Fumarat auf 10,8 pmol/Well in Anwesenheit von $100 \mu \mathrm{M}$ Fumarat, auf 7,0 pmol/Well in Anwesenheit von $200 \mu \mathrm{M}$ Fumarat und auf $5,1 \mathrm{pmol} / \mathrm{Well}$ in Anwesenheit von $300 \mu \mathrm{M}$ Fumarat ab. Bei Einsatz von $5 \mu \mathrm{M}$ Succinat wurden bei den entsprechenden Fumaratkonzentrationen Succinataufnahmen von 110,7 pmol/Well, 46,1 pmol/Well, 29,1 pmol/Well und 21,9 pmol/Well gemessen. Unter beiden Konzentrationen von Succinat blieb bei der höchsten Fumaratkonzentration von 300 $\mu \mathrm{M}$ ein nicht Fumarat-hemmbarer Anteil von ca. $20 \%$ erhalten. Diese Daten wurden als 
Dixon-Plot aufgetragen (Abbildung 3.6). Aus dem Schnittpunkt der beiden Geraden lässt sich eine $\mathrm{K}_{\mathrm{I}}$ für Fumarat von $65,2 \pm 17,3 \mu \mathrm{M}$ ablesen.

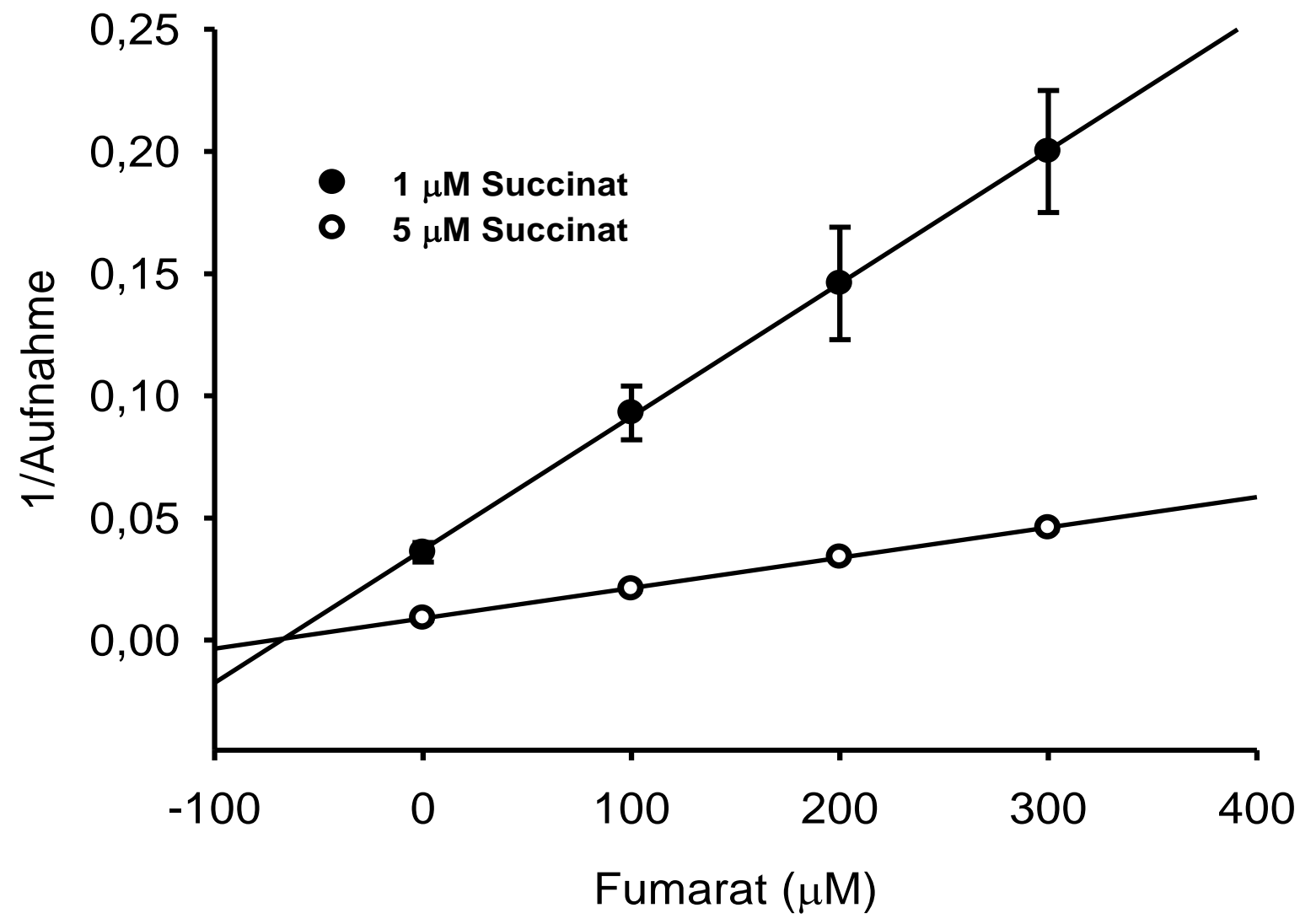

Abbildung 3.6: Dixon-Plot zur Ermittlung einer Inhibitorkonstanten $K_{I}$ für Fumarat.

Als Succinatkonzentrationen wurden $1(O)$ und $5(O) \mu M$ Succinat eingesetzt. Die Konzentrationen an Fumarat betrugen 100, 200 und $300 \mu \mathrm{M}$, die Inkubationszeit betrug 5 Minuten. Wiederum handelt es bei der Darstellung um Mittelwerte aus drei unterschiedlichen Zellpassagen.

Eine andere Form, die Hemmung von Fumarat auf die Aufnahme von Succinat zu charakterisieren, besteht in der Bestimmung einer $\mathrm{IC}_{50}$. Die $\mathrm{IC}_{50}$ ist diejenige Konzentration eines Hemmstoffs, bei der die Aufnahme des ursprünglichen Substrats zu $50 \%$ gehemmt ist. Experimentell wird die Aufnahme von Succinat in Ab- und Anwesenheit mehrerer Konzentrationen des Inhibitors gemessen. Es wurde eine Konzentration von $1 \mu \mathrm{M}\left[{ }^{14} \mathrm{C}\right]-$ Succinat und Fumaratkonzentrationen von 100, 200 und $300 \mu \mathrm{M}$ Fumarat gewählt. Die 
Ergebnisse sind in Abbildung 3.7 zusammengefasst. Aufsteigende Konzentrationen an Fumarat hemmen die Aufnahme von Succinat. Bei Applikation von $300 \mu$ M Fumarat beträgt die Succinataufnahme nur ca. $20 \%$ ihres Werts in Abwesenheit von Fumarat. Die $\mathrm{IC}_{50}$ für den hemmbaren Anteil konnte aus diesen Daten zu ca. $62 \mu \mathrm{M}$ bestimmt werden.

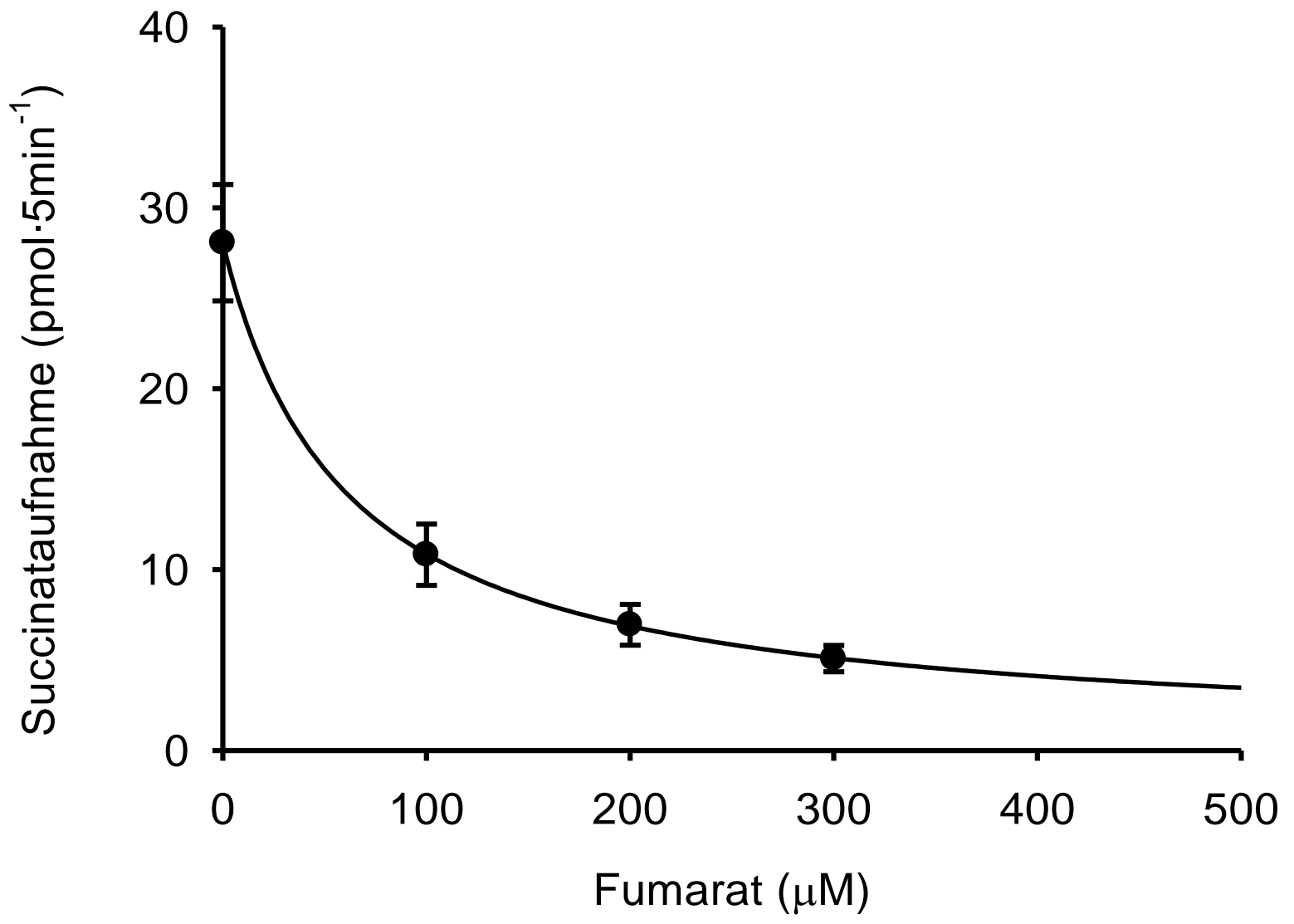

Abbildung 3.7: Bestimmung einer $\mathrm{IC}_{50}$ für die Hemmung der Aufnahme von $\left[{ }^{14} \mathrm{C}\right]$-Succinat durch aufsteigende Konzentrationen von Fumarat.

Als Fumaratkonzentrationen wurden 100, 200 und $300 \mu$ M, eingesetzt, die Konzentration an $\left[{ }^{14} \mathrm{C}\right]-$ Succinat lag bei $1 \mu \mathrm{M}$, die Inkubationszeit bei 5 Minuten.

\section{2.) Ergebnisse der elektrophysiologischen Experimente}

Nach den in 3.1 beschriebenen Ergebnissen konnte davon ausgegangen werden, dass der hNaDC3 Fumarat, jedoch nicht dessen Derivate Diethyl- und Dimethylfumarat in Anwesenheit von Natrium transportiert. Um den hNaDC3 im Hinblick auf seine Interaktionen mit diesen Substanzen näher zu charakterisieren, wurden elektrophysiologische Messungen 
mit der Zwei-Elektroden-Spannungsklemme an Xenopus-laevis-Oozyten, die den hNaDC3 exprimiert hatten, durchgeführt.

\subsection{1.) Nachweis einer funktionellen Expression von hNaDC3 in Xenopus-laevis-Oozyten}

Vor jedem Experiment musste geprüft werden, ob die Xenopus-laevis-Oozyten den hNaDC3 exprimiert hatten. Dazu wurden Strom-Spannungs- (I/V) Kennlinien aufgenommen, wie sie exemplarisch für hNaDC3-exprimierende Oozyten in Ab- und Anwesenheit von Succinat (1 $\mathrm{mM}$ ) dargestellt sind. Zunächst wurde im Current-Clamp-Modus das Ruhemembranpotential der Oozyte gemessen. Dieses hatte sich meist ca. 10 Minuten nach Einstich der Spannungsmessenden und der Strom-einspeisenden Elektrode und Perfusion mit Oozyten-Ringer (ORi) eingestellt und lag zwischen -15 und -80 mV. Um im Voltage-Clamp-Modus ein Halte- oder Klemmpotential $\left(\mathrm{V}_{\mathrm{c}}\right)$ von $-60 \mathrm{mV}$ zu erhalten, mussten sowohl hyperpolarisierende Ströme, wenn das Ruhemembranpotential niedriger als $-60 \mathrm{mV}$ lag, als auch depolarisierende Ströme, wenn das Ruhemembranpotential $-60 \mathrm{mV}$ überstieg, eingespeist werden. Anschließend für $\mathrm{V}_{\mathrm{c}}$ für 5 Sekunden in $10 \mathrm{mV}$-Schritten von $-60 \mathrm{mV}$ bis auf $-90 \mathrm{mV}$ und von $-90 \mathrm{mV}$ ebenfalls in $10 \mathrm{mV}$-Schritten auf $0 \mathrm{mV}$ eingestellt und die Ströme registriert, die notwendig waren, um $\mathrm{V}_{\mathrm{c}}$ auf dem entsprechenden Potential zu halten (Abbildung 3.8A (O)). Nach Wechsel der Perfusion auf ORi plus $1 \mathrm{mM}$ Succinat (Abbildung 3.8A (O)) wurde der Vorgang wiederholt. Die Subtraktion der Ströme in Anwesenheit von Succinat zu denen in Abwesenheit ergab die Succinat-vermittelten Ströme (Abbildung 3.7B). 
A

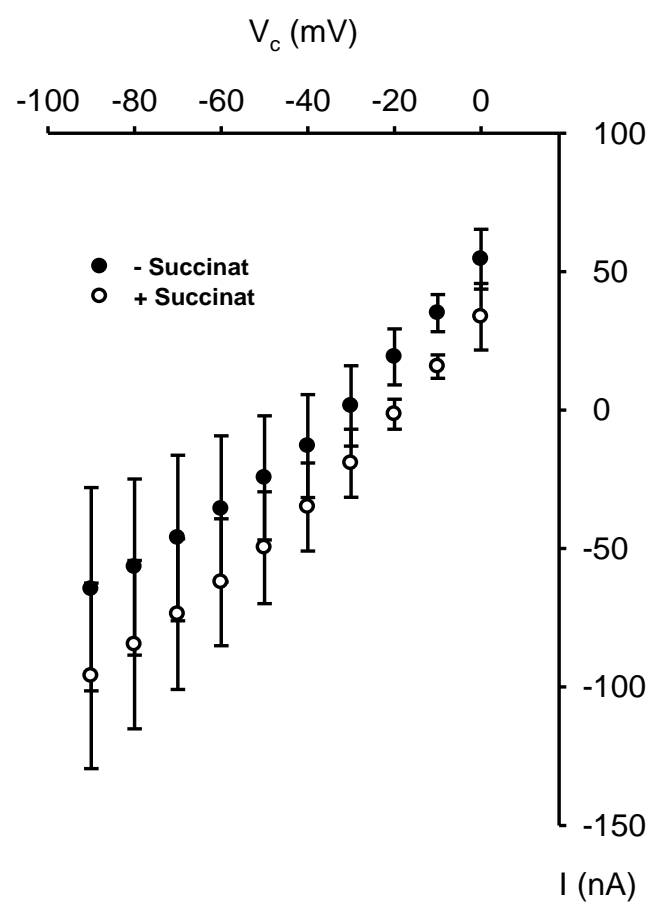

B

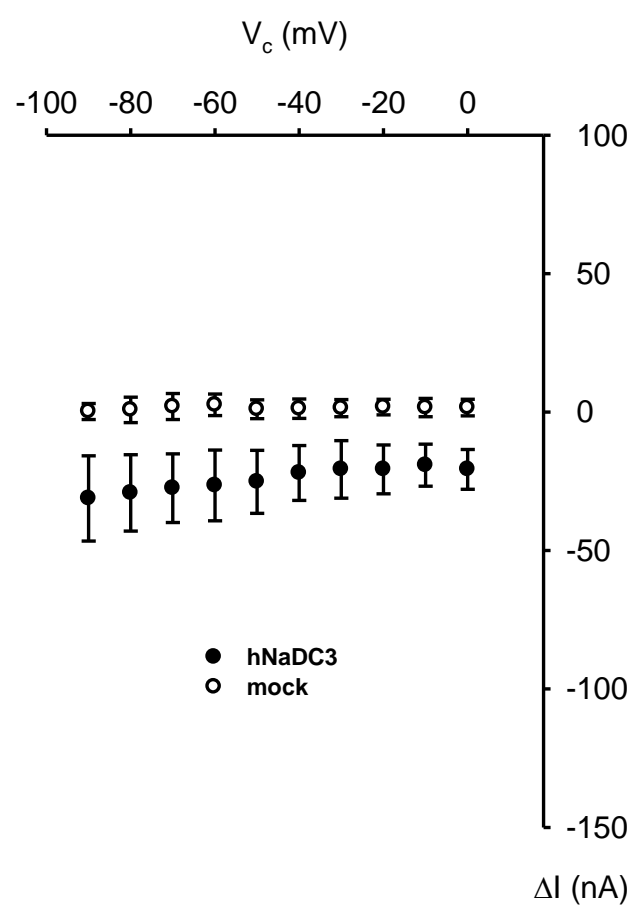

Abbildung 3.8: Strom - Spannungs (I/V) - Kennlinien hNaDC3-exprimierender Oozyten in Ab- und Anwesenheit von Succinat.

Dargestellt sind die Mittelwerte aus Messungen an $4 \mathrm{hNaDC} 3$-exprimierenden Oozyten. (A) In Abwesenheit von Succinat variieren die einzuspeisenden Ströme zwischen $-64,7 \pm 36.7 \mathrm{nA}$ bei $-90 \mathrm{mV}$ und $54,5 \pm 10,8 \mathrm{nA}$ bei 0 $\mathrm{mV}(\bullet)$. Unter Perfusion von ORi plus $1 \mathrm{mM}$ Succinat (O) werden bei $-90 \mathrm{mV}$ Ströme von $-96,0 \pm 33,5 \mathrm{nA}$ und bei $0 \mathrm{mV}$ Ströme von 33,7 \pm 12,0 nA registriert. (B) Die aus (A) berechneten Differenzströme (O - ๑), d.h. die Succinat-vermittelten Ströme sind in (B) als - dargestellt. Zum Vergleich sind die mit Wasser injizierten Oozyten, sogenannten mocks, gewonnenen Ströme als $\mathrm{O}$ diesen gegenübergestellt.

Aus Abbildung 3.8B ist ersichtlich, dass die Amplitude der Succinat-vermittelten Ströme hNaDC3-exprimierender Oozyten (O) mit Depolarisation abnimmt, die Amplitude der Succinat-mediierten Ströme in den mocks (O) sehr gering ist und keine Potentialabhängigkeit aufweist. 


\subsection{2.) Vergleich der Amplituden der Fumarat-, Dimethylfumarat-, Diethylfumarat- mediierten Ströme mit den von Succinat hervorgerufenen Strömen}

Nachdem in Abbildung 3.8 gezeigt worden ist, dass der hNaDC3 funktionell in den Oozyten exprimiert werden kann, wurde in einem zweiten Schritt getestet, ob auch Fumarat und seine Derivate substratabhängige Ströme induzieren können. In den Abbildungen 3.4 und 3.5 zusammengefassten Daten war nur eine Hemmung der Aufnahme von Succinat durch Fumarat, nicht aber durch Dimethyl- oder Diethylfumarat beobachtet worden. Basierend auf diesen Ergebnissen sollte auch nur ein Fumarat-vermittelter Strom, nicht aber Dimethylfumarat- und Diethylfumarat-vermittelte Ströme detektiert werden. Dies war, wie Abbildung 3.9 zeigt, der Fall. Die dieser Abbildung zugrundeliegenden Ergebnisse wurden folgendermaßen erhoben. Zuerst wurde in hNaDC3-exprimierenden Oozyten durch Perfusion von ORi plus $1 \mathrm{mM}$ Succinat getestet, ob der hNaDc3 ausreichend exprimiert war; das heißt, ob bei einem $V_{c}$ von $-60 \mathrm{mV}$ auf Perfusion von Succinat ein ausreichend großer Einwärtsstrom detektiert werden konnte. Anschließend wurden I/V-Kennlinien, wie sie in Abbildung 3.8A beschrieben worden sind, für Succinat und, nach einer Auswaschphase, von je 15 Minuten für Fumarat, Dimethyl- und Diethylfumarat aufgenommen. Für jede Substanz wurden anschließend die Differenzströme ausgerechnet und in Abbildung 3.9 als Funktion von $\mathrm{V}_{\mathrm{c}}$ aufgetragen. Dieses experimentelle Verfahren wurde auch bei den mocks durchgeführt. Mocks antworteten auf die unterschiedlichen Perfusionen nur mit Differenzströmen $<4 \mathrm{nA}$, sodass auf eine gesonderte Abbildung verzichtet wurde.

An den hNaDC3-exprimierenden Oozyten konnten nur für Succinat und Fumarat substratinduzierte Ströme in Abhängigkeit des angelegten $V_{c}$ nachgewiesen werden, wobei die Amplitude der substratinduzierten Ströme bei Fumarat (O) etwas niedriger als bei Succinat (- $\mathrm{zu}$ sein scheint. Sowohl für Succinat als auch für Fumarat nahmen die Amplituden der Ströme mit Depolarisation ab. Das Nullstrompotential liegt für beide Substanzen zwischen +60 und $+80 \mathrm{mV}$. Dies entspricht ungefähr dem Nernstpotential der Oozyten für Natrium und zeigt, dass beide Substanzen Natrium-abhängig transloziert werden. Die Daten zeigen zusätzlich, dass Fumarat ein Substrat des hNaDC3 ist. Dimethyl- und Diethylfumarat sind keine Substrate des hNaDc3, da sie keine oder nur sehr geringe substratabhängigen und vor allem keine potentialabhängigen Ströme induzierten. Auch sind die von Dimethyl- und Diethylfumarat hervorgerufenen Ströme in hNaDc3-exprimierenden Oozyten und in mocks nicht voneinander verschieden. 


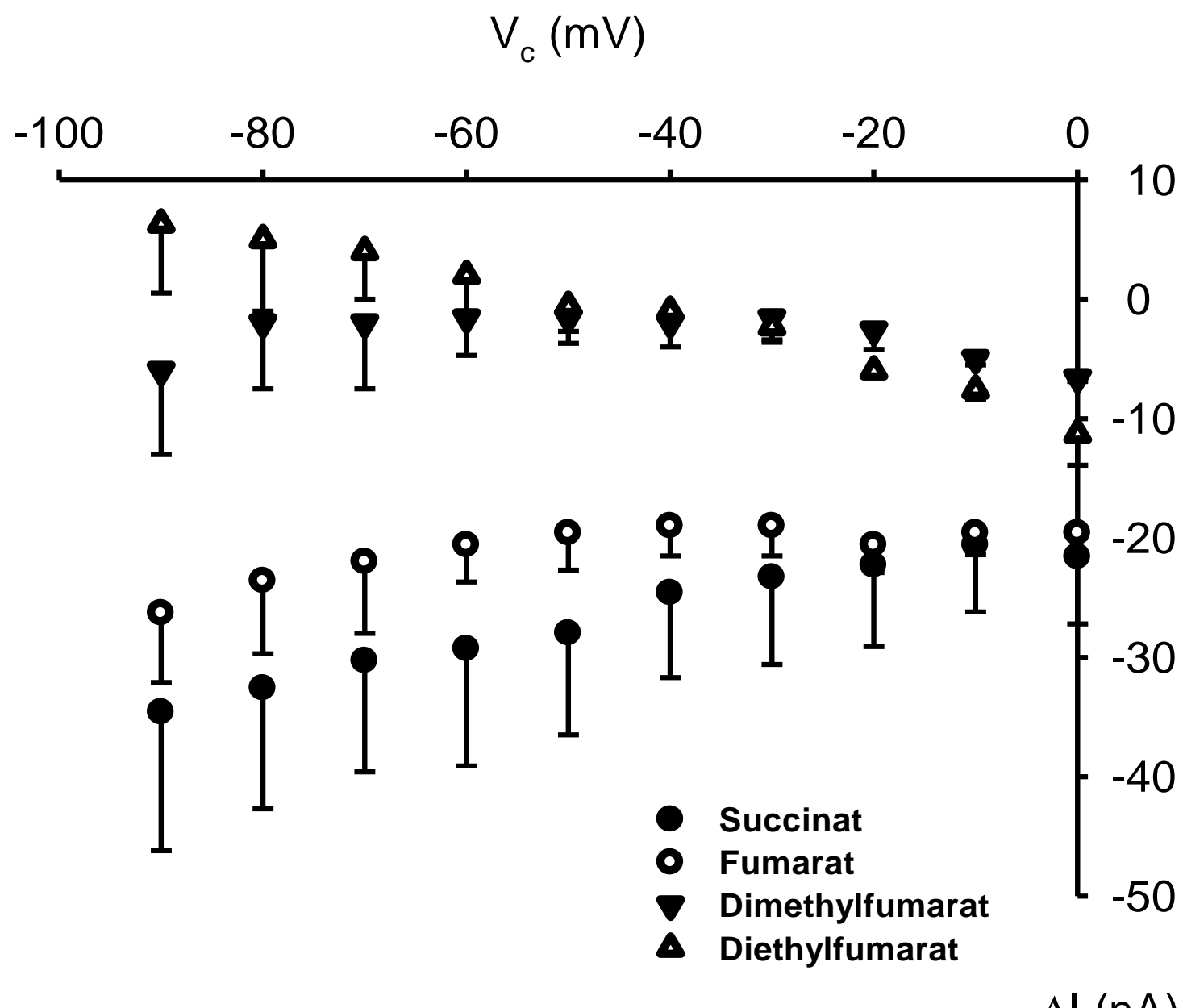

$\Delta \mathrm{l}(\mathrm{nA})$

Abbildung 3.9: Durch Succinat, Fumarat, Dimethyl- und Diethylfumarat (je $1 \mathrm{mM}$ ) hervorgerufene substratabhängige Differenzströme in Abhängigkeit von $\mathbf{V}_{\mathbf{c}}$.

Dargestellt sind Mittelwerte an vier hNaDC3-exprimierenden Oozyten von vier unterschiedlichen Spendertieren. Auf die Darstellung der Ergebnisse in den mocks wurde aus Gründen der Übersichtlichkeit verzichtet. Diese Ströme liegen für alle Substanzen im Bereich um $0 \pm 4 \mathrm{nA}$. Als Substratkonzentration wurde jeweils $1 \mathrm{mM}$ eingesetzt. Nach Applikation von Succinat wurden bei den unterschiedlichen Oozyten Fumarat, Dimethyl- und Diethylfumarat in unterschiedlicher Reihenfolge appliziert.

Um die Ergebnisse besser herausarbeiten zu können, wurden bei einem $V_{c}$ von $-60 \mathrm{mV}$ der Succinat-mediierte Strom zu $100 \%$ gesetzt und die von den anderen Substanzen hervorgerufenen Ströme dazu in Relation gesetzt (Abbildung 3.10). Bei -60 mV induzieren Diethylfumarat und Dimethylfumarat jeweils nur 1,9 $\pm 1,6$ bzw. 6,5 $\pm 5,5 \%$ der Succinatmediierten Ströme. 


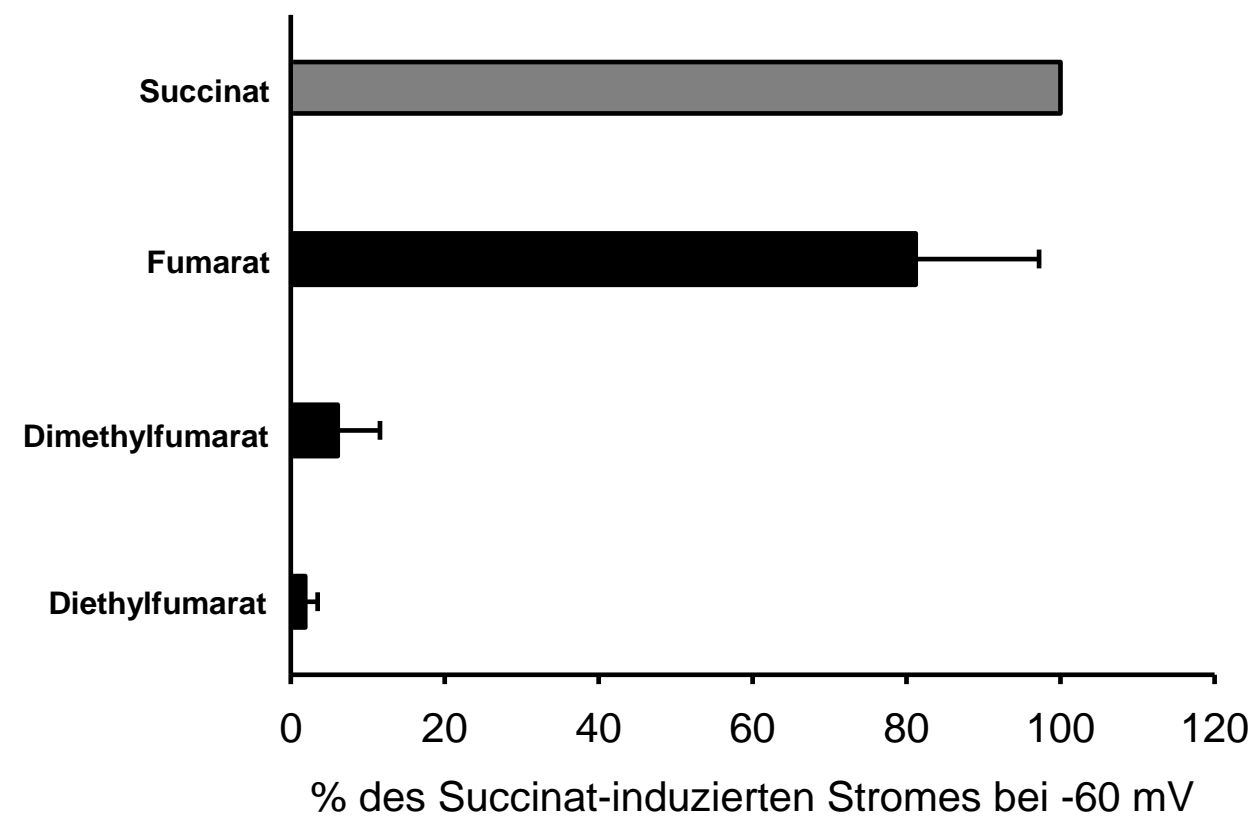

Abbildung 3.10: Durch den Transport verschiedener Substrate mittels hNaDC3 ableitbare Einwärtsströme; prozentual gemessen an den Einwärtsströmen, die durch Succinat-Transport entstanden sind.

Hier werden die in der Zwei-Elektroden-Spannungsklemme aufgezeichneten Ströme bei -60 mV Membranpotential miteinander verglichen, in dem das Experiment mit Succinat als Referenz dient und in diesem Falle mit $100 \%$ gleichgesetzt wird. Fumarat erreicht circa $85 \%$ des bei Succinat unter $-60 \mathrm{mV}$ erreichten Einwärtsstroms, Dimethylfumarat um die $10 \%$, Diethylfumarat etwa $3 \%$.

\subsection{3.) Bestimmung einer $K_{M}$ für Fumarat}

Nachdem Fumarat sowohl die Aufnahme von Succinat suffizient gehemmt hatte als auch bei einem $V_{c}$ von -60 mV einen Strom mit einer Amplitude vergleichbar der von Succinat hervorgerufen hat, wurde eine $K_{M}$ für Fumarat bei einem $V_{c}$ von $-60 \mathrm{mV}$ bestimmt. Es wurden folgende Konzentrationen an Fumarat in aufsteigender Reihe appliziert: 0,01, 0,025, 0,05, 0,1 und $1 \mathrm{mM}$. Die Fumarat-assoziierten Ströme sättigten ab einer Konzentration von 0,1 mM. Mocks zeigten bis zu einer Konzentration von $1 \mathrm{mM}$ Fumarat keine Fumaratinduzierten Ströme, sodass auf eine Darstellung verzichtet wurde. Aus den in Abbildung 3.11 gezeigten Daten lässt sich eine $\mathrm{K}_{\mathrm{M}}$ für Fumarat von $26,2 \pm 3,1 \mu \mathrm{M}$ berechnen. 


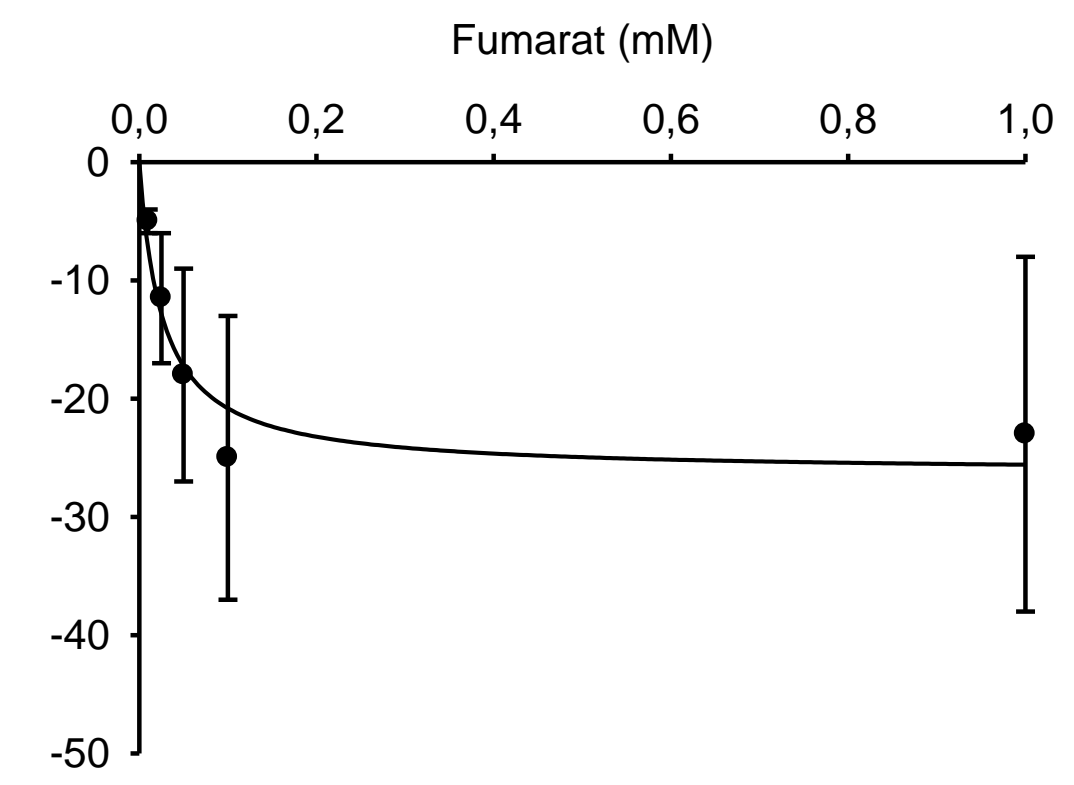

$\Delta \mathrm{l}(\mathrm{nA})$

Abbildung 3.11: Bestimmung einer $K_{M}$ für Fumarat an hNaDC3-exprimierenden Oozyten bei einem $V_{c}$ von $-60 \mathrm{mV}$.

Mit der Zwei-Elektroden-Spannungsklemme sind bei einem $\mathrm{Vc}$ von $-60 \mathrm{mV}$ die durch aufsteigende Konzentrationen an Fumarat-induzierten Einwärtsströme gemessen worden und als Funktion der Fumaratkonzentration im Bad aufgetragen worden. Die Abbildung zeigt Mittelwerte von drei Oozyten aus drei unterschiedlichen Spendertieren. 


\section{4.) Diskussion}

Ziel der vorliegenden Arbeit war es, den Einfluss von Fumarat, Dimethyl- und Diethylfumarat auf den Natrium-abhängigen Dicarboxylattransporter des Menschen, hNaDC3, zu untersuchen. Fumaratderivate werden zunehmend in der Therapie der Psoriasis und der Multiplen Sklerose eingesetzt. Während bei der Behandlung der Psoriasis die Pharmaka häufig in Form von Salben auf die Haut aufgebracht werden und deshalb keiner besonderen Transporter bedürfen, müssen bei einer suffizienten Behandlung der Multiplen Sklerose die Medikamente die Blut-Hirn-Schranke überwinden, um an Neuronen und Astrozyten der betroffenen Gebiete zu gelangen. Da der NaDC3 zumindest bei Maus und Ratte im cerebralen Cortex exprimiert ist (HUANG et al. 2000, PAJOR et al. 2001) und seine Expression mit dem Alter der Tiere, zumindest bei der Ratte zunimmt (FUJITA et al. 2005; YODOYA et al. 2006), erschien es sinnvoll, den NaDC3 auf seine Interaktionen mit den Fumaraten zu untersuchen.

\section{1.) Vor- und Nachteile des Versuchsaufbaus}

Als experimentelles Design wurden einmal stabil mit dem hNaDC3-transfizierte HEK293Zellen und den hNaDC3-exprimierende Xenopus-laevis-Oozyten und die entsprechend Vektor-transfizierten HEK293-Zellen und mit einer der RNA äquivalenten Menge an Wasser injizierte Oozyten gewählt. Beide Expressionssysteme zeichnen sich dadurch aus, dass sie wenig endogene Transporter besitzen. Die Experimente wurden entweder an hNaDC3transfizierten HEK293-Zellen oder hNaDC3-exprimierendem Oozyten und den entsprechenden Kontrollen durchgeführt.

Der Einsatz von zwei Expressionssystemen reduziert den Einfluss des Expressionssystems auf die Ergebnisse und ermöglicht den Einsatz unterschiedlicher experimenteller Methoden. HEK293-Zellen eignen sich gut für radiochemische Versuche, Xenopus-laevis-Oozyten eignen sich aufgrund ihrer Größe gut für elektrophysiologische Messungen mit der ZweiElektroden-Spannungsklemme. Da der NaDC3, unabhängig von der Spezies aus der er stammt, ein elektrogener Transporter ist, der 3 Natriumionen zusammen mit einem divalenten Dicarboxylat transloziert, ist es möglich über diese Methode auch nicht radioaktiv markierte Substrate zu erfassen. Außerdem können bei dieser Methode subsequent mehrere mögliche Substanzen an einer Oozyte getestet werden. Dies ist bei den HEK293-Zellen nicht der Fall. Für jeden Datenpunkt müssen Zellen eines neuen Wells herangezogen werden. 
Ein zusätzlicher Vorteil der Methode besteht in der festen Vorgabe eines definierten Haltepotentials, sodass der Einfluss eines elektrischen Gradienten auf das Transportgeschehen weitgehend ausgeschlossen werden kann. Andererseits kann bei dieser Technik das Haltepotential variiert werden und gezielt der Einfluss des Potentials untersucht werden. Ein solches Vorgehen ist bei radiochemischen Versuchen nicht möglich.

\section{2.) Substratspezifität des hNaDC3}

Unabhängig davon, ob radiochemische oder elektrophysiologische Methoden zum Einsatz kamen, wurden Succinat und Fumarat, nicht jedoch Dimethyl- und Diethylfumarat als Substrate des hNaDC3 identifiziert. Fumarat in aufsteigenden Konzentrationen hemmte die Aufnahme von $\left[{ }^{14} \mathrm{C}\right]$-Succinat an hNaDC3-transfizierten HEK293-Zellen und induzierte in hNaDC3-exprimierenden Oozyten einen potentialabhängigen Strom. Die jeweiligen Kontrollen blieben von diesem Manöver unbeeinflusst. Eine Interaktion von Fumarat mit dem NaDC3 wurde schon in früheren Publikationen in unterschiedlichen experimentellen Ansätzen beobachtet (KEKUDA et al. 1999, CHEN X et al. 1999, STEFFGEN et al. 1999, WANG et al. 2000, PAJOR et al. 2001, FUJITA et al. 2005, BURCKHARDT BC et al. 2005, YODOYA et al. 2006). Dimethylfumarat und Diethylfumarat wurden bisher noch nicht auf ihre Interaktionen mit dem $\mathrm{NaDC} 3$ untersucht.

Succinat und Fumarat besitzen beide ein Kohlenstoffgrundgerüst von 4 C-Atomen und zwei endständige Carboxylgruppen. Sie unterscheiden sich nur durch eine Doppelbindung im Kohlenstoffgrundgerüst bei Fumarat. Dies hat auf den Transport von Fumarat über den NaDC3 keinen Einfluss. Der in dieser und in obigen Arbeiten detektierte Fumarat-sensitive Strom lag in der gleichen Größenordnung wie der Succinat-sensitive Strom. Auch die Hemmung der Aufnahme von $\left[{ }^{14} \mathrm{C}\right]$-Succinat durch Fumarat war in allen Arbeiten vergleichbar. Dimethylfumarat und Diethylfumarat bestehen aus einem Kohlenstoffgrundgerüst von 4 C-Atomen, besitzen aber statt der endständigen Carboxylgruppen des Fumarats Methylgruppen. Der Ersatz der Carboxylgruppen durch Methylgruppen verhindert eine Interaktion mit dem humanen NaDC3. Dimethyl- und Diethylfumarat scheinen eine Struktur zu besitzen, die nicht in die Bindungstaschen des hNaDC3 passt. Deshalb konnte keine Hemmung der Aufnahme von $\left[{ }^{14} \mathrm{C}\right]$-Succinat und kein substratassoziierter Strom von Dimethylfumarat und Diethylfumarat in dieser Arbeit nachgewiesen werden. 


\section{3.) $K_{I}$ und $I C_{50}$ für Fumarat, Bestimmung einer $K_{M}$ für Fumarat}

$\mathrm{K}_{\mathrm{I}}$ und $\mathrm{IC}_{50}$ für die Hemmung der Aufnahme von Succinat durch Fumarat wurden zu ungefähr $65 \mu \mathrm{M}$ bestimmt. Aus diesen Versuchen lässt sich allerdings nicht ableiten, ob Fumarat die Aufnahme von Succinat kompetitiv oder im Sinne eines sogenannten „mixed type“ hemmt. Hierzu hätten Eadie-Hofstee Analysen durchgeführt werden müssen. In diesem Verfahren wird die Michaelis-Menten-Konstante $\left(\mathrm{K}_{\mathrm{M}}\right)$ für das prototypische Substrat des Transporters, im Falle des hNaDC3 also des Succinats, in Ab- und Anwesenheit einer hohen Konzentration des Hemmstoffs, in diesem Fall des Fumarats, ermittelt. Bei kompetitiver Hemmung erhöht sich die $K_{M}$ für Succinat, da das Fumarat Succinat von der Bindungsstelle verdrängt. Alternativ wäre es auch möglich, dass sich aus Succinat und Fumarat ein SubstratInhibitorkomplex bildet, der dann über den hNaDC3 transloziert wird. Versuche zur Identifikation des Inhibitortyps wurden in dieser Arbeit nicht ausgeführt, da der Fokus auf der Interaktion von Dimethylfumarat und Diethylfumarat mit dem NaDC3 lag; diese aber leider keine Wirkung auf die Succinataufnahme hatten.

In dieser Arbeit wurde auch eine $\mathrm{K}_{\mathrm{M}}$ für Fumarat bestimmt. Dies erschien sinnvoll, da Fumarat sowohl die Aufnahme von Succinat in den hNaDC3-transfizierten HEK293-Zellen hemmte, als auch in hNaDC3-exprimierenden Oozyten im untersuchten Potentialbereich einen Einwärtsstrom erzeugte. Die $\mathrm{K}_{\mathrm{M}}$ für Fumarat, bestimmt über die Fumarat-assoziierten Ströme, lag bei $26,3 \mu \mathrm{M}$ und damit in der Größenordnung der $\mathrm{K}_{\mathrm{M}}$ für Succinat, die in dieser Arbeit bei 18,9 $\mu \mathrm{M}$ lag. Fumarat stellt, ähnlich Succinat, ein hoch-affines Substrat des hNaDC3 dar.

\section{4.) Fumarat und Fumaratderivate in der Pharmakologie unter Einbeziehung des hNaDC3}

\subsection{1.) Fumarate in der Psoriasis-Therapie}

Fumarate und ihre Derivate zeigten in verschiedenen Versuchsreihen, dass es unter ihrem Einfluss zur Immunmodulation bis hin zur -suppression kommen kann, weshalb sie bei der am ehesten durch autoimmunologische Prozesse verursachten Psoriasis vulgaris seit 1959 zum Einsatz kommen. Wissenschaftlich untersucht und für die Therapie der Psoriasis vulgaris zugelassen wurden für den oralen Gebrauch Monomethyl- und Dimethylfumarat (ALTMEYER et al. 1994). 
Nun zeigen unsere Ergebnisse, dass der hNaDC3 Fumarat, jedoch nicht seine Derivate Diethyl- und Dimethylfumarat transportiert, was vor allem an den endständigen Methyl- und Ethylgruppen liegt, die sehr wahrscheinlich nicht mit den Bindungstaschen des hNaDC3 interagieren können. Die Resorption der lipophilen Stoffe im Dünndarm erfolgt also nicht über den hNaDC3, jedoch könnte dieser an der renalen Elimination von MMF und DMF beteiligt sein, sofern es zuvor zur Abspaltung der Methyl- beziehungsweise Ethylgruppe gekommen ist.

Da beide Fumarat-Derivate aufgrund ihrer Ethyl- und Methylgruppen lipophil sind, ist die topische Anwendung zu erwägen, da lipophile Substanzen gut in Gewebe eindringen. Die Eliminierungsprozesse würden dann, nach Aufnahme in die Blutzirkulation, genau wie bei der systemischen Anwendung stattfinden.

\subsection{2.) Fumarate in der Therapie der Multiplen Sklerose}

Die Multiple Sklerose ist eine durch autoimmune Prozesse vermittelte Erkrankung des ZNS. Durch eine Entzündungsreaktion kommt es zur Demyelinisierung der Axone. Daher werden durch ihre immunmodulatorische Wirkung Fumarate und ihre Derivate in der Therapie diskutiert. Um eine Erkrankung des ZNS therapieren zu können, müssen die Wirkstoffe zunächst einmal die Blut-Hirn-Schranke überwinden, die partiell durch Astrozyten gestellt wird. Diese versorgen Neurone mit Stoffen, die die Blut-Hirn-Schranke auf dem ein oder anderen Wege überwinden können, so zum Beispiel mit wichtigen Vorläufern von Neurotransmittern, die im Tricarbonsäure-Zyklus entstehen und nicht in Neuronen de novo synthetisiert werden können, da Neurone keine Pyruvat-Carboxylase besitzen (YU et al. 1983; SHANK et al. 1985; CESAR und HAMPRECHT 1995). Der NaDC3 konnte in Astrozyten nachgewiesen werden und besitzt dort bezüglich $\left[{ }^{14} \mathrm{C}\right]-$ Succinat auch die gleichen Transporteigenschaften wie von uns untersucht (YODOYA et al. 2006). Wenn man nun noch einmal unsere Ergebnisse betrachtet, kann der NaDC3 in der Therapie zentralnervöser Erkrankungen eine Eintrittspforte zur Überwindung der Blut-Hirn-Schranke sein, sofern man mit Fumaraten, nicht mit Diethyl- oder Dimethylfumarat therapiert. Jedoch transportiert der NaDC3 in Astrozyten nicht nur Succinat oder möglicherweise Fumarat, sondern nachgewiesenermaßen auch $N$-Acetyl-L-Aspartat in der gleichen Stöchiometrie, also 1:3 zu Natrium (FUJITA et al. 2005). $\mathrm{N}$-Acetyl-L-Aspartat ist dabei neben Glutamat und Taurin quantitativ betrachtet eines der häufigsten Aminosäuren des Nervensystems (TSAI und COYLE 1995) und ist in seiner Anwesenheit in wichtigen Prozessen beteiligt, wie zum 
Beispiel der Myelinisierung (TSAI und COYLE 1995; BASLOW 1997; CLARK 1998). Da Fumarat und $\mathrm{N}$-Acetyl-L-Aspartat sich dann gegenseitig inhibieren könnten, sollte vor allem bei Kindern und Schwangeren vorsichtig mit hohen Dosen Fumarat umgegangen werden, damit es nicht zu Reifestörungen des ZNS kommt. Wobei die Affinität des NaDC3 in Experimenten zu $N$-Acetyl-L-Aspartat bei einer $\mathrm{K}_{\mathrm{M}}$ von etwa $100 \mu \mathrm{M}$ sehr viel geringer ausfällt als die von Succinat mit einer $\mathrm{K}_{\mathrm{M}}$ von etwa $30 \mu \mathrm{M}$ (FUJITA et al. 2005). 


\section{5.) Zusammenfassung}

Der hNaDC3 ist ein Transporter der SLC13-Familie, dessen Transkripte bisher in Niere, Leber, Plazenta und Gehirn nachgewiesen werden konnten. Er transportiert im Natriumabhängigen, elektrogenen Symport Dicarboxylate; unter anderem Succinat. Ziel dieser Arbeit war es, die Transporteigenschaften des hNaDC3 auf Fumarat und seine Derivate Diethyl- und Dimethylfumarat zu untersuchen und sie mit Succinat, dem prototypischen Substrat, zu vergleichen. Hierzu wurde die Aufnahme von radioaktiv markiertem Succinat in Ab- und Anwesenheit der Fumarate gemessen. Mit der Zwei-Elektroden-Spannungsklemme konnten an Oozyten des Xenopus laevis substratassoziierte Ströme abgeleitet werden. Die Versuchsreihen identifizierten neben Succinat Fumarat, nicht jedoch Dimethyl- und Diethylfumarat, als Substrat des hNaDC3. In den „Aufnahmeexperimenten“ wurde dies durch Hemmung der intrazellulären Succinatkonzentration durch Fumarat, nicht jedoch durch dessen Derivate, gezeigt. Elektrophysiologisch stellten sich Substrat- und Potential-abhängige Ströme über der Membran dar, die in Anwesenheit von Succinat und Fumarat, jedoch nicht von Diethyl- und Dimethylfumarat, abgeleitet werden konnten.

Fumarate beziehungsweise ihre Derivate stellen durch ihre immunmodulatorische Wirkung in der Therapie von Psoriasis vulgaris und Multipler Sklerose eine immer größer werdende Bedeutung dar. So spielt es für die topische Anwendung bei Psoriasis-Patienten keine Rolle, ob endogene Transporter Fumarat/-derivate transportieren. Bei der Multiplen Sklerose (MS) jedoch, wo es die Blut-Hirn-Schranke zu überwinden gilt, sind Transporteigenschaften von Transportern in Astrozytenmembranen, so auch dem $\mathrm{hNaDC} 3$, entscheidend für Dosisbestimmung und Wirksamkeit. Von einem hNaDC3-vermittelten Transport der Fumaratderivate Monomethyl- (MMF) und Dimethylfumarat (DMF), die derzeit in der MSTherapie angewendet werden, ist nicht auszugehen.

Offen für weitere Untersuchungen bleibt, ob Fumarat an der gleichen Bindungsstelle wie Succinat bindet und damit ein kompetitiver Inhibitor ist. Weiterhin über welchen Weg MMF und DMF in der bisher in Studien nachgewiesenermaßen wirksamen Therapie das ZNS erreichen. 


\section{6.) Literaturverzeichnis}

Altmeyer PJ, Matthes U, Pawlak F, Hoffmann K, Frosch PJ, Ruppert P, Wassilew SW, Horn T, Kreysel HW, Lutz G, et al. (1994): Antipsoriatic effect of fumaric acid derivatives. Results of a multicenter double-blind study in 100 patients. J Am Acad Dermatol; 30(6): 977-81.

Aposhian HV, Aposhian MM (1990): Meso-2,3-Dimercaptosuccinic acid: chemical, pharmacological and toxicological properties of an orally effective chelating agent. Annu Rev Pharmacol Toxicol; 30: 279-306.

Aruga S, Wehrli S, Kaissling B, Moe OW, Preisig PA, Pajor AM, Alpern RJ (2000): Chronic metabolic acidosis increases NaDC-1 mRNA and protein abundance in rat kidney. Kidney Int; $\underline{\mathbf{5 8 ( 1 )}: 206-15 .}$

Aruga S, Pajor AM, Nakamura K, Liu L, Moe OW, Preisig PA, Alpern RJ (2004): OKP cells express the Na-dicarboxylate cotransporter NaDC-1. Am J Physiol Cell Physiol; 287(1): 64-72.

Bai L, Pajor AM (1997): Expression cloning of NaDC-2, an intestinal $\mathrm{Na}(+)-$ or Li(+)dependent dicarboxylate transporter. Am J Physiol; 273(2 Pt 1): G267-74.

Bai X, Chen X, Feng Z, Hou K, Zhang P, Fu B, Shi S (2006): Identification of basolateral membrane targeting signal of human sodium-dependent dicarboxylate transporter $3 . J$ Cell Physiol; 206(3): 821-30.

Bai XY, Chen X, Sun AQ, Feng Z, Hou K, Fu B (2007): Membrane topology structure of human high-affinity, sodium-dependent dicarboxylate transporter. FASEB J; $\underline{\mathbf{2 1 ( 1 0 )}:}$ 2409-17.

Barnard EA, Miledi R, Sumikawa K (1982): Translation of exogenous messenger RNA coding for nicotinic acetylcholine receptors produces functional receptors in Xenopus oocytes. Proc R Soc Lond B Biol Sci; 215(1199): 241-6.

Baslow MH (1997): A review of phylogenetic and metabolic relationship between the acylamino acids, $\mathrm{N}$-acetyl-Laspartic acid and $\mathrm{N}$-acetyl-L-histidine, in the vertebrate nervous system. J Neurochem; $\underline{\mathbf{6 8}(4):}$ 1335-44.

Beck L, Markovich D (2000): The mouse Na(+)-sulfate cotransporter gene Nas1. Cloning, tissue distribution, gene structure, chromosomal assignment, and transcriptional regulation by vitamin D. J Biol Chem; 275(16): 11880-90. 
Buntinx M, Gielen E, Van Hummelen P, Raus J, Ameloot M, Steels P, Stinissen P (2004): Cytokine-induced cell death in human oligodendroglial cell lines. II: Alterations in gene expression induced by interferon-gamma and tumor necrosis factor-alpha. J Neurosci Res; $\underline{76(6):}$ 846-61.

Burckhardt BC, Burckhardt G (2011): In vitro and in vivo evidence of the importance of organic anion transporters (OATs) in drug therapy. Handb Exp Pharmacol; (201): 29104.

Burckhardt BC, Lorenz J, Kobbe C, Burckhardt G (2005): Substrate specificity of the human renal sodium dicarboxylate cotransporter, $\mathrm{hNaDC}-3$, under voltage-clamp conditions. Am J Physiol Renal Physiol; 288(4): F792-9.

Burckhardt G (1984): Sodium-dependent dicarboxylate transport in rat renal basolateral membrane vesicles. Pflugers Arch; 401(3): 254-61.

Bureau F, Vanderplasschen A, Jaspar F, Minner F, Pastoret PP, Merville MP, Bours V, Lekeux P (2002): Constitutive nuclear factor-kappaB activity preserves homeostasis of quiescent mature lymphocytes and granulocytes by controlling the expression of distinct Bcl-2 family proteins. Blood; 99(10): 3683-91.

Castagna M, Takai Y, Kaibuchi K, Sano K, Kikkawa U, Nishizuka Y (1982): Direct activation of calcium-activated, phospholipid-dependent protein kinase by tumorpromoting phorbol esters. J Biol Chem; 257(13): 7847-51.

Cesar M, Hamprecht B (1995): Immunocytochemical examination of neural rat and mouse primary cultures using monoclonal antibodies raised against pyruvate carboxylase. $J$ Neurochem; 64(5): 2312-8.

Chen X, Tsukaguchi H, Chen XZ, Berger UV, Hediger MA (1999): Molecular and functional analysis of SDCT2, a novel rat sodium-dependent dicarboxylate transporter. J Clin Invest; 103(8): 1159-68.

Chen XZ, Shayakul C, Berger UV, Tian W, Hediger MA (1998): Characterization of a rat Na+-dicarboxylate cotransporter. J Biol Chem; 273(33): 20972-81.

Clark JB (1998): N-acetyl aspartate: a marker for neuronal loss or mitochondrial dysfunction. Dev Neurosci; 20(4-5): 271-6.

Dantzler WH (2002): Renal organic anion transport: a comparative and cellular perspective. Biochim Biophys Acta; 1566(1-2): 169-81.

Dawson PA, Beck L, Markovich D (2003): Hyposulfatemia, growth retardation, reduced fertility, and seizures in mice lacking a functional NaSi-1 gene. Proc Natl Acad Sci U $S A ; \underline{100(23):}$ 13704-9. 
Dawson PA, Steane SE, Markovich D (2004): Behavioural abnormalities of the hyposulphataemic Nas1 knock-out mouse. Behav Brain Res; 154(2): 457-63.

Dawson PA, Steane SE, Markovich D (2005): Impaired memory and olfactory performance in NaSi-1 sulphate transporter deficient mice. Behav Brain Res; 159(1): 15-20.

De Jong R, Bezemer AC, Zomerdijk TP, Van de Pouw-Kraan T, Ottenhoff TH, Nibbering PH (1996): Selective stimulation of T helper 2 cytokine responses by the anti-psoriasis agent monomethylfumarate. Eur J Immunol; 26(9): 2067-74.

Del Prete G, De Carli M, Almerigogna F, Giudizi MG, Biagiotti R, Romagnani S (1993): Human IL-10 is produced by both type 1 helper (Th1) and type 2 helper (Th2) T cell clones and inhibits their antigen-specific proliferation and cytokine production. $J$ Immunol; 150(2): 353-60.

Dumont JN (1972): Oogenesis in Xenopus laevis (Daudin). I. Stages of oocyte development in laboratory maintained animals. J Morphol; 136(2): 153-79.

Enomoto A, Endou H (2005): Roles of organic anion transporters (OATs) and a urate transporter (URAT1) in the pathophysiology of human disease. Clin Exp Nephrol; 9(3): 195-205.

Fiorentino DF, Bond MW, Mosmann TR (1989): Two types of mouse T helper cell. IV. Th2 clones secrete a factor that inhibits cytokine production by Th1 clones. $J$ Exp Med; 170(6): 2081-95.

Fujita T, Katsukawa H, Yodoya E, Wada M, Shimada A, Okada N, Yamamoto A, Ganapathy V (2005): Transport characteristics of N-acetyl-L-aspartate in rat atsrocytes: involvement of sodium-coupled high-affinity carboxylate transporter NaC3/NaDC3-mediated transport system. J Neurochem; 93(3): 706-14.

Ganapathy V, Ganapathy ME, Tiruppathi C, Miyamoto Y, Makesh VB, Leibach FH (1988): Sodium-gradient-driven, high-affinity, uphill transport of succinate in human placental brush-border membrane vesicles. Biochem J; 249(1): 179-84.

Girard JP, Baekkevold ES, Feliu J, Brandtzaeg P, Amalric F (1999): Molecular cloning and functional analysis of SUT-1, a sulphate transporter from human high endothelial venules. Proc Natl Acad Sci U S A; 96(22): 12772-7.

Gold R, Linington C, Lassmann H (2006): Understanding pathogenesis and therapy of multiple sclerosis via animal models: 70 years of merits and culprits in experimental autoimmune encephalomyelitis research. Brain. 129(Pt 8): 1953-71.

Graham FL, van der Eb AJ (1973a): A new technique for the assay of infectivity of human adenovirus 5 DNA. Virology; 52(2): 456-67. 
Graham FL, van der Eb AJ (1973b): Transformation of rat cells by DNA of human adenovirus 5. Virology; 54(2): 536-9.

Graham FL, Smiley J, Russell WC, Nairn R (1977): Characteristics of a human cell line

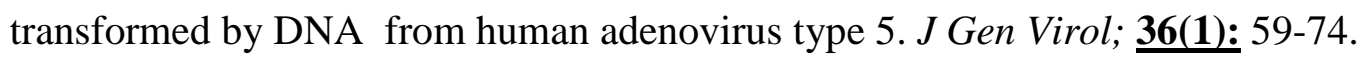

Gurdon JB, Lane CD, Woodland HR, Marbaix G (1971): Use of frog eggs and oocytes for the study of messenger RNA and its translation in living cells. Nature; 233(5316): 177-82.

Hagos Y, Burckhardt BC, Larsen A, Mathys C, Gronow T, Bahn A, Wolff NA, Burckhardt G, Steffgen J (2003): Regulation of sodium-dicarboxylate cotransporter3 from winter flounder kidney by protein kinase C. Am J Physiol Renal Physiol; 286(1): F86-93.

Hayden MS, West AP, Ghosh S (2006): NF-kappaB and the immune response. Oncogene; 25(51): 6758-80.

Held KD, Epp ER, Clark EP, Biaglow JE (1988): Effect of dimethyl fumarate on the radiation sensitivity of mammalian cells in vitro. Radiat Res; 155(3): 495-502.

Hentschel H, Burckhardt BC, Schölermann B, Kühne L, Burckhardt G, Steffgen J (2003): Basolateral localization of flounder Na+-dicarboxylate cotransporter (fNaDC$3)$ in the kidney of Pleuronectes americanus. Pflugers Arch; 446(5): 578-84.

Holter W, Majdic O, Kalthoff FS, Knapp W (1992): Regulation of interleukin-4 production in human mononuclear cells. Eur J Immunol; 22(10): 2765-7.

Huang W, Wang H, Kekuda R, Fei YJ, Friedrich A, Wang J, Conway SJ, Cameron RS, Leibach FH, Ganapathy V (2000): Transport of N-acetylaspartate by the $\mathrm{Na}(+)$ dependent high-affinity dicarboxylate transporter $\mathrm{NaDC} 3$ and its relevance to the expression of the transporter in the brain. J Pharmacol Exp Ther; 295(1): 392-403.

Inoue K, Zhuang L, Ganapathy V (2002a): Human Na+-coupled citrate transporter: primary structure, genomic organization, and transport function. Biochem Biophys Res Commun; 299(3): 465-71.

Inoue K, Zhuang L, Maddox DM, Smith SB, Ganapathy V (2002b): Structure, function, and expression pattern of a novel sodium-coupled citrate transporter $(\mathrm{NaCT})$ cloned from mammalian brain. J Biol Chem; 277(42): 39469-76.

Inoue K, Zhuang L, Maddox DM, Smith SB, Ganapathy V (2003): Human sodiumcoupled citrate transporter, the orthologue of Drosophila Indy, as a novel target for lithium action. Biochem J; 374(Pt 1): 21-6. 
Inoue K, Fei YJ, Zhuang L, Gopal E, Miyauchi S, Ganapathy V (2004): Functional features and genomic organization of mouse $\mathrm{NaCT}$, a sodium-coupled transporter for tricarboxylic acid cycle intermediates. Biochem J; 378(Pt 3): 949-57.

Kekuda R, Wang H, Huang W, Pajor AM, Leibach FH, Devoe LD, Prasad PD, Ganapathy V (1999): Primary structure and functional characteristics of a mammalian sodium-coupled high affinity dicarboxylate transporter. J Biol Chem; 274(6): 3422-9.

Lee A, Beck L, Markovich D (2000): The human renal sodium sulphate cotransporter (SLC13A1; hNaSi-1) cDNA and gene: organization, chromosomal localization, and functional characterization. Genomics; 70(3): 354-63.

Lehmann JC, Listopad JJ, Rentzsch CU, Igney FH, von Bonin A, Hennekes HH, Asadullah K, Docke WD (2007): Dimethylfumarate induces immunosuppression via glutathione depletion and subsequent induction of heme oxygenase 1. J Invest Dermatol; 127(4): 835-45.

Litjens NH, Rademaker M, Ravensbergen B, Rea D, van der Plas MJ, Thio B, Walding A, van Dissel JT, Nibbering PH (2004a): Monomethylfumarate affects polarization of monocyte-derived dendritic cells resulting in down-regulated Th1 lymphocyte responses. Eur J Immunol; 34(2): 565-75.

Litjens NH, van Strijen E, van Gulpen C, Mattie H, van Dissel JT, Thio HB, Nibbering PH (2004b): In vitro pharmacokinetics of anti-psoriatic fumaric acid esters. BMC Pharmacol; 4: 22.

Loewe R, Holnthoner W, Gröger M, Pillinger M, Gruber F, Mechtcheriakova D, Hofer E, Wolff K, Petzelbauer P (2002): Dimethylfumarate inhibits TNF-induced nuclear entry of NF-kappa B/p65 in human endothelial cells. J Immunol; 168(9): 4781-7.

Markovich D, Murer H (2004): The SLC13 gene family of sodium sulphate/carboxylate cotransporters. Pflugers Arch; 447(5): 594-602.

Markovich D, Aronson PS (2007): Specificity and regulation of renal sulphate transporters. Annu Rev Physiol; 69: 361-75.

Markovich D, Forgo J, Stange G, Biber J, Murer H (1993): Expression cloning of rat renal Na+/SO4(2-) cotransport. Proc Natl Acad Sci U S A; 90(17): 8073-7.

Markovich D, Regeer RR, Kunzelmann K, Dawson PA (2005): Functional characterization and genomic organization of the human $\mathrm{Na}(+)$-sulfate cotransporter hNaS2 gene (SLC13A4). Biochem Biophys Res Commun; 326(4): 729-34. 
Mertz JE, Gurdon JB (1977): Purified DNAs are transcribed after microinjection into Xenopus oocytes. Proc Natl Acad Sci U S A; 74(4): 1502-6.

Miller DS (2002): Xenobiotic export pumps, endothelin signaling, and tubular nephrotoxicants - a case of molecular hijacking. J Biochem Mol Toxicol; 16(3): 121-7.

Motojima M, Hosokawa A, Yamato H, Muraki T, Yoshioka T (2002): Uraemic toxins induce proximal tubular injury via organic anion transporter 1- mediated uptake. $\mathrm{Br} J$ Pharmacol; 135(2): 555-63.

Mrowietz U, Asadullah K (2005): Dimethylfumarate for psoriasis: more than a dietary curiosity. Trends Mol Med; 11: 43-8.

Mrowietz U, Christophers E, Altmeyer P (1999): Treatment of severe psoriasis with fumaric acid esters: scientific background and guidelines for therapeutic use. The German Fumaric Acid Ester Consensus Conference. Br J Dermatol; 141: 424-9.

Nakada T, Zandi-Nejad K, Kurita Y, Kudo H, Broumand V, Kwon CY, Mercado A, Mount DB, Hirose S (2005): Roles of Slc13a1 and Slc26a1 sulfate transporters of eel kidney in sulphate homeostasis and osmoregulation in freshwater. Am J Physiol Regul Integr Comp Physiol; 289(2): R575-R585.

Nibbering PH, Thio B, Zomerdijk TP, Bezemer AC, Beijersbergen RL, van Furth R (1993): Effects of monomethylfumarate on human granulocytes. J Invest Dermatol; 101(1): 37-42.

Nieboer C, de Hoop D, Langendijk PN, van Loenen AC, Gubbels J (1990): Fumaric acid therapy in psoriasis: a double-blind comparison between fumaric acid compound therapy and monotherapy with dimethylfumaric acid ester. Dermatologica; 181(1): $33-7$.

Ockenfels HM, Schultewolter T, Ockenfels G, Funk R, Goos M (1998): The antipsoriatic agent dimethylfumarate immunomodulates T-cell cytokine secretion and inhibits cytokines of the psoriatic cytokine network. Br J Dermatol; 139(3): 390-5.

Pajor AM (1995): Sequence and functional characterization of a renal sodium/dicarboxylate cotransporter. J Biol Chem; 270(11): 5779-85.

Pajor AM (1996): Molecular cloning and functional expression of a sodium-dicarboxylate cotransporter from human kidney. Am J Physiol; 270(4 Pt 2): F642-8.

Pajor AM (2000): Molecular properties of sodium/dicarboxylate cotransporters. J Membr Biol; 175(1): 1-8.

Pajor AM (2006): Molecular properties of the SLC13 family of dicarboxylate and sulphate transporters. Pflugers Arch; 451(5): 597-605. 
Pajor AM, Sun NN (2000): Molecular cloning, chromosomal organization, and functional characterization of a sodium-dicarboxylate cotransporter from mouse kidney. Am J Physiol Renal Physiol; 279(3): F482-90.

Pajor AM, Gangula R, Yao X (2001): Cloning and functional characterization of a highaffinity $\mathrm{Na}(+) /$ dicarboxylate cotransporter from mouse brain. Am J Physiol Cell Physiol; 280(5): C1215-23.

Schillings S, Goelz S, Linker R, Luehder F, Gold R (2006): Fumaric acid esters are effective in chronic experimental autoimmune encephalomyelitis and suppress macrophage infiltration. Clin Exp Immunol; 145(1): 101-7.

Sebök B, Bonnekoh B, Geisel J, Mahrle G (1994): Antiproliferative and cytotoxic profiles of antipsoriatic fumaric acid derivates in keratinocyte cultures. Eur J Pharmacol; 270(1): 79-87.

Segal BM, Klinman DM, Shevach EM (1997): Microbial products induce autoimmune disease by an IL-12-dependent pathway. J Immunol; 158(11): 5087-90.

Sekine T, Cha SH, Hosoyamada M, Kanai Y, Watanabe N, Furuta Y, Fukuda K, Igarashi T, Endou H (1998): Cloning, functional characterization, and localization of a rat renal Na+-dicarboxylate transporter. Am J Physiol; 275(2 Pt 2): F298-305.

Sekine T, Miyazaki H, Endou H (2006): Molecular physiology of renal organic anion transporters. Am J Physiol Renal Physiol; 290(2): F251-61.

Shank RP, Campbell GL (1982): Glutamine and alpha-ketoglutarate uptake and metabolism by nerve terminal enriched material from mouse cerebellum. Neurochem Res; $\underline{7(5):}$ 601-16.

Shank RP, Bennett GS, Freytag SO, Campbell GL (1985): Pyruvate carboxylase: an strocyte-specific enzyme implicated in the replenishment of amino acid neurotransmitter pools. Brain Res; 329(1-2): 364-7.

Shein HM, Enders JF (1962): Transformation induced by simian virus 40 in human renal cell cultures. I. Morphology and growth characteristics. Proc Natl Acad Sci U S A; 48: 1164-72.

Sigel E, Minier F (2005): The Xenopus oocyte: system for the study of functional expression and modulation of proteins. Mol Nutr Food Res; 49(3): 228-34.

Smith LD, Xu WL, Varnold RL (1991): Oogenesis and oocyte isolation. Methods Cell Biol; 36: $45-60$.

Sproule B (2002): Lithium in bipolar disorder: can drug concentrations predict therapeutic effect? Clin Pharmacokinet; 41(9): 639-60. 
Stangel M, Moharregh-Khiabani D, Linker RA, Gold R (2008): Fumarat in der Behandlung der Multiplen Sklerose. Mögliche Wirkmechanismen und Studien. Nervenarzt; 79(2): 212-7.

Steffgen J, Burckhardt BC, Langenberg C, Kühne L, Müller GA, Burckhardt G, Wolff NA (1999): Expression cloning and characterization of a novel sodium-dicarboxylate cotransporter from winter flounder kidney. J Biol Chem; 274(29): 20191-6.

Storch MK, Stefferl A, Brehm U, Weissert R, Wallström E, Kerschensteiner M, Olsson T, Linington C, Lassmann H (1998): Autoimmunity to myelin oligodendrocyte glycoprotein in rats mimics the spectrum of multiple sclerosis pathology. Brain Pathol; 8(4): 681-94.

Sumikawa K, Houghton M, Emtage JS, Richards BM, Barnard EA (1981): Active multisubunit Ach receptor assembled by translation of heterologous mRNA in Xenopus oocytes. Nature; 292(5826): 862-4.

Thomas P, Smart TG (2005): HEK293 cell line: a vehicle for the expression of recombinant proteins. J Pharmacol Toxicol Methods; 51(3): 187-200.

Treumer F, Zhu K, Gläser R, Mrowietz U (2003): Dimethylfumarate is a potent inducer of apoptosis in human T cells. J Invest Dermatol; 121(6): 1383-8.

Tsai G, Coyle JT (1995): N-acetylaspartate in neuropsychiatric disorders. Prog Neurobiol; 46(5): 531-40.

Vanholder R, De Smet R, Glorieux G, Argilés A, Baurmeister U, Brunet P, Clark W, Cohen G, De Deyn PP, Deppisch R, Descamps-Latscha B, Henle T, Jörres A, Lemke HD, Massy ZA, Passlick-Deetjen J, Rodriguez M, Stegmayr B, Stenvinkel P, Tetta C, Wanner C, Zidek W; European Uremic Toxin Work Group (EUTox) (2003): Review on uremic toxins: classification, concentration, and interindividual variability. Kidney Int; 63(5): 1934-43.

Varghese A, Tenbroek EM, Coles J Jr, Sigg DC (2006): Endogenous channels in HEK cells and potential roles in $\mathrm{HCN}$ ionic current measurements. Prog Biophys Mol Biol; 90(1-3): $26-37$.

Wagner CA, Friedrich B, Setiawan I, Lang F, Bröer S (2000): The use of Xenopus laevis oocytes for the functional characterization of heterologously expressed membrane proteins. Cell Physiol Biochem; 10(1-2): 1-12.

Wang H, Fei YJ, Kekuda R, Yang-Feng TL, Devoe LD, Leibach FH, Prasad PD, Ganapathy V (2000): Structure, function, and genomic organization of human $\mathrm{Na}(+)-$ 
dependent high-affinity dicarboxylate transporter. Am J Physiol Cell Physiol; 278(5): C1019-30.

Wierinckx A, Brevé J, Mercier D, Schultzberg M, Drukarch B, Van Dam AM (2005): Detoxication enzyme inducers modify cytokine production in rat mixed glial cells. $J$ Neuroimmunol; 166(1-2): 132-43.

Yodoya E, Wada M, Shimada A, Katsukawa H, Okada N, Yamamoto A, Ganapathy V, Fujita T (2006): Functional and molecular identification of sodium-coupled dicarboxylate transporters in rat primary cultured cerebrocortical astrocytes and neurons. J Neurochem; 97(1): 162-73.

Yu AC, Dreijer J, Hertz L, Schousboe A (1983): Pyruvate carboxylase activity in primary cultures and neurons. J Neurochem; 41(5): 1484-7.

Zalups RK (2000): Molecular interactions with mercury in the kidney. Pharmacol Rev; 52(1): 113-43.

Zhou F, You G (2007): Molecular insights into the structure-function relationship of organic anion transporters OATs. Pharm Res; 24(1): 28-36.

Zhu K, Mrowietz U (2001): Inhibition of dendritic cell differentiation by fumaric acid esters. J Invest Dermatol; 116(2): 203-8. 


\section{Danksagung}

Zuerst möchte ich Prof. Dr. phil. nat. B. C. Burckhardt für die beispielhafte, verständnisvolle und sehr bemühte Betreuung meiner Arbeit danken. Sie hatte zu allen Phasen des Schaffens eine offene Tür für Anliegen und Fragen.

Weiterhin möchte ich mich bei Herrn S. Petzke, Frau I. Markmann und Frau K. Brauburger bedanken. Ihre Anleitung, Hilfe- und Bereitstellung von Materialien trug mich sowohl in schwierigen Anfängen als auch zur Fertigstellung der Experimente. 


\section{Lebenslauf}

Am 07.02.1987 wurde ich, Andrea Isabella Schmidt, als einziges Kind des Ehepaares Isabella Stoffran-Schmidt, Diplom-Ingenieurin, und Christian Schmidt, Werkzeugmacher, in München geboren. Im württembergischen Affalterbach wuchs ich die meiste Zeit meiner Kindheit auf, wo ich von 1993-1997 die Grundschule besuchte. Der Wechsel auf die weiterführende Schule, das Goethe-Gymnasium Ludwigsburg, erfolgte unmittelbar im Anschluss. Dort verbrachte ich die folgenden 8 Jahre, bis ich 2005 das Abitur absolvierte.

Der Wunsch, Medizin zu studieren, bestand schon langjährig. Die Umstände jedoch ergaben zunächst sportliche Höhepunkte mit einer Weltmeisterschaftsteilnahme im Synchroneiskunstlauf 2006. Nahtlos daran konnte dann glücklicherweise der Studienbeginn an der Georg-August-Universität Göttingen zum Sommersemester desselben Jahres angeknüpft werden. Mein Praktisches Jahr verbrachte ich für Innere Medizin in Uznach (Schweiz), für Herz-/Gefäßchirurgie in Paris (Frankreich), für Allgemein-/Viszeralchirurgie in Lissabon (Portugal) und für das Wahltertial Mund-Kiefer-Gesichtschirurgie in der Universitätsklinik Göttingen. Das Staatsexamen und damit das Medizinstudium schloss ich am 12.06.2012 erfolgreich ab. Im Anschluss daran widmete ich mich wieder meiner Promotion, die ich parallel zum Studium im Frühjahr 2009 unter der Anleitung und Obhut von Prof. Dr. phil. nat. B. C. Burckhardt in der Abteilung „Vegetative Physiologie und Pathophysiologie“ (Prof. Dr. med. G. Burckhardt) begann.

Aus dem Interesse an pathophysiologischen Zusammenhängen der Inneren Medizin, sowie der Begeisterung für manuellen Tätigkeiten operativer Arbeitsfelder heraus, entschied ich mich für die Weiterbildung zur Allgemein-/Viszeralchirurgin. Am 01.12.12 nahm ich die Arbeit in eben diesem Fach an der Klinik der Albert-Ludwigs-Universität in Freiburg im Breisgau auf. 